\title{
FATORES DE RISCO COROMARIANO
}

\section{EII IDOSOS}

\section{ESTUDO PROSPECTIVO}

\section{ENEIDE POMPIANI DE MOURA}

Tese de Doutorado apresentada ao Departamento de Prática de Saúde Pública da Faculdade de Saúde Pública da Universidade de São Paulo Para obtenção do Grau de Doutora.

Área de concentração:

Serviços de Saúde Pública

\section{ORIENTADOR: PROF. DR. JANUÁRIO DE ANDRADE}

São Paulo

2002 
DEDICATÓRIA

(2) amas é uma energia que existe de acordo com a nossa vontade e pureza de sentimentos, curando tudo o que existe dentro e fora de nós pela vibração e sintonia com o Amor Infinito do Criador. Esta é a energia emanada pelos meus amados filhos Thalita ofancion a quem dedico este trabalho. 


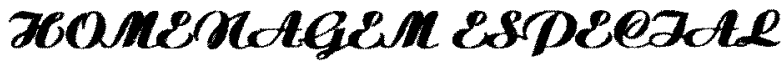

Ota quevida $\mathscr{P}_{\text {rof. }} \mathscr{D}_{\boldsymbol{x}}$ Samudisia de OAndrade que soube compreender e sentir as diferenças entre as pessoas e a complexidade da vida de cada uma delas. 


\section{AGRADECIMENTOS}

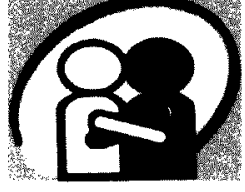

Aos meus pais IDENE e GERALDO, que acreditaram que com discernimento e determinação é possível superar os obstáculos da vida e alcançar a meta estabelecida.

Aos amigos da Secretaria do Estado da Saúde do NRS4 - DIR I, particularmente a Dra. Vânia Soares de Azevedo Tardeli e Dra. Laís Moisés que apoiaram integralmente a minha participação na pós-graduação no Mestrado e agora também no Doutorado.

Aos idosos que nos ensinam diariamente que o maior milagre é estar vivo.

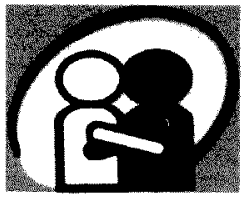

Em fim, a todas as pessoas que participaram direta ou indiretamente na realização do presente trabalho. 


$$
\begin{gathered}
\text { À Ti, meu Deus, } \\
\text { Eu rendo graças, } \\
\text { pelas bênçäos recebidas } \\
\text { durante estes anos de estudo... } \\
\text { Foram tantos acontecimentos, } \\
\text { tantas pessoas envolvidas... } \\
\text { Que graças à presença de Deus, } \\
\text { ELe pode me dar a força necessária } \\
\text { para continuar prosseguindo sempre... }
\end{gathered}
$$

Que as pessoas que se interessarem em ler este trabalho tenfam a certeza que é possivel retardar o processo do envelhecimento físico mas que a essência do "ser"... esta nunca envelhece... pois, está centrada no amor incondicional que faz parte de uma energia única que é Deus.

Eneide Pompiani de Moura 


\section{RESUMO}

Este estudo foi a continuação da pesquisa, "Fatores de Risco Coronariano e Riscos auto-criados em idosos". Foram avaliados 353 idosos durante quatro anos (1997-2001) para o acompanhamento dos fatores de risco coronariano: pressão arterial, glicemia de jejum, peso, colesterol total, hábito de fumar, atividade fisica esportiva, antecedentes familiares para doença coronariana e idade/sexo. Foi usado um protocolo de educação médica de risco coronariano para pacientes e/ou acompanhantes dos idosos, classificação do risco coronariano segundo a "Tabela de Risco Coronariano da American Heart Association de 1973" e também foram considerados os exames laboratoriais e clínicos. Resultados: No grupo estudado $88 \%$ eram do sexo feminino, com idade média de 72,4 anos ( $D P=5,8$ anos). Ao longo dos anos apresentaram uma redução significativa dos fatores de risco coronarianos $(\mathrm{p}<0,001)$. O comportamento médio e a média de risco indicou diferenças significativas durante o periodo de estudo $(\mathrm{p}<0,001)$. As maiores contribuições dos fatores de risco coronariano em relação ao risco coronariano total foram: idade/sexo e atividade fisica esportiva e os que menos contribuíram foram: fumo e antecedentes familiares. Houve diminuição significativa dos casos com classificação de risco coronariano moderado e alto $(p<0,001)$. As mudanças de risco coronariano foram devido a um melhor controle: no colesterol total, na glicemia de jejum, na pressão arterial, no peso e nas ações educativas realizadas pelo médico. Conclusão: Os idosos melhoraram anualmente os seus hábitos de saúde, com diminuição dos fatores de risco coronariano principalmente devido ao melhor controle: dos niveis de colesterol total, da hipertensão arterial, da obesidade, do baixo peso e do diabetes sugerindo que protocolos e programas de educação permanente podem contribuir positivamente para o controle dos fatores de risco coronariano e melhora da qualidade de vida dos idosos.

Palavras chaves: idosos, fatores de risco coronariano, doença coronariana. 


\section{SUMMARY}

This study is a sequence of the piece of research on "Coronary Risk Factors and Self Created Risks in Elderly". We evaluated 353 cases, during a 4 year period (1997-2001), aiming to follow up the coronary risk factors for coronary disease as age/sex, arterial pressure, fasting glycemia, weight, total cholesterol level, smoking habits, sportive physical activity and family history of coronary disease. We used the protocol of medical education of coronary risks for patients and/or for those who were accompanying the elderly, classifying the risk by the table of coronary risk factors of the American Heart Association. We also considered clinical and laboratory exams of the sample. Results: $88 \%$ of female on the study; a 72.4 average age ( $D P=5,8$ years); a significant drop in the follow up of coronary risk factors $(p<0,001)$. The behavior average and the risk averages of factors indicated significant differences during the follow up period $(p<0,001)$. The most significant contributions of the risk factors were: age/sex and sportive physical activity and the less significant contributions were smoking habits and personal record of coronary disease. There were significant changes in the follow up as for risk factors and a fall in moderate and high risk $(p<0,001)$. The drop dues to a better control in high cholesterol level, the use of hypoglicemics, the control of arterial systolic pressure, obesity and information that doctor provide their patients with. Conclusion: the elderly improved their health habits yearly, decreasing the risk of coronary disease mainly because of cholesterol level, arterial hypertension, obesity, low weight and diabetes mellitus, showing that a permanent orientation program can contribute positively to control the risk factors of coronary disease and improving the quality of life in the elderly.

Key words: elderly, coronary risk factors, coronary disease 


\section{ÍNDICE}

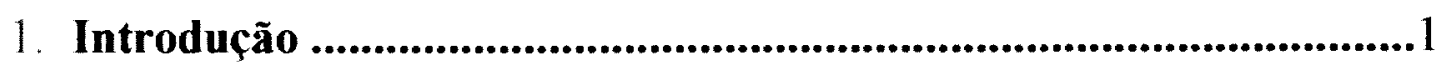

1.1 - Impacto Social das Doenças Cardiovasculares............................... 1

1.2 - Dimensões da Concepção de Saúde..................................................4

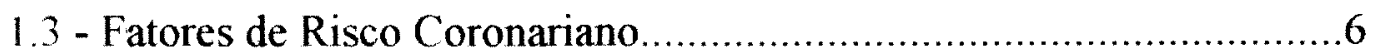

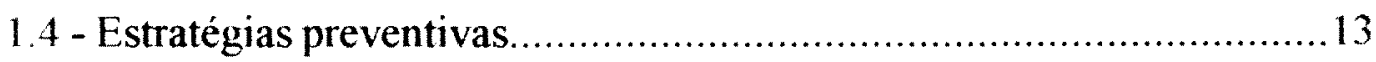

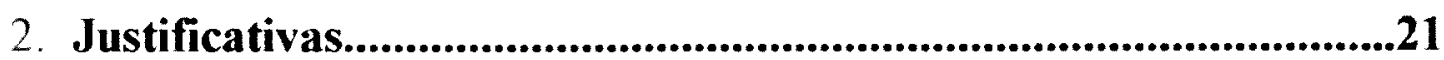

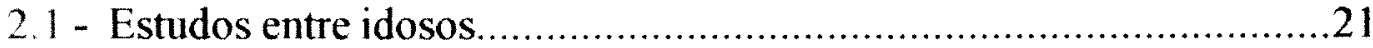

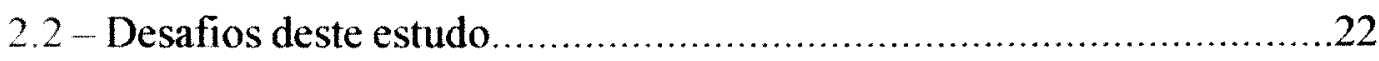

2.3 - Referências Bibliográficas Complementares..............................25





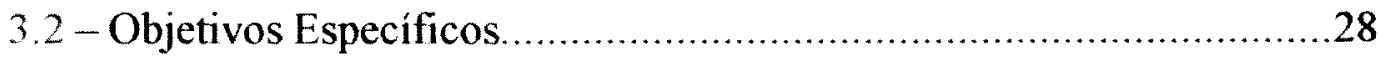

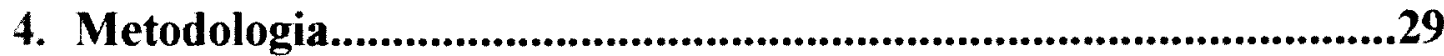

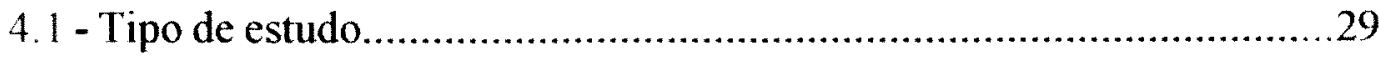

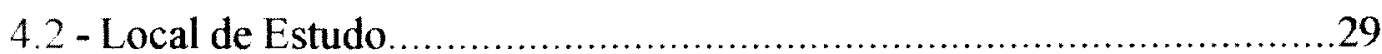

4.3 - Características do atendimento no Ambulatório durante o estudo.....29



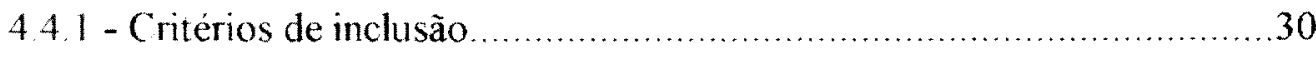

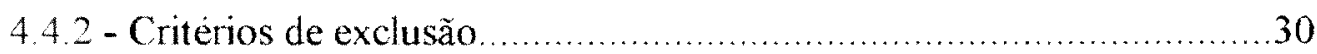

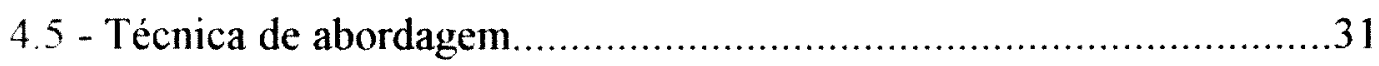


4.6 - Termo de Anuência. 33

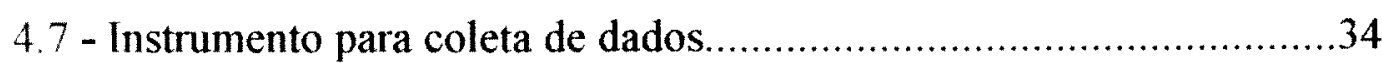

4.8 - Critérios para coleta de exame de sangue .......................................34

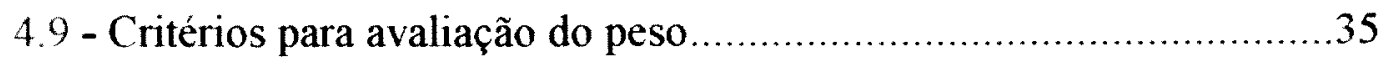

4.10 - Critérios para avaliação da atividade física..................................36

4. 11 - Critérios para avaliação da pressão arterial...................................37

4.12 - Critérios para avaliação do perfil lipídico........................................39

4.13 - Critérios para avaliação da glicemia plasmática............................39

4.14 - Critérios para avaliação da análise estatística..............................42

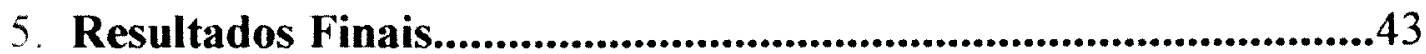

5.1 - Análise da seleção dos casos acompanhados ao longo

do tempo

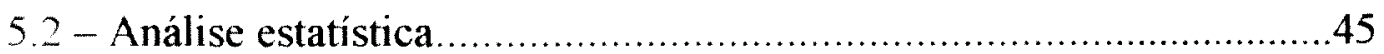

5.3 - Análise das variáveis idade e sexo ao longo do tempo.....................45

5.4 - Comportamento médio dos fatores de risco coronarianos ao longo do tempo

5.5 - Contribuição dos fatores de risco coronariano em relação ao risco

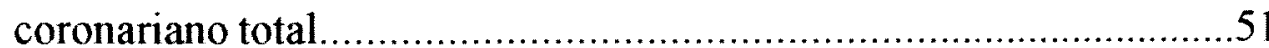

5.6 - Prevalência de hipertensão arterial sistólica e diabetes mellitus ao longo do tempo

5.7 - Comportamento da classificação do risco coronariano ao longo do tempo 
5.8 - Referências bibliográficas da análise estatística.

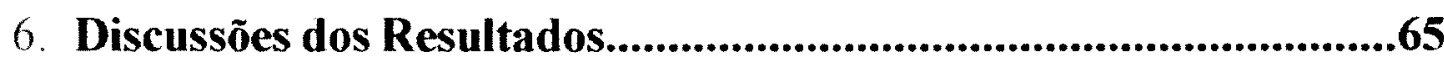

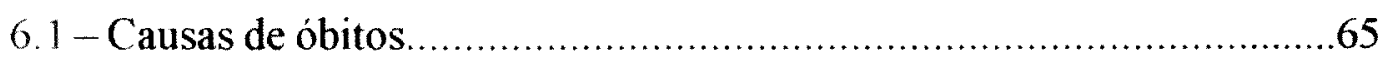

6.2 - Fatores de Risco Coronarianos ao longo dos anos................... 70

6.3 - Referências bibliográficas Complementares............................8 80



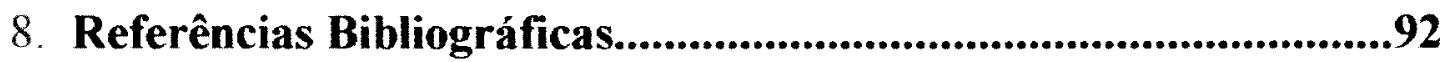

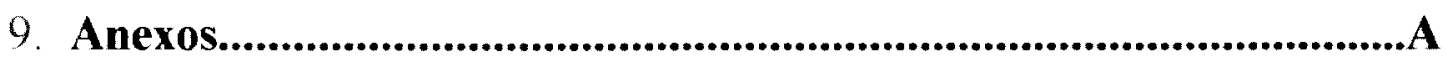

9.1 - Anexo I - Quadro 1 - Tabela de Risco Coronariano

da American Heart Association, 1973.

9.2 - Anexo II - Quadro 2 - Distribuição da Altura (m) e

Peso Normal $(\mathrm{kg})$ segundo o IMC de $24,9 \mathrm{Kg} / \mathrm{m}^{2}$ A II

9.3 - Anexo IlI a - Termo de Anuência para participação no estudo

"Fatores de Risco Coronariano em Idosos". A III a

9.4 - Anexo III b - Termo de Anuência para participação no estudo

"Fatores de Risco Coronariano em Idosos" A III b

9.5 - Anexo IV - Of. COEP/126/01 - Parecer do Comitê de Ética e

Pesquisa da FSP/USP

9.6 - Anexo V - Comunicado do Exame de Qualificação. A V 
1. Muredughato 


\section{Introdução}

\subsection{Impacto Social das Doenças Cardiovasculares}

No Brasil, as Doenças Cardiovasculares (DCV) são causas expressivas de morbidade e mortalidade ${ }^{(1-5.78-9.9395 .120)}$. Em 1930 as DCV eram responsáveis por apenas $11.8 \%$ dos óbitos, em 1996 passou para $27.4 \%$ se mantendo em $1998 \mathrm{com}$ $27.7 \% 0^{(95.101 .117)}$

No Estado de São Paulo, segundo os dados do Datasus $(1998)^{(95.101 .117)}$, o indice de mortalidade foi semelhante ao Nacional com $30,8 \% \%^{(95.101 .117)}$. Na mesma época. os cinqüenta procedimentos mais freqüentes em internação Hospitalar que levaram ao óbito representaram 20,4\% por Doenças do Aparelho Circulatório. As causas de óbitos mais freqüentes foram por: Acidente Vascular Cerebral Agudo com 21.31 óbitos/100.000 habitantes. Infarto Agudo do Miocárdio com 17.16 óbitos/ 100.000 habitantes. Insuficiência Cardiaca com 10,46 óbitos/100.000 habitantes, Insuficiência Coronariana Aguda com 2.29 óbitos/100.000 habitantes e Crise Hipertensiva com 1.69 óbitos $/ 100.000$ habitantes.

O impacto das DCV sobre as diferentes faixas etárias cresce progressivamente com a elevação da faixa etária. Em 1996 a taxa de mortalidade geral ficou em 4.57 óbitos/100.000 habitantes sendo que 673.34 óbitos/100.000 habitantes estavam na faixa etária entre 20 a 49 anos e para a faixa etária com mais de 50 anos estava em 2.554 .7 óbitos/100.000 habitantes ${ }^{(117)}$.

Marcopito $^{(83)}$ mostrou que as doenças isquêmicas do coração sofreram uma nítida redução nas taxas de mortalidade (ajustadas por idade) no período de 1980 a 1996 no Estado de São Paulo. A queda foi mais pronunciada quanto razão masculino/feminino mostrou-se maior para o sexo feminino (razão 
masculino/feminino de 1,7 em 1980 para 1,8 em 1996). As tendências observadas no Estado de São Paulo assemelham-se àquelas dos Estados Unidos da América de 1980 a 1988 e de 1990 a $1994^{(83)}$

Segundo Laurenti ${ }^{(75}$ descrição do padrão da morbidade, bem como uma aproximação da magnitude das doenças do aparelho cardiovasvascular para o pais como um todo, pode ser feita por meio da única fonte existente que é a internação hospitalar, fornecida pelo Sistema de informações Hospitalares SIH/SUS. Ainda que este sistema trate somente de internações pagas pelos SUS deve se destacar que representa $80 \%$ da assistência médico-hospitalar oferecida à população, representando cerca de 12 milhões de internações por ano.

No Instituto Dante Pazzanese de Cardiologia do Estado de São Paulo ${ }^{(64)}$, durante o ano 2.000, foram realizadas 6879 internações. As doenças do aparelho circulatório representaram $83,3 \%$ das internações (5.733 internações) sendo $59,3 \%$ (3.398) do sexo masculino numa proporção de 1,4 internações do sexo masculino para 1 internação para o sexo feminino.

Segundo o Datasus ${ }^{(9899)}$, no Brasil, em 1997, para a faixa etária com idade superior a 20 anos, as doenças do aparelho circulatório foram a segunda morbidade hospitalar proporcional por diagnóstico mais freqüente com 13,7\% (1.111.996 AlHs) onde foi superada somente pela categoria gravidez, parto e puerpério com morbidade de $28,2 \%$ (2.294.033 AlHs). Em maio do ano $2.000^{(100)}$, no Brasil, houveram 1.025.876 internações (AIHs) sendo $9 \%$ (92.152 AIHs) para as doenças do aparelho circulatório e $24,5 \%$ para gravidez, parto e puerpério. No Estado de São Paulo as doenças do aparelho circulatório apresentaram um maior número de AIHs com $20,6 \%$ ( 18.995 AIHs) do total desta categoria em relação aos outros estados. 
No Brasil, o impacto dos gastos em internações hospitalares SUS para as doenças cardiovasculares em 1996 representou 17,2\% do total das internações neste periodo representando $\mathrm{R} \$ 468.452 .511,00^{(117)}$. Laurent $\mathrm{f}^{(75)}$ mostrou que os gastos com internações por doenças isquêmicas do coração em 1997 atingiu valor superior a cem milhões de reais. Este valor representa, aproximadamente, $0,012 \%$ do PIB daquele ano. Segundo a Secretaria de Estado de Saúde ${ }^{(115-6)}$ no Estado de São Paulo, em 1998, houveram 2.380.248 procedimentos de internação hospitalar (AIHs) com um gasto de R\$16.922.209,95 pagos pelo SUS. As doenças cardiovasculares representaram 4,5\% (com 106.331 AIHs). A insuficiência cardiaca foi a maior causa de internação e custo hospitalar com 62.932 AIHs representando R\$28.349.067,47.

A segunda causa de internação foi para o acidente vascular cerebral agudo com 32.859 AIHs representando R\$11.274.470,01.

Assim, a necessidade de investimentos em prevenção deve ser prioridade nas ações de Saúde Pública. Embora tenha havido avanço tecnológico quanto ao diagnóstico e ao tratamento ainda é alto $\mathrm{c}$ índice de óbitos para as doenças do aparelho cardiovascular ${ }^{(120)}$

$\dot{E}$ importante considerarmos que mesmo nos casos não fatais, os individuos que sofreram algum evento cardiovascular são freqüentemente acometidos de invalidez parcial ou total requerendo cuidados mais especificos tanto de seus familiares como dos serviços de saúde ${ }^{(120)}$

O impacto social das doenças do aparelho circulatório pode ser minimizad através das ações de promoção à saúde observando as necessidades sentidas pelo usuário e pelos prestadores de $\operatorname{serviços~}^{(120)}$. 


\section{2 - Dimensões da Concepção de Saúde}

Como proposta de ação em saúde é necessário entender as várias dimensões que a concepção de saúde poderá assumir ${ }^{(120)}$.

Segundo Medeiros ${ }^{(87-8)}$ a habilidade ou capacidade de um indivíduo para desempenhar tarefas ou atividades da vida diária com satisfação, no caso específico, as relacionadas com sua participação no cuidado com a saúde, não depende somente do seu estado físico e mental, mas do contexto social em que vive e, em particular da sua cultura.

O modelo de Crenças em Saúde valoriza a concepção que um individuo possui sobre a sua própria saúde e de sua relação com o meio ambiente ${ }^{(24,120)}$. A compreensão da própria saúde, por uma pessoa, é influenciada pelo meio sóciocultural, ideológico e psicológico em que o indivíduo está inserido. Por isso, as noções de saúde também mudam de tempos em tempos, de cultura para cultura, de sociedade para sociedade e de individuo para indivíduo ${ }^{(48.111-2)}$.

A saúde também poderá ser pensada sob a visão dos fenomenólogos, como sugerida por $\mathrm{Gil}^{(50)}$, considera que a saúde se baseia em valores, símbolos e sistemas de significados compartilhados nos grupos de referência. Assim, sob uma visão mais holística a saúde deve ser pensada como um bem-estar integral: físico, mental, social e espiritual. Os indivíduos devem assumir sua responsabilidade inalienável frente as questões de sua saúde. As práticas da medicina holística devem ajudar as pessoas a desenvolver atitudes, disposições, hábitos e práticas que promovam seu bem-estar integral. O sistema de saúde deve ser orientado para tratar as causas ambientais, comportamentais e sociais que provocam doença. 
As pessoas devem se voltar para a harmonia com a natureza. utilizar práticas e meios naturais de tratamento ${ }^{(5) 1)}$.

Fstudo realizado por Rassi ${ }^{(20)}$ sobre os fatores de risco coronariano e riscos auto-criados em idosos (com idade média de 72.3 anos) demonstrou que $72 \%$ dos idosos não se consideram em risco coronariano enquanto na avaliação médica $86,4 \%$ estavam em risco moderado. Este estudo esclareceu que os conceitos de saúde eram distintos entre o usuário de serviço e o prestador de serviço de saúde ${ }^{(120)}$.

Os prolissionais de saúde. que buscam ações de saúde para melhorar a adesão ao tratamento e a mudança no estilo de vida do seu paciente. necessitarão de uma compreensão quanto a percepção subjetiva dos valores e crenças do próprio paciente 18.1121 .

Assim. para que uma ação de saúde possa ter um impacto positivo. principalmente quando relacionado as mudanças no estilo de vida. será necessário antecipadamente conhecer os conceitos de saúde da população alvo e a partir dai. planejar. organizar e avaliar açòes de saúde segundo a relação paciente-familiasociedade-serviços de saúde $1+18.12 .120 \%$.

Na carta de ()ttawa ${ }^{(*)}$ para a promoção da Saúde, de 21 de novembro de 1986. descreve: "A saúde vive e se cria na vida cotidiana: nos centros educacionais, no trabalho e no lazer. $A$ saúde é o resultado dos cuidados que cada um dispensa a si mesmo e aos demais. é a capacidade de tomar decisóes e controlar a própria vida e assegurar que a sociedade em que vive ofereça a todos os seus membros a possibilidade de ser saudável". "A promoção da saúde começa na participação efetiva

(*) Ministério da Saúde. Promoçåo da Saúde. Secretaria de Políticas de Saúde, 2001. 
e concreta da comunidade na eleição de prioridades. na tomada de decisões e na elaboração e desenvolvimento de estratégias para alcançar melhor nivel de saúde".

\subsection{Fator de risco coronariano}

O conceito de fator de risco é fundamentado em estudos epidemiológicos, clínicos, anatomopatológicos e experimentais como os de Framingham ${ }^{(10.26 .28 .33-4.54)}$

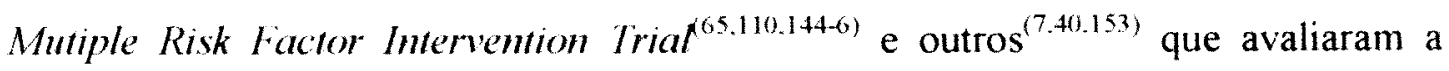
incidència de doença arterial coronariana e suas associações aos múltiplos fatores de risco $^{(30)}$, mostraram que quanto maior o número de fatores de risco maior a incidência de eventos coronários.

Segundo o Ministério da Saide ${ }^{i 95 /}$ (1993), um fator de risco, na concepção mais ampla, é um traço associado com risco aumentado de desenvolver doença.

Com o aumento da população idosa no Brasil, presume-se que haverá um aumento, em número absoluto, de pessoas vitimadas por enfermidades cardiovasculares $(1.36 .43 .118 .120)$

Sendo a doença arterial coronariana uma entidade multicausal, é esperado que o maior o número de fatores de risco associados condicione a uma maior probabilidade de um individuo desenvolver enfermidades cardiovasculares ${ }^{(6,7,13.21 .30}$. $35.40 .82 .92 .103 .124 .138-40.145 .153 .168)$

Em geral, os fatores de risco podem ser classificados em dois grandes grupos: os fatores de risco não modificáveis $e$ os fatores de risco modificáveis ${ }^{(1.6,21.28 \cdot 46,52,85,97)}$.

No relatório apresentado pelo National (holesterol Education Program (171) (1994) e outros estudos ${ }^{(1,82)}$ os fatores de risco para as enfermidades cardiovasculares 
não modificáveis considerados como clássicos estão relacionados com o sexo, a idade, a história familiar para doença coronariana, a raça e a sazonalidade. Segundo $\operatorname{Izar}^{((6))}(2000)$ os polimorfismos genéticos, como preditores de doença aterosclerótica, vêm ganhando mais importância. Entre os fatores genéticos, alguns relacionam-se a expressão de lipoproteinas aterogênicas, alterações na coagulabilidade, no estresse oxidativo, niveis aumentados de peptideos vasoativos, como a enzima de conversão da angiotensina, podendo atuar quer no desenvolvimento da doença aterosclerótica quer como substrato do evento agudo ${ }^{(66,76,104)}$. Alguns genes apresentam forte correlação com doença coronaria, enquanto a expressão de outros está restrita a subgrupos populacionais ${ }^{(16,47,66)}$

Os fatores de risco para as enfermidades cardiovasculares modificáveis estão relacionados com: hipertensão arterial, diabetes, dislipidemia, obesidade, consumo de álcool, sedentarismo, tabagismo, reposição hormonal por estrógeno em mulheres menopausadas, estresse, personalidade tipo A, profissão de risco e hábitos alimentares $^{(6,10,28.33-4.69 .71 .82 .97 .112-3.108,124.128-9.138-40)}$

Outros marcadores de risco, mais recentemente, tèm sido associados à doença arterial coronarianária como ${ }^{(13 \omega)}$. niveis séricos elevados de triglicérides ${ }^{(81 .}$ ${ }^{1(19)}$, lipoproteina a $[\operatorname{Lp}(\mathrm{a})]^{(17-9.67 .8(1-1.125 .130 .132)}$, homocisteína ${ }^{(106,14 \times .151 .163)}$, resistencia à insulina $^{(21.170)}$, inibidores do plasminogênio ${ }^{(57,60)}$, de fibrinogênio ${ }^{(11-2,29,44,68,86,119)}$, estresse oxidativo, estresse psicossocial, marcadores inflamatórios ${ }^{(58.122-3.135 .154)} \mathrm{e}$ agentes infecciosos ${ }^{(32,62,91,136,162)}$

Vários estudos tem demonstrado que após os 60 anos a prevalência das doenças cardiovasculares é praticamente a mesma em ambos os sexos $1.2 \times 33-4,82,85,161$. $164)$ 
Entre as pessoas com história familiar, principalmente com parentesco de

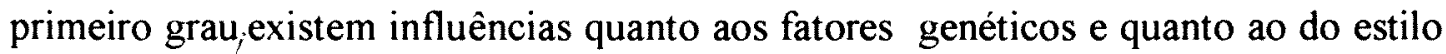
de vida adquirido pelas famílias ${ }^{(1.82 .85 .140 .201)}$.

Quanto à raça, segundo o Ministério da Saude ${ }^{(95)}$, a raça branca parece ter um risco maior para a doença das coronária e a raça negra para a hipertensão arterial.

Nos estudos de Framingham ${ }^{(10.27-8)}$ e Multiple Risk Factor Intervention Trial ${ }^{(10)}(1986)$, a probabilidade de risco para o desenvolvimento da doença coronariana foi associada a combinação de três fatores de risco dito principais: hipertensão arterial, dislipidemia e tabagismo.

No Brasil, segundo Lotufo ${ }^{(79)}(1996)$, os de três principais fatores de risco associados para o desenvolvimento da doença coronariana são: hipertensão arterial, obesidade e diabetes. Entre idosos, o estudo de Rassi (1998) identifica: obesidade, sedentarismo, dislipidemia, hipertensão arterial e diabetes como sendo os principais fatores de risco associados para doença coronariana. Segundo o II Consenso Brasileiro sobre Dislipidemia $(1996)^{(30)}$ os fatores de risco para doença coronariana mais importantes são: hipercolesterolemia por aumento do LDL-c, hipertensão arterial, tabagismo, diabetes e hereditariedade com história de doença arterial prematura.

Segundo os resultados da Trird National Health and Nutrition Examination Survey ${ }^{(22)}(1988-91)$, a hipertensão em idosos ficou em $64 \%$ semelhante ao encontrado no estudo de $\operatorname{Rassi}^{(120)}$ (1998) onde a prevalência foi de $67,7 \%$ e no ambulatório do serviço de Geriatria do Hospital das Clínicas da Faculdade de Medicina da Universidade de São Paulo onde a prevalência esteve em $65,7 \%{ }^{(25)}$. 
O controle da pressão arterial têm relação direta com a redução na incidência de eventos cardiovasculares ${ }^{(6,8,33.45,69.82 .97 .105,128-9,140.145)}$. Estudos com a participação dos idosos como: EWPHE ${ }^{(41)}(1985)$, SHEP ${ }^{(150)}(1991)$, STOP-HYPER TENSION $^{(31)}(1991)$, Syst-Eur ${ }^{(143)}(1997)$, The veterans administration cooperative study group on antihypertensive $\operatorname{agents}^{(159-60)}\left(1967\right.$ e 1970), The Oslo Study ${ }^{(59)}$ (1980), Management committee national heart foundation of $\operatorname{Australia}^{(90)}(1980)$, $\operatorname{MRC}^{(89)}(1983)$, MRFIT $^{(102)}(1985), \operatorname{IPPPSH}^{(152)}(1985), \operatorname{HAPPHY}^{(166)}(1987)$, Framin gham Heart Study ${ }^{(72)}(1988)$, MAPHY ${ }^{(165)}(1988)$ demonstraram os beneficios da redução da pressão arterial em idosos.

O Ministério da Saúde ${ }^{(94)}$ (1988) realizou um estudo multicêntrico sobre prevalência de Diabetes Mellitus (DM) no Brasil, onde, na cidade de São Paulo para a faixa etária de 30 a 69 anos ficou em $9,66 \%$ semelhante a população americana que era $6,6 \%$ para a mesma faixa etária.

Em nível nacional o Ministério da Saúde ${ }^{(96)}$ (1996) relatou que a prevalência de DM foi semelhante para ambos os sexos e aumentou com a idade. Em relação a faixa etária de 30 a 39 anos ficou em $2,7 \%$ e para a faixa etária de 60 a 69 anos ficou em $17,4 \%$. Quanto ao tipo de DM, $90 \%$ foi do tipo $2,8 \%$ foi do tipo 1 e $2 \%$ foi do tipo secundário ou associado à outras síndromes como doenças pancreáticas, doenças endócrinas, iatrogenias e doenças genéticas. Entre idosos, no estudo de Rassi ${ }^{(120)}$ (1998), a prevalência de DM ficou em $18,7 \%$ onde $87,1 \%$ eram do tipo 2 e $12,9 \%$ estavam em uso de insulina NPH 100. 
Estudos epidemiológicos como os de Stamler $^{(144-6)}$, demonstraram que a incidência de morbidade e mortalidade por doença arterial coronariana, em individuos diabéticos, esteve em aproximadamente duas a três vezes maior do que a observada na população geral. Foi também observado que a incidência de infarto do miocárdio chegou a ser sete vezes maior nos portadores de DM. Assim, os individuos com DM estão sujeitos a um risco de morte e/ou eventos coronarianos iguais as pessoas que já apresentaram infarto do miocárdio. Do ponto de vista de prevenção estes pacientes diabéticos devem ser considerados, pela equipe de saúde, como se fossem coronarianos.

No Brasil, os dados de 1998 do Datasus ${ }^{(101)}$ demonstraram que a mortalidade por DM, segundo o local de residência, foram semelhante quando comparado com o Estado de São Paulo com 3,0 óbitos/100.000 habitantes e 3,1 óbitos/100.000 habitantes respectivamente.

Segundo o Consenso brasileiro sobre diabetes $(2001)^{(15)}$ em relação ao tratamento do DM tipo 2, o estudo mais importante nesta linha foi o United Kingdom Prospective Diabetes Study (UKPDS) ${ }^{(181-3)}$. Este estudo analisou as consequências do controle rigoroso da hiperglicemia ${ }^{(156-7)}$ e da pressão arterial ${ }^{(158)}$ o que resultou na diminuição das complicações do DM e da mortalidade geral

Estudos realizados pela Associação Brasileira de Estudos da Obesidade $(\mathrm{ABESO})^{(14)}$, entidade ligada a International Obsity Task Force/OMS, identificaram 17,3\% dos brasileiros com obesidade (Índice de Massa Corpórea superior a $25 \mathrm{Kg} / \mathrm{m}^{2}$ ) no periodo de $1974 / 5$ em 1989 ficou 32,8\% e para o ano 2001 ficou estimado em 46\%. Entre os idosos, no estudo de Rassi ${ }^{(120)}(1998)$, a obesidade ficou em $62,9 \%$ dos idosos. 
Vários estudos demonstraram a associação entre a hipertensão arterial e o excesso de peso ${ }^{(28.84)}$. Levantamento realizado por Martinez ${ }^{(84)}$ demonstrou que $85 \%$ dos diabéticos com mais de 50 anos eram hipertensos e obesos; $80 \%$ dos obesos apresentavam hipertensão arterial e intolerância a glicose e $67 \%$ dos hipertensos eram diabéticos e obesos; estes dados foram semelhantes aos estudos de Framingham $^{(28)}$

Assim, considerando a freqüente associação do excesso de peso nos pacientes diabéticos, estudos como os de Scheen ${ }^{(133)}$ e Willianson ${ }^{(169)}$ mostraram que pequenas reduções de peso $(5 \%$ a $10 \%)$ se associaram a uma melhora significativa dos niveis pressóricos, nos índices de controle metabólico e reduziram a mortalidade relacionada ao diabetes.

O II Consenso Brasileiro de Dislipidemia ${ }^{(30)}(1996)$ com apoio da Sociedade Brasileira de Cardiologia/Departamento de Aterosclerose, Sociedade de Patologia Clínica e de Análises Clínicas, baseado no National Cholesterol Education Program $(1993)^{(39.149)}$ e American Heart Association ${ }^{(4.7,137)}$ propuzeram os valores de referência para o colesterol total (CT), lipoproteina de baixa densidade (LDL-c) e lipoproteina de alta densidade (HDL-c) para os indivíduos com idade igual ou superior a 20 anos onde como valores desejáveis para o colesterol total $<200 \mathrm{mg} / \mathrm{dl} \mathrm{e}$ niveis diferentes para o LDL-c de acordo com o risco cardiovascular de um indivíduo. No quadro I sumariza as recomendações para prevenções primárias e secundárias $^{(20,39,63,73)}$. 
Quadro 1 - Prevenção primária e secundária segundo o número fatores de risco e os valores de LDL-c desejáveis.

\section{Prevenção primária $\quad$ Valores de LDL-c desejáveis}

Menos de dois fatores de risco $\quad<160 \mathrm{mg} / \mathrm{dl}$

Dois ou mais fatores de risco $\quad<130 \mathrm{mg} / \mathrm{dl}$

Prevenção secundária ou $\quad<130 \mathrm{mg} / \mathrm{dl}$

Presença de diabetes mellitus

Obs: Em ambas as situações se deve buscar, se possível, um valor de HDL-c $>35$ $\mathrm{mg} / \mathrm{dl} \mathrm{e}$ de triglicérides $<200 \mathrm{mg} / \mathrm{dl} \mathrm{e}<150 \mathrm{mg} / \mathrm{dl}$ nos casos de diabetes mellitus.

O risco de Doença Cardiovascular aumenta significativa e progressivamente acima dos valores desejáveis de CT e LDL-c. Para o HDL-c, a relação de risco é inversa: quanto mais elevado seu valor, menor o risco de DCV. HDL-c $>60 \mathrm{mg} / \mathrm{dl}$ é um "fator protetor" de DAC enquanto que o HDL-c $<35 \mathrm{mg} / \mathrm{dl}$ tem um risco aumentado para DCV. A hipertrigliceridemia ( $\geq 200 \mathrm{mg} / \mathrm{dl}$ ) aumenta o risco de DCV, quando associados HDL-c diminuídos e/ou LDL-c aumentados. A hipertrigliceridemia do tipo endógina está presente em manifestações metabólicas como hiperuricemia e intolerância a glicose $\mathrm{e}^{30}$.

O II Consenso Brasileiro de Dislipidemia ${ }^{(30)}(1996)$ chama também atenção para as dislipidemias secundárias, onde as alterações mais freqüentes se referem ao aumento dos níveis desejáveis de triglicérides, diminuição do HDL-c e em alguns casos do colesterol total. Dentre as doenças que podem desenvolver a dislipidemia secundária temos: hipotiroidismo, síndrome nefrótica, insuficiência renal crônica, diabetes, obesidade, icterícia obstrutiva, alcoolismo e dislipidemias secundárias ao 
uso de medicamentos como: diuréticos, betabloqueadores, anticoncepcionais, corticóides e anabolizantes.

As dislipidemias associadas com outros fatores de risco aumentama prevalência de eventos coronarianos ${ }^{(30.134)}$.

Estudos da Scandinavian Simvastatin Study Group ${ }^{(131)}(1994)$ indicaram que o conhecimento de doença coronariana e a intervenção nos níveis das lipoproteinas levam a um decréscimo da mortalidade coronariana entre idosos

O conceito de que no idoso (idade igual ou superior a 65 anos) o controle dos fatores de risco, em particular as dislipidemias, não seria fundamental foi modificado. Sendo a doença aterosclerótica altamente freqüente após os 60 anos de idade, em ambos os sexos, qualquer redução do risco tem importante repercussão na sua morbidade e mortalidade ${ }^{(30)}$

\section{4 - Estratégias preventivas}

A estratégia de prevenção nas enfermidades cardiovasculares inclui medidas primárias, secundárias e terciárias ${ }^{(4,6.36,46,52-3.56,70.118 .129 .142)}$.

Segundo Alvarez et al. ${ }^{(6)}(1993)$, a prevenção primária inclui ações contra os fatores de risco para as enfermidades cardiovasculares, em uma comunidade, mediante modificação no estilo de vida, assim como, a identificação e o manejo dos fatores de risco a que uma pessoa está exposta.

Assim, segundo Stamler ${ }^{(146)}(1994)$, os cuidados com a prevenção primária dizem respeito ao aparecimento dos primeiros eventos clínicos das enfermidades ateroscleróticas como a cardiopatia coronariana, a enfermidade cerebrovascular ou a 
enfermidade vascular periférica. A principal estratégia na prevenção primária está no cuidado profilático antes de sua ocorrência.

O objetivo da prevenção secundária é a detecção das pessoas nas primeiras fases de uma enfermidade (antes que se manifestem os sintomas ou sinais) e o seu correto tratamento para reduzir a prevalência de uma enfermidade e a incapacidade que a origina ${ }^{(6)}$.

Essas estratégias de saúde baseiam-se em ensaios clínicos e epidemiológicos (10,23,28,33-4,71,144-5,147.167) que demonstraram acentuada redução da morbidade e mortalidade cardiovascular, através da modificação dos fatores de risco.

Segundo o II Consenso de Dislipidemia ${ }^{(30)}(1996)$ a terapêutica das dislipide mias, de comprovada eficiência, tem por finalidade fundamental a prevenção primá ria e secundária da doença arterial crônica e da doença aterosclerótica cerebrovascular e periférica. Eventualmente, pode objetivar a regressão de xantomas e a diminuição dos riscos de pancreatite aguda. Deve ser indicada sistematicamente e mantida indefinidamente.

A terapêutica deve ser iniciada com mudanças individualizadas no estilo de vida, que compreendem hábitos alimentares saudáveis, busca e manutenção do peso ideal, exercício físico aeróbico regular, combate ao tabagismo e promoção do equilibrio emocional. Não sendo atingidos os objetivos propostos, deve ser considerada a introdução de drogas isoladas ou associadas, dependendo das necessidades, com manutenção da dietoterapia. Excepcionalmente, outras medidas podem vir a ser adotadas, caso não ocorra sucesso no uso dessas drogas ou pela impossibilidade do paciente perseverar nos objetivos propostos ${ }^{(30)}$. 
Considerações a respeito da composição da dieta, segundo o Consenso de Dislipidemia $^{(30)}(1996)$, para reduzir a ingestão de colesterol, deve-se restringir o consumo de leite integral e seus derivados (queijos, principalmente amarelos, mantei ga, creme de leite), biscoitos amanteigados, croissants, folhados, sorvetes cremosos, embutidos em geral (linguiça, salsicha e frios), carnes vermelhas gordurosas, carne de porco (bacon, torresmos), vísceras (figado, miolo, miúdos); pele de animais terrestres, animais marinhos (camarão, lagosta, sardinha e outros frutos do mar).

Especial atenção deve se dar à redução na ingestão de gema de ovo (225mg/unidade), lembrando-se de que esta participa também no preparo de diversos alimentos (bolos, tortas, panquecas, macarrão, etc). Deve ser lembrado que o colesterol só existe em alimentos do reino animal ${ }^{(30)}$.

Para diminuir o consumo de ácidos graxos saturados, aconselha-se restrição na ingestão de gordura animal (carne vermelha, leite e derivados), da polpa do coco e do uso de alguns óleos vegetais (dendê e coco) no preparo de alimentos. Os ácidos graxos poliinsaturados da série N-6 têm como precursor o ácido linoléico e como fontes alimentares os óleos vegetais, exceto os de coco, cacau e palma (dendê). Os efeitos demonstrados, até o momento, são a redução do CT e do LDL-c e o aumento do HDL-c. A coç̧ão em escala doméstica não altera o grau de insaturação dos ácidos graxos. O precursor dos poliinsaturados omega-3 é o ácido alfalinoléico, cujas fontes são o tecido verde de plantas (não disponivel para o organismo humano) e a gordura de algumas espécies de peixe (ácido eicosapentaenóico e docosahexaenóico). Indivíduos que ingerem regularmente peixe têm níveis menores de CT e TG. Estes ácidos graxos poliinsaturados podem, às vezes, aumentar o HDL-c, o que é um efeito desejável. Os ácidos graxos monoinsaturados, cujo precursor é o ácido oléico, têm 
como principais fontes dietéticas azeite de oliva, óleo de canola, azeitona, abacate e oleaginosas (castanhas, nozes e amêndoas). Entre os principais efeitos citados, incluem-se o de diminuir o CT e o LDL-c e o de reduzir a agregação plaquetária, porém em menor grau do que os ácidos graxos poliinsaturados. As margarinas são substitutas das manteigas e têm composição lipídica variada. Possuem diferentes proporções de ácidos graxos saturados, poliinsaturados, monoinsaturados e de ácidos graxos na forma transisomérica. Não possuem colesterol ${ }^{(30)}$.

As Fibras são carboidratos complexos, não absorvidos pelo intestino, e com ação reguladora na função gastrointestinal. A quantidade recomendada de fibras para adultos é de 20 a $30 \mathrm{~g} / \mathrm{dia}$, o que se consegue aumentando a ingestão de vegetais folhosos, leguminosas e cereais. Podem ser classificadas em fibras solúveis e insolúveis. As Fibras solúveis em água são representadas pela pectina (frutas) e as gomas (leguminosas, aveia e cevada). Atuam retardando o esvaziamento gástrico e aumentando o tempo de trânsito intestinal; tornam mais lenta a absorção da glicose, retardam a hidrólise do amido e reduzem os níveis de CT e LDL-c. As Fibras insolúveis em água são constituídas pela celulose (trigo) e hemicelulose (grãos) e lignina (hortaliças). Atuam encurtando o tempo de trânsito intestinal e aumentando o volume fecal; torna mais lenta a absorção de glicose e retardam a absorção de amido. As fibras insolúveis não têm ação sobre o $\mathrm{CT}$, mas são úteis na diminuição da ingestão calórica ${ }^{(30)}$.

Em termos práticos, a mudança de hábitos alimentares deve ser feita sem que o paciente necessite se ater a detalhes de cardápios alimentares e à composição em gordura dos alimentos. A base da alimentação deve consistir de carnes brancas (aves sem pele e peixes), carne vermelha sem gordura aparente, todos os cereais, vegetais, 
frutas, óleos vegetais (exceto de coco e de palma), margarina cremosa, leite desna tado e seus derivados. Deve se ter em conta que a dieta estritamente vegetariana pode ser eficiente, mas envolve outros princípios e, a longo prazo, pode acarretar deficiências nutricionais ${ }^{(30)}$.

No tratamento farmacológico são destacados alguns medicamentos, que possuem diferentes mecanismos de ação, disponíveis em nosso país como as Vastatinas, primeira escolha para a terapêutica da hipercolesterolemia isolada, poligênica ou familiar heterozigota. Resultam na diminuição do colesterol total (ao redor de $30 \%$ ) e do LDL-c ( $20 \%$ a $40 \%$ ), dos triglicérides e das VLDL (ao redor de $20 \%$ ) e elevação do HDL-c (até $10 \%$ ). Apresenta boa tolerância em idosos. Apresentações: Lovastatina, Sinvastatina, Pravastatina e a Fluvastatina ${ }^{(30)}$.

Outro medicamento são os seqüestradores de ácidos biliares. Resultam na diminuição do colesterol total e do LDL-c (até 30\%), podem elevar o triglicérides ao redor de $10 \%$ a $20 \%$ e elevar em até $8 \%$ o HDL-c. São indicados como primeira escolha no tratamento das diversas formas de hipercolesterolemia familiar, em crianças e mulheres em idade fértil sem controle contraceptivo adequado e em gestantes ${ }^{(30)}$. Apresentação: Colestiramina ${ }^{(30)}$

Temos ainda os Fibratos que levam a diminuição do dos triglicérides e das VLDL-c (até $70 \%$ ), do colesterol total e do LDL-c (até $20 \%$ ), elevam as taxas do HDL-c (até $25 \%$ ) e não têm ação sobre os quilomicrons. Em alguns casos com hipertrigliceridemia acentuada, pode ocorrer aumento transitório do LDL-c. Potencializam a ação de anticoagulantes orais e possuem efeito hipoglicemiante. São drogas de primeira escolha no tratamento das hipertrigliceridemias endógenas, da disbetalipoproteinemia e das hiperlipidemia mista quando os triglicérides forem 
muito elevados. São de uso alternativo nas hipercolesterolemias ${ }^{(30)}$. Apresentações: Bezafibratos, Gemfibrozil, Fenofibratos e Etofibratos ${ }^{(30)}$.

O Ácido Nicotínico e derivado é outra opção para a redução do CT e LDL-c (até $30 \%$ ), dos triglicérides e VLDL-c (até $80 \%$ ) e elevação do HDL-c (até 30\%). Sua intolerância é mais freqüente que os anteriores. São indicados como alternativa no tratamento das hiperlipidemias mistas e da hipercolesterolemia isoladas ${ }^{(30)}$. Apresentações: ácido nicotínico e o derivado acipimox ${ }^{(30)}$

O Probucol, de mecanismo de ação hipolipemiante não totalmente esclarecido, resulta na diminuição do colesterol total e LDL-c (15\% a 20\%), aumento do HDL-c (até 30\%) e não altera os níveis séricos de triglicérides. Pode ser usado em associação com outras drogas no tratamento de hipercolesterolemia isolada. Apresentação: Probucol.

Por último temos os Ácidos Graxos Ômega-3, que diminuem a produção das VLDL-c e modificam o metabolismo das prostaglandinas. Requer doses elevadas (10 a 20g/d) limitando o seu uso eventualmente à associação com os fibratos e em raros casos de hipertrigliceridemias resistentes resistentes ${ }^{(30)}$.

Em mulheres no período climatérico pós-menopausal a reposição hormonal é importante arma terapêutica coadjuvante. $O$ uso de estrogênios tem sido associado à redução do LDL-c (até 25\%), ao aumento do HDL-c (até 20\%), à diminuição de fatores pró-trombóticos, como fibrinogênio e $\mathrm{Lp}(\mathrm{a})^{(30)}$. Estudos epidemiológicos observacionais sugerem a diminuição do risco coronariano (em torno de $50 \%$ ) e aumento da sobrevida em usuárias de estrogênios conjulgados eqüinos ${ }^{(30,74,134,155)}$. 
Na presença de diminuição isolada de HDL-c, não é recomendado o uso de medicamentos $^{(30)}$. Entretanto, deve-se estimular o controle da obesidade, diabetes, a prática de exercícios físicos aeróbicos continuados e o abandono do vício de fumar.

Estudos como National Cholesterol Education Program $(\mathrm{NCEP})^{(110)}(2.000)$ com 4.888 pacientes em tratamento para hipercolestorelemia mostraram que $63 \%$ dos pacientes com dois ou mais fatores de risco não atingiram as metas do NCEP e $82 \%$ dos pacientes com DCV não atingiram as metas do NCEP. Assim, apesar das recomendações, a maior parte dos individuos sob risco coronariano de DCV e mortalidade elevada não atingiram as metas propostas de prevenção. Entretanto, vale observar que os efeitos benéficos demonstrados nos estudos de prevenção primária e secundaria começam a aparecer entre o $1^{\circ}$ e o $2^{\circ}$ anos de seguimento e alcançam sua plenitude, em tomo do $5^{\circ}$ ano. O tratamento efetivo e permanente das dislipidemias pode diminuir a velocidade de progressão da placa aterosclerótica, promover sua estabilização e regressão, e evitar o aparecimento de novas lesões em artérias nativas e enxertos de veia safena. Essas ocorrências levam a grandes beneficios clínicos, com redução da incidència de novos eventos cardiovasculares e aumento da sobrevida ${ }^{(30)}$

No tratamento do idoso, deve-se levar em consideração: idade biológica e cronologica, perfil de longevidade familiar, associação de outros fatores de risco comuns nessa faixa etária (hipertensão arterial e diabetes), presença de doença ateros clerótica, estado fisico geral, doenças crônicas associadas e interações medicamento $\operatorname{sas}^{(30)}$ 
Estudos clínicos recentes em idosos de prevenção primária ${ }^{(37-8)}$ e secundária (38,49,77,93,113.127) sugerem que a redução expressiva do LDL-c diminui significativa mente a morbidade e a mortalidade por doença arterial crônica. Nessa faixa etária, deve ser dada especial atenção ao afastamento de causas secundárias de dislipidemia, principalmente hipotireoidismo, diabetes e insuficiência renal crônica ${ }^{(30)}$.

Para a hipercolesterolemia, deve ser indicada inicialmente com dieta, com especial atenção para a ingestão calórica e as necessidades vitaminicas e minerais (cálcio ). As recomendações para o tratamento farmacológico de idosos, de ambos os sexos, são as mesmas dos adultos em geral. As vastatinas são as drogas de primeira escolha no tratamento da hipercolesterolemia. Os demais hipolipemiantes podem ser usados, levando-se em consideração a maior possibilidade de efeitos colaterais. Para hipertrigliceridemia, o tratamento segue os mesmos princípios do adulto jovem ${ }^{(30)}$.

Igual importância terapêutica deve ser dada ao controle de outros fatores de risco, como Hipertensão Arterial e Diabetes. Na escolha das drogas anti-hipertensivas, lembrar que diuréticos como tiazidicos e betabloqueadores sem atividade simpatomimética intrínseca podem ter efeitos adversos sobre o perfil lipídico ${ }^{(30)}$.

O exercicio físico aeróbico praticado regurlamente, em particular caminhadas ( 30 minutos, 3 a 4 vezes por semana no mínimo), é indicado como medida associada para o controle dos fatores de risco, respeitando as limitações próprias da idade ${ }^{(30)}$. 
2. 


\section{Justificativas}

\section{1 - Estudos entre idosos}

Segundo Ramos ${ }^{(181)}$ (2.002) os estudos longitudinais, com amostras populacionais, especialmente desenhados para avaliar os fatores de risco para mortalidade em idosos, ainda são relativamente raros na literatura. Alguns estudos discutem fatores de risco para mortalidade em idosos, mas baseiam-se em amostras não populacionais, ou analisam amostras populacionais que não foram originalmente selecionadas para estudar idosos.

Estudos prospectivos entre idosos, acompanhados no mínimo por cinco anos, de prevenção primária como: AFCAPS/TEXCAP ${ }^{(38)}$ (idosos com idade média de 73 anos) e WOSCOPS ${ }^{(180)}$ (idosos com idade média de 64 anos) e os estudos de prevenção secundária como: $4 \mathrm{~S}^{(73)}$ (idosos com idade média de 70 anos), $\mathrm{CARE}^{(177)}$ (idosos com idade média de 75 anos), LIPID $^{(113)}$ (idosos com idade média de 75 anos), SHEP ${ }^{(183)}$ (idosos com idade média de 60 anos) e MRC ${ }^{(178)}$ (idosos com idade média de 65 anos) deixam claro que o controle dos fatores de risco coronariano entre idosos repercutem diretamente na diminuição da morbidade e da mortalidade.

No Brasil, estudos longitudinais com base populacional foram apresentados recentemente como "Simpósio: Estudos Longitudinais com Idosos na comunidade, no Brasil" durante o XIII Congresso Brasileiro de Geriatria e Gerontologia ${ }^{(176)}$ (2.002), onde estão em andamento os Projetos como: o Projeto Epidoso ${ }^{(179.181)}$ do Município de São Paulo, Projeto Veranópolis ${ }^{(174)}$ do Rio Grande do Sul, Projeto Bambui ${ }^{(173-4)}$ de Minas Gerais e de Imigrantes Japoneses que vivem na Região Sul do Brasil ${ }^{(175)}$ 


\section{2 - Desafios deste estudo}

Este trabalho foi desenhado com o objetivo de analisar os idosos residentes na zona norte de São Paulo durante o período de 1997 a 2.001. Esses idosos têm como referencia o local onde o estudo foi desenvolvido, conforme descrito no item 4 Metodologia.

Atraves do trabalho apresentado por Rassi, "Fatores de Risco ('oronariano e Riscos auto-criados em idosos ${ }^{\text {(20) }}(1998)$ foi possivel estabelecer, o assim considerado, ponto zero para o acompanhamento médico-geriátrico dos idosos expostos aos fatores de risco coronariano particularmente no que se refere ao controle da pressão arterial. colesterol, glicemia e peso. Como também conhecer a opiniào dos idosos aos fatores de risco coronariano e compara-los com a avaliação médica-geriátrica. Além de identificar o perfil sócio-econòmico destes idosos

Assim, como características epidemiológicas do grupo de idosos em estudo destacamos a faixa etária entre 65 a 94 anos, com idade média de 72,3 anos $(\mathrm{DP}=5,8$ anos $), 86,4 \%$ (286 idosos) do sexo feminino, $78,2 \%$ (259 idosos) da raça branca, $56,5 \%$ (187 idosos) com rendimento entre zero a um salário minimo/mês, $51,7 \%$ (171 idosos) viúvos, $38,4 \%$ (127 idosos) casados, $9,9 \%$ (33 idosos) separados/divorciados, $53,5 \%$ (177 idosos) com até três anos de estudo, 23,6\% (78 idosos) moram sozinho, $26,6 \%$ moram com o marido/esposa/companheiro/companheira, $49,8 \%$ (165 idosos) moram com algum familiar ${ }^{(126)}$.

As classificações dos riscos coronarianos foram observados que: $86,4 \%$ (286 idosos) apresentaram risco moderado enquanto na opinião dos idosos 71,6\% (237 idosos) relataram não estarem exposto aos riscos coronarianos estudados ${ }^{(120)}$. 
A associação dos très fatores de risco mais frequentes, com $70,4 \%$ (233) dos idosos, deu-se para: idade/sexo, obesidade e falta de atividade fisica esportiva Os outros fatores de risco associados aos mais frequentes foram: $35,7 \%$ (144 idosos) dislipidemia, $17,3 \%$ (70 idosos) hipertensào arterial e 13,6\% (55 idosos) diabetes. Na opinião dos idosos somente $2,7 \%$ (9 idosos) identificaram três principais fatores de risco coronariano: dislipidemia, falta de atividade fisica esportiva e obesidade ${ }^{(120)}$

A prevalência da obesidade, IMC maior que $24,9 \mathrm{~kg} / \mathrm{m}^{2}$, foi $62,9 \%$ (208 idosos) $\mathrm{Na}$ opinião dos idosos, 81,3\% (269 idosos) consideraram a obesidade como risco coronariano

A prevalència de atividade fisica esportiva foi $20,2 \%$ (62 idosos). $\mathrm{Na}$ opinião dos idosos que praticam atividade fisica esportiva $86,6 \%$ (58 idosos) consideram que esta ajuda o coração, ja na opinião dos idosos que não praticam atividade fisica esportiva somente $31,1^{\circ} \%(82$ idosos) consideram que a prática da pratica de atividade fisica esportiva ajuda o coração ${ }^{(120)}$.

A prevalència de dislipidemia, dosagem do colesterol total acima de 200 $\mathrm{mg} / \mathrm{dl}$, foi $79,7 \%$ (264 idosos). A incidencia ficou em $21,5 \%$ (71 idosos) Na opiniào dos idosos, $56,2 \%$ (186 idosos) consideraram que o colesterol total como fator de risco coronariano ${ }^{(120)}$.

A prevalència de hipentensão anterial, pressão arterial acima de $130 \times 85$ $\mathrm{mmHg}$, foi $67,7 \%$ (224 idosos) $\mathrm{Na}$ opinião dos idosos, $14,5 \%$ (48 idosos) consi deraram a pressão arterial como risco coronariano ${ }^{(120)}$. 
A prevalência de diabetes, glicemia de jejum acima de $110 \mathrm{mg} / \mathrm{dl}$, foi $18,7 \%$ (62 idosos) onde 87,1\% (54 idosos estão em uso de hipoglicemiante oral e 12,9\% (8 idosos) em uso de insulina NPH 100 mista/humana. A incidência de diabetes foi $1,5 \%$ (5 idosos). Na opinião dos idosos $64,9 \%$ (39 idosos) consideraram a diabetes como fator de risco coronariano ${ }^{(120)}$.

$\mathrm{Na}$ opinião de $19,1 \%$ (63) idosos) idade/sexo são fatores de risco coronariano $^{(120)}$

A prevalência de tabagismo foi $8,7 \%$ (29 idosos). Na opinião dos idosos tabagistas $44,8 \%$ ( 13 idosos) consideram o tabagismo como risco coronariano. A prevalència de ex-tabagista foi $25,1 \%$ (83 idosos). Na opinião dos idosos extabagistas $28,9 \%$ (24 idosos) consideram o ex-tabagismo como risco coronaria no ${ }^{(120)}$. E interessante observar que, neste estudo, 66,2\% (219) dos idosos negam tabagismo e não consideraram o fumo como risco coronariano para a própria saude $e^{(120)}$

Acreditamos que o envolvimento dos idosos e de seus acompanhantes (familiares ou cuidadores) possa ter um papel importante no controle dos fatores de risco coronarianos modificaveis

Isto será possivel, à medida que o médico e/ou equipe de saude, conduza e esclareça os idosos para que estes se tornem independentes e responsáveis pelo auto-cuidado. Os acompanhantes necessitam de esclarecimentos constantes do tratamento proposto para reforçar a adesão do idoso às propostas indicadas.

Segundo Romano $(2.002)^{(182)}$, qualidade de vida depende muito do autocuidado e da participação ativa do individuo em seu tratamento. 
Estes são os desafios do presente trabalho, onde acompanharemos durante quatro anos um grupo de idosos no manejo dos fatores de risco coronarianos

\section{3- Referências Bibliográficas Complementares}

172. Barreto SM. Avaliação da interpretação computadorizada do ECG em estudos populacionais em idosos. Projeto Bambui. In: Anais do XIII Congresso Brasileiro de Geriatria e Gerontologia e Il Congresso de Geriatria e Gerontologia da SBGG-RJ - "Contradições do Envelhecer no Brasil: Tecnologia e Carências", 2002, 19 a 22 junho, p. 6

173. Barreto SM, Passos VMA, Lima-Costa MF. Hipertensão Sistólica isolada em idosos na comunidade: prevalència e fatores associados. Projeto Bambui In: Anais do XIII Congresso Brasileiro de Geriatria e Gerontologia e II Congresso de Geriatria e Gerontologia da SBGG-RJ - "Contradições do Envelhecer no Brasil: Tecnologia e Carências"; 2002, 19 a 22 junho, p.6.

174 Correia MBS, Silva MVO, Araujo KA, Souza CM, Schwanke CHA, Cruz IBM, Moriguchi EH. Estudo Comparativo do perfil lipídico de duas populações de longevos: Salvador/ Ba e Veranópolis/RS. In: Anais do XIII Congresso Brasileiro de Geriatria e Gerontologia e Il Congresso de Geriatria e Gerontologia da SBGG-RJ - "Contradições do Envelhecer no Brasil: Tecnologia e Carências"; 2002, 19 a 22 junho, p.33 
175. Cruz IBM, Taufer M, Gewe HRC, Oliveira G, Schwanke CH, Leal NYF, Moriguchi EH, Moriguchi Y, Carvalho D. Estudo de associação entre evolução da pressão arterial sistêmica durante 30 anos de seguimento em imigrantes japoneses que vivem na Região Sul do Brasil e polimorfismo genético da enzima conversora da angiotensina. In: Anais do XIII Congresso Brasileiro de Geriatria e Gerontologia e II Congresso de Geriatria e Gerontologia da SBGG-RJ - "Contradições do Envelhecer no Brasil: Tecnologia e Carências"; 2002,19 a 22 junho, p. 9.

176. Drucker C, Costa MFL, Ramos LR, Cruz I. Simpósio: Estudos Longitudinais com idosos na Comunidade, no Brasil. [videocassete produções TVMED - fita $n^{\circ} 17$ do XIII Congresso Brasileiro de Geriatria e Gerontologia e II Congresso de Geriatria e Gerontologia da SBGG-RJ "Contradiçōes do Envelhecer no Brasil: Tecnologia e Carências"; 2002, 19 a 22 junho]. www.tvmed com.br.

177. Flaker GC, Warnica JW, Sacks FM et al. Cholesterol and recurrent events (CARE) Investigators. Provastatin prevents clinical events in revascularized patients with average cholesterol concentrations. J Am Coll Cardiol 1999; $34: 106-12$

178. MRC Working Party. Medical research council trial of tretment of hypertension in older adults: principal results. BMJ 1992; 304:405-12. 
179. Oil-Jr LA, Irikawa T, Cruz EC, Kaiikawa MM, Cendoroglo MS, Ramos LR. Mortalidade proporcional por causas em uma coorte de idosos residentes na comunidade no Municipio de São Paulo de 1991 a 1998. In: Anais do XIII Congresso Brasileiro de Geriatria e Gerontologia e II Congresso de Geriatria e Gerontologia da SBGG-RJ - "Contradições do Envelhecer no Brasil: Tecnologia e Carências", 2002, 19 a 22 junho, p.29.

180. PPP Project Investigators. Design, rationale and baseline chacacteristics of the prospective pravastatin pooling (PPP) Project. A combined analysis of three large-scale randomized trials: Long term intervention with pravastatin in ischaemic disease (LIPID), cholesterol and recurrent events (CARE) and West of Scotland coronary prevention study (WOSCOPS). Am J Cardiol $1995 ; 76: 899-905$.

181. Ramos, LR. Epidemiologia do Envelhecimento. In: Freitas EU, Py L, Neri AL, Cançado FAX, Gorzoni ML, Rocha SM. Tratado de Geriatria e Gerontologia. Editora Guanabara Koogan S.A. RJ - RJ, 2002. p. 72-8.

182. Romano BW, Coelho MGC. Aspectos psicológicos na determinação do comportamento dos pacientes diante das doenças crônicas. In: Mion Jr D, Nobre F. Risco Cardiovascular Global: convencendo o paciente a reduzir o risco. Lemos Editorial, $3^{\text {a }}$ ed. São Paulo - SP, 2002, p.44-56.

183. SHEP Cooperative research group. Prevention of stroke by antihypertensive drug treatment in older persons with isolated systolic hipertension: final results of the systolic hypertension in the Elderly Program (SHEP). JAMA $1991 ; 265: 3255-64$. 
3. Ondertros 
3- Objetivos

3.1- Objetivos Gerais

Analisar anualmente, os fatores de risco coronarianos entre os idosos em acompanhamento ambulatorial médico-geriátrico durante quatro anos consecutivos.

\section{2- Objetivos Específicos}

Descrever o comportamento médio dos fatores de risco coronariano ao longo dos anos.

- Descrever a contribuição dos fatores de risco coronariano em relação ao risco coronariano total.

Comparar as proporções de pacientes classificados com risco coronariano: potencial, moderado e alto ao longo dos anos.

- Comparar as proporções de pacientes com Hipertensão Arterial Sistólica associado ou não a Diabetes Mellitus.

Descrever o comportamento da classificação do risco coronariano ao longo dos anos. 


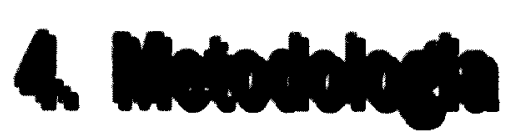




\section{Metodologia}

\section{1 - Tipo de Estudo}

Estudo Descritivo Prospectivo

\section{2 - Local de Estudo}

Ambulatório de Especialidades Municipal da Administração Regional da Saúde 7 (ARS - 7) da cidade de São Paulo, que compreende os bairros de: Vila Maria, Santana, Jaçanã, Tucuruvi, Mandaqui, Tremembé, Vila Guilherme e Vila Medeiros $^{126}$.

\section{3 - Características do Ambulatório}

Esse ambulatório de especialidades, de atenção secundária e de referência para a zona norte de São Paulo, realizava atendimento: médico em várias especialidades, odontológico, psicológico, fisioterapêutico, fonoaudiológico, enfermagem e assistência social à população residente na ARS-7 através de consultas agendadas, não sendo realizados atendimentos de urgência ou emergência.

As consultas agendadas no setor de geriatria eram divididas em quatro consultas novas (primeira avaliação no setor) e oito consultas de retorno (acompanhamento) num total de doze consultas dia. 
Entre o final do ano 2000 e até maio de 2001 foi estabelecido um acordo informal com a direção do Ambulatório de Especialidade para garantir o acompanhamento dos pacientes em estudo e amenizar o tempo de espera de mais de 100 dias para nova avaliação médica-geriátrica. Neste entendimento, foi priorizando no agendamento, os atendimentos de consultas médico-geriátrico aos pacientes em acompanhamento prévio no setor de geriatria.

\section{4 - Seleção da população de estudo}

\subsection{1 - Critérios de Inclusão}

Participaram desse estudo, todas as pessoas com idade igual ou superior a 65 anos, que passaram no setor de geriatria em consulta médicageriátrica no periodo de 11 abril a 30 de dezembro de 1997 com pelo menos um resultado de exames de glicemia de jejum e colesterol total e que continuaram o seu acompanhamento médico-geriátrico durante quatro anos seguidos.

\subsection{2 - Critérios de Exclusão}

Foram excluídos os pacientes com menos de quatro anos de acompanhamento médico-geriátrico. 


\section{5 - Técnica de abordagem}

Durante o periodo de estudo, todos os pacientes em acompanhamento na consulta médico-geriatrica, eram orientados a estarem acompanhados por familiar ou responsável. Os exames de rotina eram realizados na primeira consulta anual.

Os exames de rotina foram baseados na "Tabela de Risco Coronariano da American Heart Association" (1973), vide anexo I, onde foram solicitados: a glicemia de jejum, o colesterol total e fraçðes e o triglicérides.

Além dos exames laboratoriais propostos pela "Tabela de Risco Coronariano da American Heart Association" foram solicitados como rotina o TSH, a urina tipo 1, o Eletrocardiograma. Outros exames foram solicitados de acordo com a necessidade de cada caso.

Os exames alterados eram monitorizados durante 0 ano.

Em todas as consultas médico-geriátricas foram padronizadas aplicaç̋̃es de um "Roteiro de Educação Médica Continuada para Pacientes e/ou com Acompanhante sobre os Fatores de Risco Coroanriano", como descrito em seguida.

Este roteiro foi baseado em estudo anterior de Rassi (120) "Fatores de Risco Coronariano e Riscos auto-criados em idosos" para atender as necessidades deste grupo de estudo como também de seus acompanhantes.

Assim, durante a consulta médica, foi possível apresentar esclarecimentos ao paciente e seu acompanhante quanto aos fatores de risco coronariano em que os pacientes estão expostos e como controlá-los.

O tempo estimado para consulta médica esteve em trinta minutos. 


\section{Roteiro de Educacão Médica Continuada para Pacientes e/ou Acompanhante}

\section{sobre os Fatores de Risco Coronariano}

- Fazer uso continuo e corretamente da medicação prescrita (a médica deverá esclarecer ao paciente e/ou acompanhante o por que de cada medicamento prescrito, seus efeitos positivos e colaterais)

- Estimular para hábitos alimentares saudáveis como:

- Consumir carnes brancas (aves sem pele e peixe) e carne vermelha sem gordura aparente,

- Aumentar o consumo de fibras do tipo folhosas, leguminosas, cereais e frutas,

- Diminuir o consumo de açúcar refinado dando preferência ao uso de adoçantes artificiais,

- Evitar frituras, dar preferência ao uso de margarinas, azeite de oliva, óleo canola, castanhas, nozes e amêndoas,

- Buscar e/ou manter o peso ideal,

- Estimular o exercício físico aeróbico regular, principalmente as caminhadas em horário matutino ou vespertino no mínimo trinta minutos por dia em três vezes por semana,

- Reforçar a necessidade do abandono do tabagismo,

- Estimular a participação em grupos comunitários com atividades direcionadas para $3 .^{a}$ idade nas igrejas, centros de saúde, centros comunitários, associações que objetivam a promoção do equilibrio emocional, físico e social,

- A médica, com os resultados dos exames laboratoriais em mãos deverá sensibilizar o paciente ao auto-cuidado explicando o resultado de cada exame solicitado e as metas a serem atingidas em cada um deles, 
- A medida do Peso em cada consulta médica deverá ser um reforço para se alcançar o peso ideal. Entretanto deverá ser usado a estratégia do reforço positivo independente da medida de peso realizada,

- A medida da Pressão Arterial, observando-se um repouso inicial de 15', deverá ser um meio de reforço para o uso correto da medicação prescrita sendo informado a pressão arterial esperada para cada paciente como ideal,

- O controle quinzenal da pressão arterial pela enfermagem deverá ser um instrumento para monitorização da pressão arterial, bem como um estímulo para que o paciente siga corretamente a medicação prescrita e adquira hábitos saudáveis,

- O controle semanal ou quinzenal de todos os pacientes com diabetes pela enfermagem será um instrumento de monitorização de glicemia, sendo usado como reforço para o controle do diabetes. Será solicitado a todos os pacientes diabéticos que seja realizado antes ou depois da consulta médica um teste capilar de glicemia para que o médico sensibilize a necessidade do monitoramento da glicemia e os valores ideais esperados,

- Será estimulado pelo médico e pela enfermagem que o paciente aprenda a monitorizar a sua glicemia esclarecendo os valores de referencia esperados e os procedimentos básicos se sua glicemia estiver alterada.

\section{6 - Termo de Anuência}

O termo de anuência à participação do estudo foi realizado na primeira consulta médico-geriátrica, em 1997, onde foi esclarecido ao paciente e/ou acompanhante, que a proposta do atendimento médico é de acompanhamento do 
paciente com exames laboratoriais de rotina anuais além dos necessários para o acompanhamento clínico do paciente, exame clínico com: medida da pressão arterial, medida do peso, ausculta cardíaca, ausculta pulmonar e avaliação dos membros superiores e inferiores. E que será aplicado um roteiro de educação médica sobre os fatores de risco coronariano em todas as consultas médicas. Todos os pacientes e acompanhantes estiveram de acordo. Segue, em Anexo III, o modelo do "Termo de Anuência - Fatores de Risco Coronariano em idosos".

\subsection{Instrumento para coleta de dados}

Será aplicada anualmente a "Tabela de risco coronariano", segundo os resultados dos exames de rotina e avaliação clínica médica.

A médica identificará os fatores de risco coronariano, onde, para cada item avaliado (fumo, idade e sexo, peso, atividade física, antecedentes familiares, pressão arterial sistólica, glicemia de jejum e colesterol total) haverá uma pontuação correspondente.

\section{8 - Critérios para coleta de exame de sangue}

Para a coleta de exame de sangue de glicemia de jejum e do colesterol total foram respeitados os critérios segundo Glueck e Margolin ${ }^{(51)}(1995)$ adotados como referência nacional.

Assim, não foram considerados os exames em que o paciente estivesse em estado febril e/ou durante ou dentro de 4 semanas de um infarto agudo do miocárdio, acidente vascular cerebral ou de cirurgia de grande porte e/ou imediatamente após ingestão excessiva aguda de álcool e/ou durante processo infeccioso (como por 
exemplo: pneumonias, pielonefrites e etc.) e/ou diabetes gravemente descompensada e/ou durante rápida perda de peso devido à ingestão hipocalórica intensa.

A coleta das amostras de sangue realizou-se após um período de 12 horas em jejum.

O laboratório onde foram realizados os exames participa do controle de qualidade da Sociedade de Patologia Clínica, onde é respeitado o programa de padronização nacional para as dosagens das lipoproteínas como é recomendado pelo "Center for disease control".

\section{9 - Critérios para avaliação do peso}

$\mathrm{Na}$ avaliação do peso foram usadas as medidas antropométricas de peso e altura para posterior cálculo do Índice de Massa Corpórea (IMC).

O peso foi medido através de balança antropométrica com precisão de 100 gramas, com capacidade para $150 \mathrm{Kg}$, tipo plataforma, marca Welmy, modelo . $^{0}$ 110 , número de série 7175 , colocada sobre superfície plana, sendo o idoso pesado descalço e com o mínimo de roupas, situado no centro da plataforma, com os braços naturalmente ao lado do corpo sem tocar na balança. A altura foi aferida através do estadiômetro da balança com escala de medida de $0,1 \mathrm{~cm}$, com o idoso colocado em posição ereta, descalço, com os calcanhares e pernas próximos a barra de medição.

$\mathrm{Na}$ avaliação do peso, o peso normal relaciona-se ao IMC inferior a 24,9 $\mathrm{Kg} / \mathrm{m}^{2}$. Segundo a tabela adotada, a pontuação do peso relacionou-se ao calculo do peso normal. Através da fórmula de $\mathrm{IMC}=\operatorname{Peso}(\mathrm{Kg}) / \operatorname{Altura}^{2}\left(\mathrm{~m}^{2}\right)$ sabemos que o Peso Normal $(\mathrm{Kg})=24,9 \times$ Altura $^{2}\left(\mathrm{~m}^{2}\right)$. Assim, foi realizado um Quadro, Anexo I, 
relacionando altura e peso normal segundo o IMC de $24,9 \mathrm{Kg} / \mathrm{m}^{2}$ objetivando facilitar a classificação do peso atual do paciente no momento da consulta médica.

Assim, o médico pode aferir rapidamente o peso do paciente segundo a pontuação correspondente à tabela adotada.

Para classificação do peso segundo a tabela adotada e a posterior classificação do I M C adotaremos os referenciais da Figura 1.

Figura 1 - Classificação do peso $(\mathrm{Kg})$ e I M C $\left(\mathrm{Kg} / \mathrm{m}^{2}\right)$.

\begin{tabular}{cc}
\hline \multicolumn{1}{c}{ Peso } & I M C \\
$(\mathrm{Kg})$ & $\left(\mathrm{Kg} / \mathrm{m}^{2}\right)$ \\
\hline$-5 \mathrm{Kg}$ do Peso Normal $(\mathrm{PN})$ & $<20$, baixo peso ou desnutrido \\
$\mathrm{PN} \geq+4 \mathrm{Kg}$ do PN & $20 \geq 24,9$ normal ou eutrófico \\
$+5 \mathrm{Kg}$ do PN $\geq+10 \mathrm{KgdoPN}$ & $25 \geq 29,9$ obesidade leve ou Grau I \\
$+11 \mathrm{Kg}$ do PN $\geq+19 \mathrm{KgdoPN}$ & $30 \geq 36,1$ obesidade moderada ou Grau II \\
$+20 \mathrm{Kg}$ do PN $\geq+25 \mathrm{Kgdo} \mathrm{PN}$ & 36,2 a 39,9 obesidade moderada ou Grau II \\
$+26 \mathrm{Kg}$ do PN & +40, obesidade severa ou Grau III
\end{tabular}

Fonte: PN segundo Tabela de Risco Coronariano ${ }^{(14)}$ e IMC segundo a classificação da $O M S^{(56)}$

\subsection{0 - Critérios para avaliação da atividade física}

$\mathrm{Na}$ avaliação da atividade física, segundo a tabela adotada, todos os idosos em estudo foram considerados com atividade profissional sedentária.

As atividades físicas esportivas leves foram consideradas para os idosos que estavam fazendo ginástica sob a orientação de fisioterapia na "nossa" unidade de saúde onde são realizadas duas sessões/semana com duração de 1 hora sendo 10 
minutos de aquecimento, 30 minutos de atividade física, 10 minutos de alongamento e 10 minutos de relaxamento, caminhadas de 30 a 45 minutos no mínimo 3 vezes/semana e hidroginástica de 30 minutos 2 vezes/semana.

As atividades esportivas consideradas nesse estudo como moderadas foram: as caminhadas de 30 a 45 minutos mais de 3 vezes/semana, hidroginástica mais de 30 minutos e/ou mais de 3 vezes/semana.

As atividades esportivas consideradas nesse estudo como intensa foram: caminhadas de mais de 45 minutos diariamente, hidroginástica com mais de 1 hora/no mínimo 2 vezes/semana ou ginástica com fisioterapeuta da "nossa" unidade de saúde e a associação de caminhadas, hidroginásticas ou outras atividades esportivas.

Foram considerados inativos ou sedentários os idosos que não praticavam atividade física esportiva, não foram avaliados as atividades de vida diária ou outro tipo de avaliação da atividade física funcional do idoso. Foram considerados sedentários os idosos que referiam atividades como caminhar menos que 30 minutos ou a prática de esportes esporádicos.

\subsection{1 - Critérios para avaliação da pressão arterial sistólica}

$\mathrm{Na}$ avaliação da pressão arterial sistólica, os níveis de pressão arterial sistólica foram aferidos com auxílio de um esfigmomanômetro de coluna de mercúrio. Com o idoso sentado, após de um período mínimo de 5 minutos de repouso, a pressão arterial foi medida no braço não dominante ou no braço com o maior valor pressórico. $\mathrm{O}$ valor da pressão arterial sistólica correspondeu à fase I de Korotkoff. 
Foram realizadas duas medidas de pressão arterial, uma no início da avaliação clínica/médica e outra no final da avaliação clínica/médica, num intervalo mínimo de 5 minutos entre cada medida. Foi considerado, para efeito de cálculo, o valor médio das medidas de pressão arterial.

Os critérios para avaliação da Pressão Arterial foram segundo a Classificação Internacinal da Joint National Comitee - JNC ${ }^{(69)}$ (1997), Figura 2.

Figura 2 - Classificação de pressão arterial para adultos acima de 18 anos* - JNC VI

\begin{tabular}{|c|c|c|}
\hline Categoria & $\begin{array}{l}\text { Sistólica } \\
\text { (mmHg) }\end{array}$ & $\begin{array}{l}\text { Diastólica } \\
\text { (mmHg) }\end{array}$ \\
\hline Normal * * & $<130$ & $<85$ \\
\hline Normal elevada & 130 I-I 140 & 85 I-I 89 \\
\hline Hipertensão * * * Estágio 1 (leve) & 141 I-I 159 & 90 I-I 99 \\
\hline Estágio 2 (moderada) & 160 I-I 179 & 100 I-I 109 \\
\hline Estágio 3 (severa) & 180 I-I 209 & 110 I-I 119 \\
\hline Estâgio 4 (muito severa) & $>210$ & $>120$ \\
\hline
\end{tabular}

- Não utilizam drogas anti-hipertensivas e não estão em estado grave. Quando as pressões sistólicas e diastólicas se enquadram em categorias diferentes, deverá ser selecionada a categoria mais alta para classificar o status do indivíduo. Por exemplo, 160/92mmHg deverá ser classificada como estágio 2 , e 180/120mmHg deverá ser enquadrada no estágio 4.

A hipertensão sistólica isolada é definida por uma pressão arterial sistólica de $140 \mathrm{mmHg}$ ou mais e uma pressão diastólica de menor que $90 \mathrm{mmHg}$. 
** Considera-se uma pressão arterial ideal, no que se refere a riscos cardiovasculares, a pressão sistólica inferior a $120 \mathrm{mmHg}$ e a diastólica inferior a 80 $\mathrm{mm} \mathrm{Hg}$. Entretanto, os raros índices baixos devem ser avaliados como sendo de importância clínica.

* * Baseada na media de duas ou mais leituras feitas a cada duas ou mais visitas após uma análise inicial.

4.12 - Critérios para avaliação do perfil lipídico (idade $\geq 20$ anos) segundo o II Consenso sobre Dislipidemia (1996), Figura 3.

Figura 3 - Valores de referência de Colesterol Total, LDL-c, HDL-c e Triglicérides em adultos ( $\geq 20$ anos).

\begin{tabular}{llll}
\hline Lípides & Valores Desejáveis & Valores Limítrofes & Valores Aumentados \\
\hline Colesterol total & $<200 \mathrm{mg} / \mathrm{dL}$ & $200-239 \mathrm{mg} / \mathrm{dL}$ & $\geq 240 \mathrm{mg} / \mathrm{dL}$ \\
LDL-c & $<130 \mathrm{mg} / \mathrm{dL}$ & $130-159 \mathrm{mg} / \mathrm{dL}$ & $\geq 160 \mathrm{mg} / \mathrm{dL}$ \\
HDL-c & $\geq 35^{*} \mathrm{mg} / \mathrm{dL}$ & - & - \\
Triglicérides & $<200 \mathrm{mg} / \mathrm{dL}$ & - & $\geq 200 \mathrm{mg} / \mathrm{dL}$
\end{tabular}

OBS: * Será atualizada, em 2001, pelo departamento de Aterosclerose da SBC o valor do HDL-c para $40 \mathrm{mg} / \mathrm{dL}$.

\subsection{3 - Critérios para avaliação da glicemia plasmática}

Segundo o Consenso Brasileiro sobre Diabetes $(2.000)^{(12)}$ - Sociedade

Brasileira de Diabetes, Figura 4. 
Figura 4 - Valores de glicemia plasmática (em mg/dl) para diagnóstico de Diabetes Mellitus e seus estágios pré-clinicos

\begin{tabular}{llll}
\hline \multicolumn{1}{c}{ Categorias } & Jejum* & 2h após 75g glicose & \multicolumn{1}{c}{ Casual** } \\
\hline Glicemia de jejum alterada & $>110 \mathrm{e}<126$ & $<140$ ( se realizada) & \\
Tolerância a Glicose diminuída & $<126 \mathrm{e}$ & $\geq 140 \mathrm{e}<200$ & \\
Diabetes Mellitus & $\geq 126 \mathrm{ou}$ & $>200 \mathrm{ou}$ & $\geq 200$ (com sinto
\end{tabular}

*O jejum é definido como a falta de ingestão calórica de no mínimo 8 horas.

** Glicemia plasmática casual é definida como aquela realizada a qualquer hora do dia, sem observar o intervalo da última refeição.

*** Os sintomas Clássicos de diabetes incluem poliúria, polidipsia e perda não explicada de peso.

Nota: O diagnóstico de diabetes deve sempre ser confirmado pela repetição do teste em outro dia, a menos que haja hiperglicemia inequívoca com descompensação metabólica aguda ou sintomas óbvios de diabetes.

Na figura 5 apresentamos os objetivos do tratamento do Diabetes Mellitus.

Figura 5 - Objetivos do tratamento do Diabetes Mellitus

\section{Glicose plasmática}

- Jejum

- 2 horas pós-prandial

Glico-hemoglobina (\%)*

Colesterol

- Total

\section{$\mathbf{m g} / \mathbf{d l}$}

$<110$

$<140$

Limite Superior ao Método

mg/dl

$<200$ 
- HDLc

- LDLc

Triglicérides

Pressão Arterial

- Sistólica

- Diastólica

Índice de massa corporal $\left(\mathrm{kg} / \mathrm{m}^{2}\right)$
$>45$

$<100$

$<150$

$\mathbf{m m H g}$

$<135$

$<80$

$20-25$

- Quanto ao controle glicêmico, deve-se procurar atingir valores os mais próximos do normal. Como muitas vezes não é possível, aceita-se, nestes casos, valores de glicose plasmática em jejum até $126 \mathrm{mg} / \mathrm{dl}$ e de duas horas pós-prandial até 160 $\mathrm{mg} / \mathrm{dl}$ e níveis de glico-hemoglobina até um ponto percentual acima do limite superior do método utilizado. Acima destes valores, é sempre necessário realizar intervenção para melhorar o controle metabólico. 


\subsection{4 - Critérios para avaliação da análise estatística}

Foi contratada uma consultoria em epidemiologia e bioestatística L. I. M. 39 - Laboratório de Processamento de Dados Biomédicos - Departamento de Medicina Preventiva - FM/USP para análise estatística deste estudo. Como responsável direta da análise dos dados foram realizados por Liliam P. de Lima que é Mestre em Estatística IME-USP.

As médias das variáveis de interesse foram avaliadas por meio de um modelo de análise de variância (ANOVA) considerando medidas repetidas ao longo do tempo, conforme serão apresentadó no item 5. Resultados finais.

As proporções de pacientes classificados com risco potencial, moderado e alto nos anos de 1997 e 2001 foram comparadas utilizando-se o teste de homogeniedade marginal (considerando o modelo multinomial para os dados). A mesma análise foi utilizada para comparar as proporções de pacientes com diagnóstico associado de hipertensão e diabetes no início e fim do acompanhamento, conforme serão apresentados no item 5. Resultados finais. 


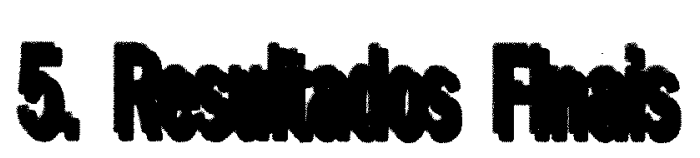




\section{5 - Resultados Finais}

\section{1 - Análise da Seleção dos casos acompanhados ao longo}

do tempo.

Neste estudo, os casos acompanhados ao longo do período de 1997 a 2.001 no setor de geriatria são a continuação de um primeiro estudo apresentado como tese de mestrado (1998) sobre "Fatores de Risco Coronariano e Riscos Autocriados em Idosos" ${ }^{(120)}$, como já apresentado neste trabalho no item 2 - Justificativa e no item 4 - Metodologia.

No primeiro estudo, do tipo descritivo transversal, a população de estudo se restringiu ao período de 11 de abril a 13 de outubro de 1997 num total de 331 idosos avaliados.

No presente estudo, a seleção dos casos abrangeu o período de 11 de abril a 20 de dezembro de 1997, o que resultou em 373 idosos avaliados.

A média de consultas de retorno durante o período de 11 de abril a 20 de dezembro de 1997 foi de 4,5 consultas médicas geriátricas. Ao longo deste estudo, esta média caiu para 3,5 consultas médicas geriátricas ao ano. Esta queda de consultas de retorno se deveu a grande demanda do setor dificultando o acesso aos pacientes em estudo.

Durante o período de estudo (1997 a 2.001) houve 20 casos de óbitos, dos pacientes selecionados para o estudo, o que resultou numa população final de 353 idosos acompanhados ao longo do tempo. 
Os 20 casos de óbitos ocorridos, durante o estudo, a idade média foi de 79,4 anos ( $\mathrm{DP}=9,4$ anos) sendo 65\% (13 idosos) do sexo masculino.

Nos atestados de óbitos as causas básicas de morte foram por:

a) $35 \%$ ( 7 casos) por origem cardiaca:

a. $71,4 \%$ ( 5 casos ) por Infarto Agudo do Miocárdio

i. $60 \%$ ( 3 casos $)$ na residência

ii. $40 \%$ ( 2 casos ) durante internação hospitalar

b. $14,3 \%$ ( 1 caso $)$ por Arritmia cardíaca

c. $14,3 \%$ ( 1 caso $)$ por Insuficiência cardíaca congestiva

b) $30 \%$ ( 6 casos $)$ por neoplasias

a. $50 \%$ ( 3 casos $)$ por neoplasia no intestino

b. $33,4 \%$ ( 2 casos $)$ por neoplasia gástrica

c. $16,6 \%$ ( 1 caso $)$ por neoplasia de próstata

c) $25 \%$ ( 5 casos $)$ por septicemias

a. $40 \%$ ( 2 casos $)$ por abdômen agudo

b. $40 \%$ ( 2 casos ) por broncopneumonia

c. $20 \%$ ( 1 casos ) por pós-operatório de colecistectomia

d) $5 \%$ ( 1 caso ) por Hemorragia Digestiva Alta

e) 5\% ( 1 caso ) por Insuficiência Hepatocítica alcoólica

É importante salientar que não houve caso de abandono de acompanhamento médico geriátrico durante o período de estudo. Entretanto, alguns pacientes eram acompanhados simultaneamente em outros serviços de saúde o que facilitou o monitoramento dos exames laboratoriais e/ou exames complementares. 


\section{2 - Análise estatística}

Inicialmente, gráficos e tabelas foram utilizados para a análise descritiva dos dados com o objetivo de descrever o comportamento médio dos fatores de risco coronarianos ao longo do período de 1997 a 2.001.

As médias das variáveis de interesse foram avaliadas por meio de um modelo de análise de variância (ANOVA) considerando medidas repetidas ao longo do tempo segundo os referenciais teóricos de $\operatorname{Neter}^{(\mathrm{D})}(1996)$ e outros ${ }^{(\mathrm{A}, \mathrm{B}, \mathrm{C})}$. As proporções de pacientes classificados com risco coronarianos: potencial, moderado e alto nos anos de 1997 e 2001 foram comparadas utilizando-se o teste de homogeniedade marginal ${ }^{(\mathrm{A}, \mathrm{B}, \mathrm{C}, \mathrm{D})}$ (considerando o modelo multinomial para os dados). A mesma análise foi utilizada para comparar as proporções de pacientes com diagnóstico associado de Hipertensão Arterial Sistólica e Diabetes Mellitus no início e fim do acompanhamento.

\section{3 - Análise das variáveis Idade e Sexo ao longo do}

tempo.

A idade dos pacientes no início do estudo variou de 65 a 95 anos, com média de 72,4 e desvio padrão de 5,8 anos; assim, no final do estudo a idade média foi de 76,4 anos.

Em relação ao sexo, $88,1 \%$ (311) dos pacientes eram do sexo feminino. 
Todos os pacientes obtiveram 6 pontos no item de avaliação Idade/Sexo segundo a Tabela de Risco Coronariano da American Heart Association (Anexo I) adotado neste estudo.

\section{4 - Comportamento Médio dos Fatores de Risco}

\section{Coronarianos ao longo do tempo.}

Inicialmente, as médias da Pressão Arterial Sistólica (PAS) em $\mathrm{mmHg}$, da Glicemia de jejum (em mg/dl), do Colesterol total (em mg/dl) e do Risco total (em unidades de pontuação) foram comparadas a fim de se estudar o comportamento médio destas variáveis ao longo dos anos de acompanhamento. As Figuras de 6 a 9 apresentam as médias (e respectivos intervalos de confiança de $95 \%)$ para estas variáveis. De uma forma geral, estas figuras mostram uma queda no risco ao longo dos anos, sendo observada uma queda acentuada a partir do ano de 2000

Em todos os casos, a ANOVA indicou diferenças significantes entre as médias ao longo dos anos $(\mathrm{p}<0,001)$, e por este motivo foram feitas comparações entre as médias de anos consecutivos. Os valores de $p$ para estas comparações são apresentados na Tabela 1. 
Figura 6 - Média e Intervalo de Confiança de 95\% para Pressão Arterial Sistólica ( P A S ) em mmHg no período de 1997 e 2.001.

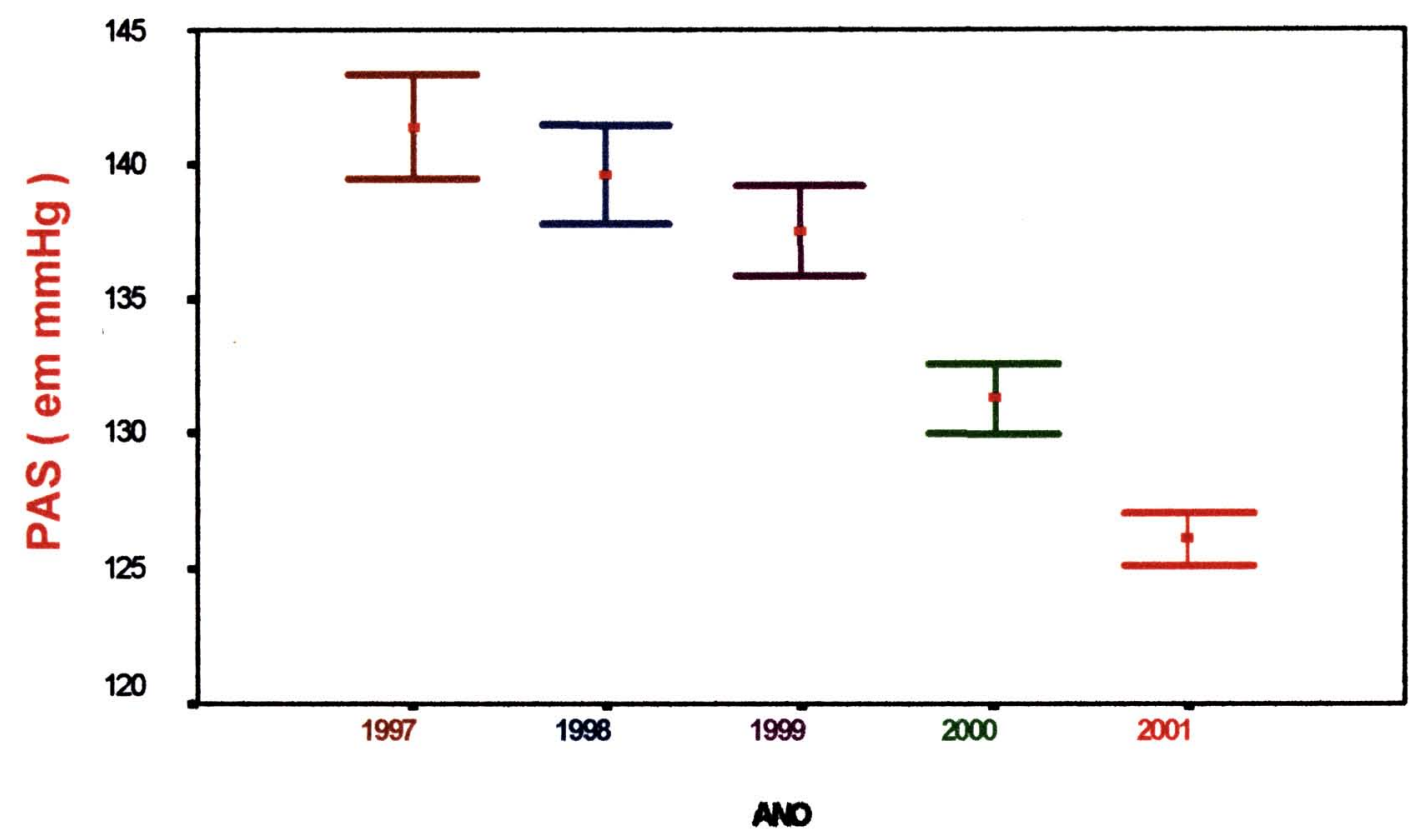


Figura 7: Média e Intervalo de Confiança de 95\% para a Glicemia de jejum em mg/dl no período de 1997 a 2001.

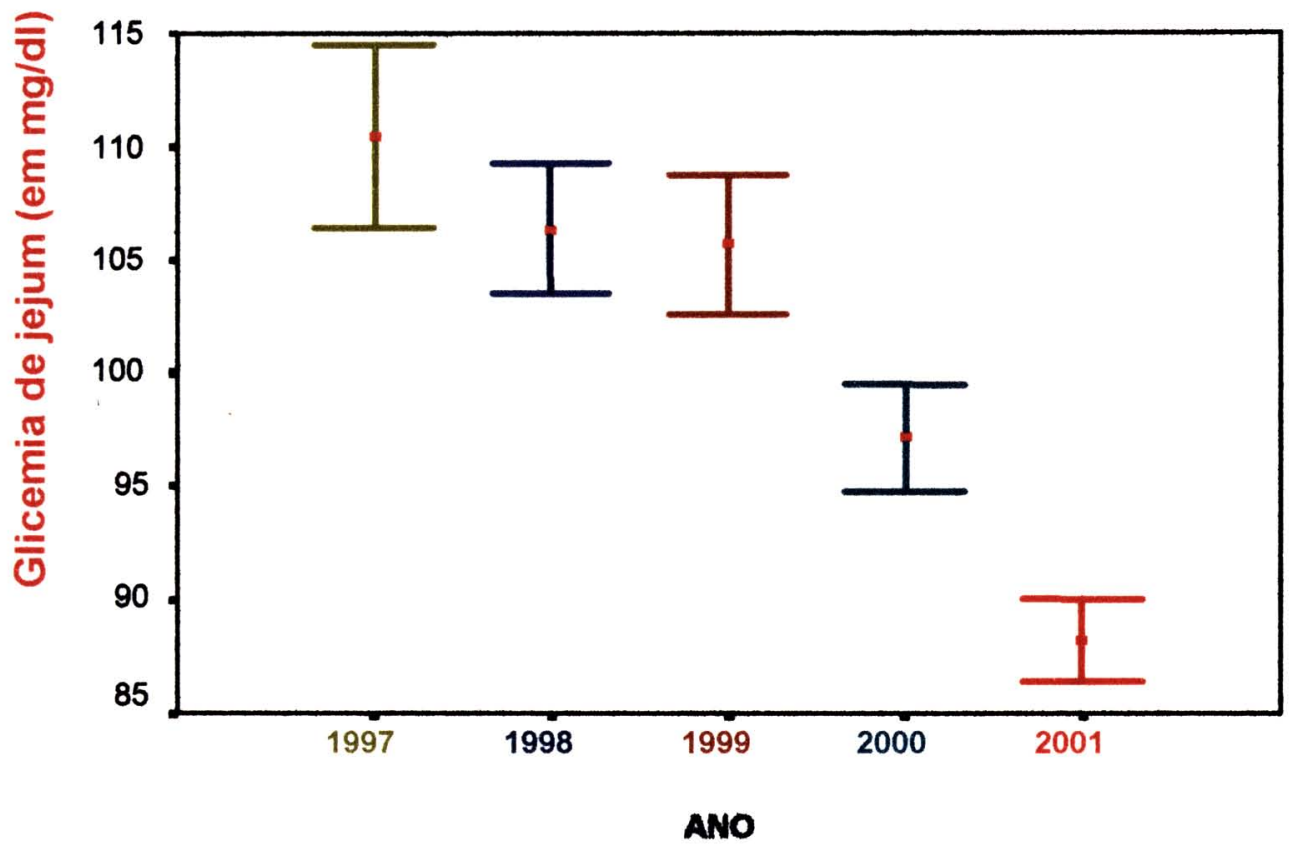

Figura 8: Média e Intervalo de Confiança de 95\% para o Colesterol total em mg/dl no período de 1997 a 2.001.

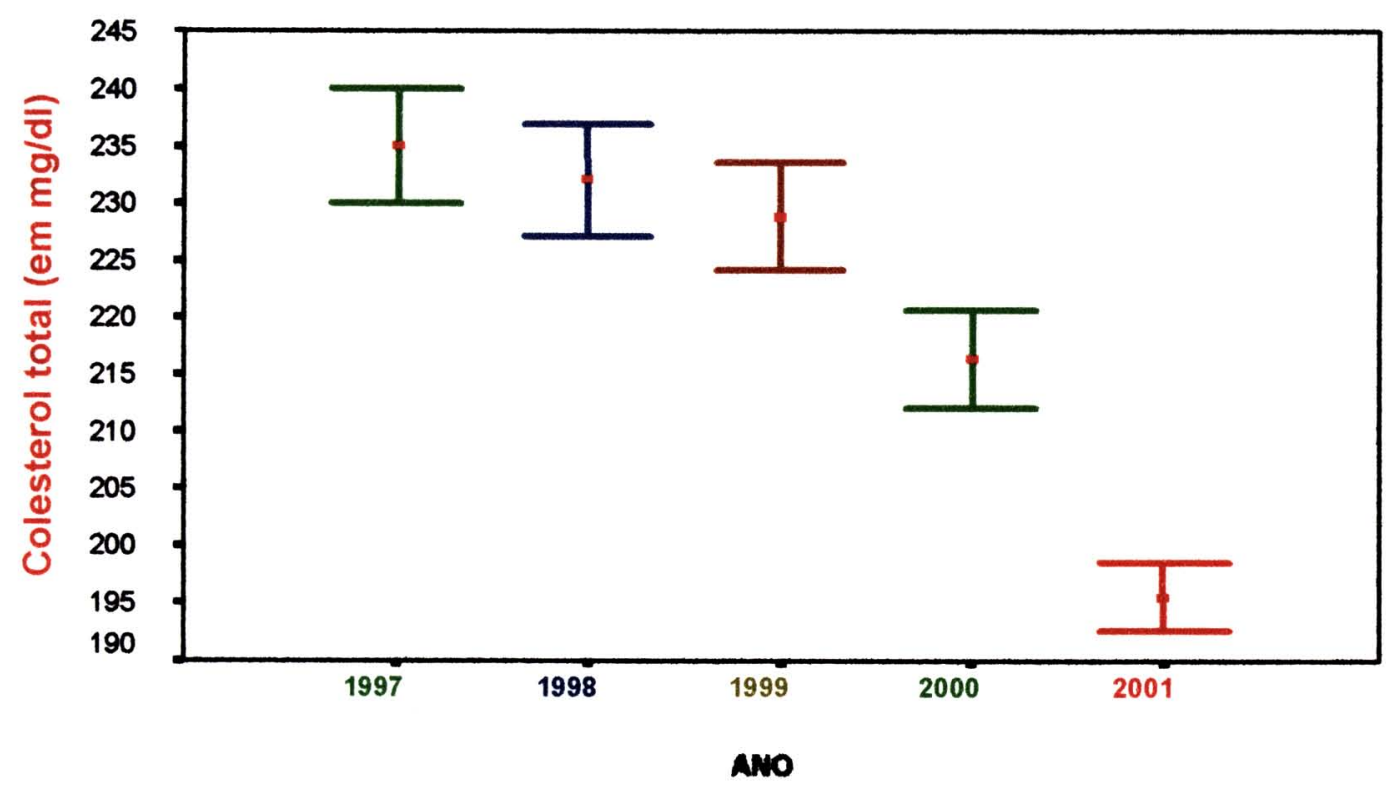


Figura 9: Média em Pontos e Intervalo de Confiança de 95\% para o Risco coronariano total no período de 1997 a 2001.



Observando a Classificação do Risco Coronariano segundo a contagem de pontos (Anexo I) para o risco total é:

0 a 8 pontos - sem risco coronariano

9 a 17 pontos - risco potencial

18 a 40 pontos - risco moderado

41 a 59 pontos - risco alto

60 a 67 pontos - faixa de perigo

mais de 68 pontos - perigo máximo 
Tabela 1: Medidas descritivas de: média, desvio padrão (d.p.), mínimo, máximo, mediana e p; para Pressão Arterial Sistólica (PAS) em mmHg, Glicemia de jejum (em mg/dl), Colesterol Total (em mg/dl) e Risco Total (em unidades de pontuação).

\begin{tabular}{|c|c|c|c|c|c|c|}
\hline & & 1997 & 1998 & 1999 & 2000 & 2001 \\
\hline \multirow{6}{*}{$\begin{array}{l}\text { PAS } \\
(\mathrm{mmHg})\end{array}$} & média & 141,4 & 139,6 & 137,5 & 131,3 & 126,1 \\
\hline & d.p. & 18,4 & 17,7 & 16,4 & 12,5 & 9,5 \\
\hline & minimo & 100,0 & 100,0 & 100,0 & 100,0 & 100,0 \\
\hline & máximo & 210,0 & 190,0 & 190,0 & 210,0 & 170,0 \\
\hline & mediana & 140,0 & 140,0 & 130,0 & 130,0 & 120,0 \\
\hline & $p$ & & 0,814 & 0,172 & $<0,001$ & $<0,001$ \\
\hline \multirow{6}{*}{$\begin{array}{l}\text { Glicemia } \\
(\mathrm{mg} / \mathrm{dl})\end{array}$} & média & 110,5 & 106,4 & 105,7 & 97,2 & $\overline{88,2}$ \\
\hline & d.p. & 38,3 & 27,6 & 29,2 & 22,5 & 17,0 \\
\hline & mínimo & 60,0 & 67,0 & 70,0 & 68,0 & 68,0 \\
\hline & máximo & 456,0 & 246,0 & 282,0 & 221,0 & 216,0 \\
\hline & mediana & 101,0 & 99,0 & 99,0 & 90,0 & 80,0 \\
\hline & $p$ & & 0,139 & $>0,99$ & $<0,001$ & $<0,001$ \\
\hline \multirow{6}{*}{$\begin{array}{l}\text { Colesterol } \\
(\mathrm{mg} / \mathrm{dl})\end{array}$} & média & 235,1 & 232,0 & 228,8 & 216,4 & 195,6 \\
\hline & d.p. & 47,5 & 45,9 & 44,8 & 40,8 & 29,3 \\
\hline & mínimo & 101,0 & 138,0 & 119,0 & 131,0 & 102,0 \\
\hline & máximo & 424,0 & 430,0 & 442,0 & 417,0 & 361,0 \\
\hline & mediana & 229,0 & 228,0 & 222,0 & 208,0 & 192,0 \\
\hline & $p$ & & $>0,99$ & $>0,99$ & $<0,001$ & $<0,001$ \\
\hline \multirow{6}{*}{$\begin{array}{l}\text { Risco total } \\
\text { (pontos) }\end{array}$} & média & 27,2 & 26,1 & 25,4 & 22,2 & $\overline{18,5}$ \\
\hline & d.p. & 7,2 & 7,0 & 6,8 & 6,5 & 5,3 \\
\hline & mínimo & 14,0 & 13,0 & 12,0 & 12,0 & 11,0 \\
\hline & máximo & 53,0 & 51,0 & 49,0 & 43,0 & 43,0 \\
\hline & mediana & 27,0 & 25,0 & 25,0 & 21,0 & 17,0 \\
\hline & $p$ & & 0,002 & 0,079 & $<0,001$ & $<0,001$ \\
\hline
\end{tabular}

Observação: Cada ano possui $n=353$ idosos.

Legenda: d.p. $=$ desvio padrão

$p=$ valor de $p$ para comparação entre as médias de anos consecutivos 
5.5 - Contribuição dos fatores de risco coronariano em relação ao risco coronariano total.

Com o objetivo de estudar a contribuição de cada fator de risco coronariano em relação ao risco coronariano total, foram calculadas as porcentagens de contribuição de cada um destes fatores que comprem o risco coronariano total.

A Figura 10 e a Tabela 2 mostram as porcentagens médias de contribuição de cada fator no risco coronariano total ao longo dos anos de acompanhamento. De uma forma geral, os fatores que mais contribuiram para o risco coronariano total foram: Idade/Sexo e Atividade fisica esportiva e os que menos contribuiram foram: Fumo e Antecedentes familiares.

Nota-se ainda, que o fator risco coronariano referente ao Colesterol Total, que representava o terceiro de maior contribuiçăo para o risco coronariano total de 1997 a 1999, apresentou uma queda acentuada nos anos seguintes, passando de uma porcentagem média de contribuição de 18,0\% em 1999 para uma de 7,4\% em 2001.

Um padrão semelhante, porém menos acentuado, foi observado também para os fatores de risco coronariano referentes à Glicemia de Jejum e Pressão Arterial Sistólica.

Os fatores de risco coronariano quanto ao Peso e Fumo mantiveram-se praticamente estáveis representadas através das porcentagens médias de contribuição de cada fator no risco coronariano ao longo dos anos. 
Figura 10 - Distribuição das porcentagens médias de contribuições dos fatores de risco coronariano: Idade/Sexo (I/S), atividade física esportiva (Ativ. Fís), Peso, Colesterol total (CT), glicemia de jejum (Glic.), Pressão Arterial Sistólica (PAS), Fumo e Antecedentes Familiares (At. Fam.) no período de 1997 a 2.001.

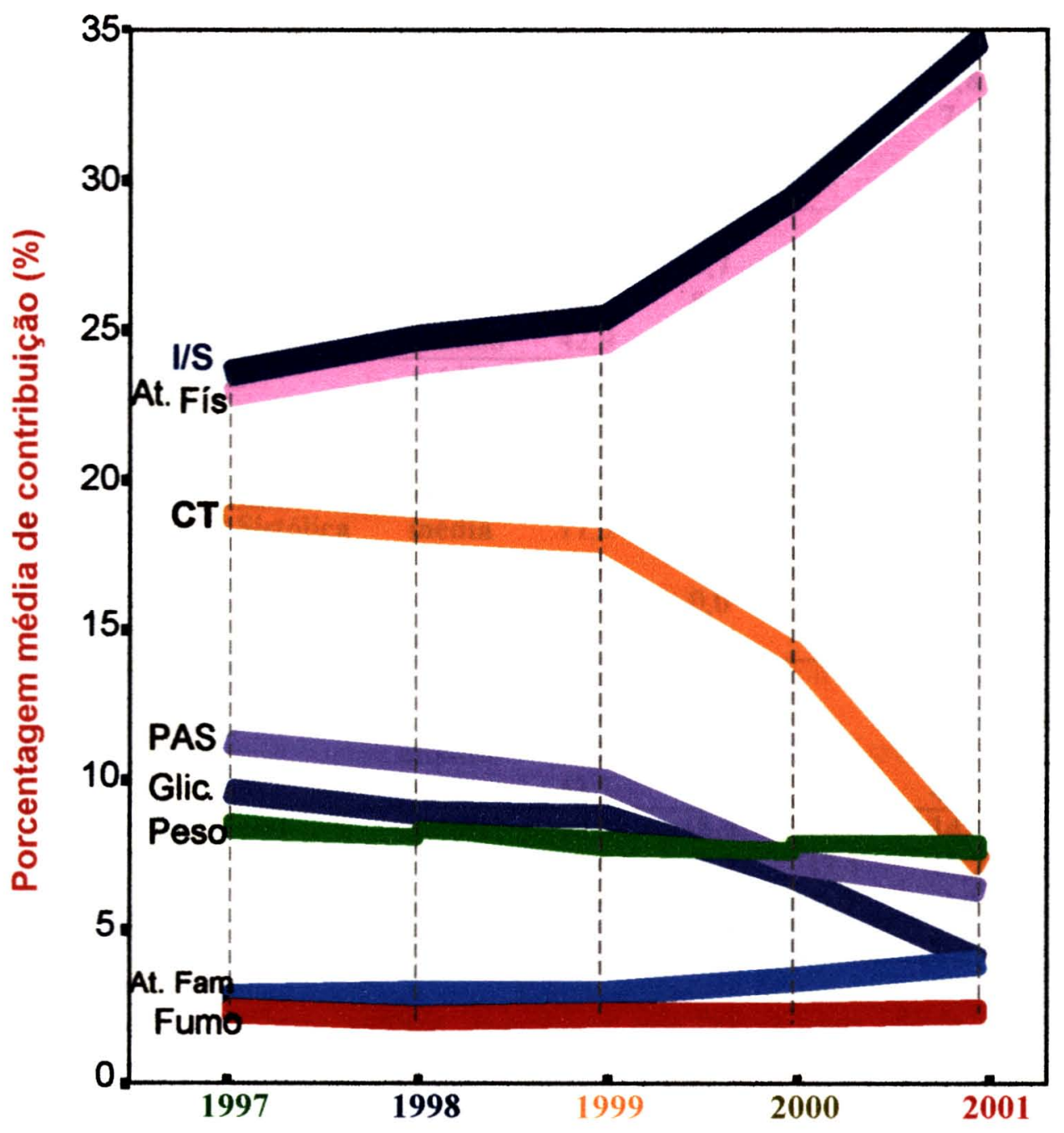


Tabela 2 - Distribuição das medidas descritivas: média, desvio padrão (d.p.), mínimo, máximo; para as porcentagens (em \%) de contribuição de cada fator no risco coronariano total no período de 1997 a 2.001 .

\begin{tabular}{|c|c|c|c|c|c|c|c|}
\hline Fator Risco Coronariano & & 1997 & 1998 & 1999 & 2000 & 2001 & Total \\
\hline \multirow[t]{4}{*}{ Fumo } & média & 2,3 & 2,1 & 2.2 & 2,3 & 2,4 & 2,3 \\
\hline & d.p. & 6,4 & 5,8 & 6.1 & 6,1 & 6,4 & 6,2 \\
\hline & mínimo & 0,0 & 0.0 & 0.0 & 0,0 & 0,0 & $\mathbf{0 , 0}$ \\
\hline & máximo & 37,5 & 37,5 & 39.1 & 39,1 & 39,1 & 39,1 \\
\hline \multirow[t]{4}{*}{ Idade/Sexo } & média & 23,6 & 24,7 & 25.4 & 29,4 & 34,6 & 27,6 \\
\hline & d.p. & 6,3 & 6,7 & 6.9 & 8,4 & 8,3 & 8,4 \\
\hline & mínimo & 11,3 & 11,8 & 12.2 & 14.0 & 14.0 & 11.3 \\
\hline & máximo & 42.9 & 46.2 & 500 & 50.0 & 54.5 & 54.5 \\
\hline \multirow[t]{4}{*}{ Peso } & média & 8,5 & 8.2 & 7.9 & 7,8 & 7,8 & 8,1 \\
\hline & d.p. & 7,1 & 7.4 & 7.5 & 7,6 & 7,7 & 7,5 \\
\hline & mínimo & 0,0 & 0,0 & 0.0 & 0,0 & 0,0 & 0,0 \\
\hline & máximo & 31,8 & 33,3 & 333 & 33,3 & 34,8 & 34,8 \\
\hline \multirow[t]{4}{*}{ Ativ. Física } & média & 22,9 & 23,9 & 24.6 & 28,4 & 33,2 & 26,6 \\
\hline & d.p. & 6,5 & 6.7 & 7.1 & 8,5 & 8,6 & 8,4 \\
\hline & mínimo & 8,6 & 8,1 & 9.1 & 9,7 & 7,1 & 7,1 \\
\hline & máximo & 42,9 & 42,9 & 50.0 & 50,0 & 50,0 & 50,0 \\
\hline \multirow[t]{4}{*}{ Ant. Fam. } & média & 2,8 & 2.9 & 2.4 & 3,4 & 4,0 & 3,2 \\
\hline & d.p. & 6,5 & 6.6 & 6.6 & 7,6 & 8,6 & 7,3 \\
\hline & mínimo & 0,0 & 0.0 & 0.0 & 0,0 & 0,0 & 0,0 \\
\hline & máximo & 34,8 & 34.8 & 36.4 & 36,8 & 36,8 & 36,8 \\
\hline \multirow[t]{4}{*}{ Pressão Arterial Sistólica } & média & 11,3 & 10,7 & 10.1 & 7,4 & 6,5 & 9,2 \\
\hline & d.p. & 8,8 & 9,0 & 9.1 & 5,6 & 4,0 & 7,8 \\
\hline & mínimo & 0,0 & 0.0 & 0,0 & 0,0 & 0,0 & $\mathbf{0 , 0}$ \\
\hline & máximo & 39,1 & 38,5 & 37.5 & 36,0 & 37,5 & 39,1 \\
\hline \multirow[t]{4}{*}{ Glicemia jejum } & média & 9,6 & 9.0 & 8.8 & 6,9 & 4,1 & 7,7 \\
\hline & d.p. & 9,3 & 8.8 & 0.1 & 8,3 & 6,4 & 8,6 \\
\hline & minimo & 0,0 & 0,0 & 0.0 & 0,0 & 0,0 & $\mathbf{0 , 0}$ \\
\hline & maximo & 43,5 & 45,5 & 435 & 40,0 & 30,0 & 45,5 \\
\hline \multirow[t]{4}{*}{ Colesterol Total } & média & 18,8 & 18,3 & 18.0 & 14,4 & 7,4 & 15,4 \\
\hline & d.p. & 12,6 & 13,2 & 1.3 .1 & 13,2 & 10,1 & 13,2 \\
\hline & mínimo & 0,0 & 0.0 & 0.0 & 0,0 & 0,0 & 0,0 \\
\hline & máximo & 43,5 & 41.7 & +5.5 & 42,9 & 40,9 & 43,5 \\
\hline
\end{tabular}




\section{6 - Prevalência de Hipertensão Arterial Sistólica e}

Diabetes Mellitus ao longo do tempo.

A Tabela 3 mostra a distribuição de freqüências de pacientes classificados como hipertensos (para PA sistólica $\geq 140 \mathrm{mmHg}$ ) e diabéticos (para glicemia de jejum $\geq 126 \mathrm{mg} / \mathrm{dl}$ ). Por esta tabela, nota-se que a porcentagem de pacientes com diagnóstico associado de hipertensão e diabetes (grupo $\mathrm{sim} / \mathrm{sim}$ ) apresentou uma queda constante ao longo dos anos de acompanhamento, passando de $11,0 \%$ em 1997 para apenas 0,6\% em 2001. Além disso, a porcentagem de pacientes sem diagnóstico associado destas doenças (grupo não/não) apresentou uma aumento constante no mesmo período, passando de $49,6 \%$ em 1997 para $92,4 \%$ em 2001.

Para uma análise estatística destas porcentagens, devido ao pequeno número de pacientes observados em cada casela da Tabela 4 , foram considerados três tipos de pacientes, a saber: pacientes com "diagnóstico associado" de hipertensão e diabetes (grupo $\mathrm{sim} / \mathrm{sim}$ ), pacientes com "apenas um diagnóstico" (grupo não/sim e sim/não) e pacientes "sem diagnóstico" (grupo não/não). Então, uma análise foi realizada a fim de testar se as proporções destes 3 tipos de pacientes mudou quando comparamos o início (1997) com o final do estudo (2001).

Desta análise, conclui-se que houve uma queda significante de pacientes com diagnóstico associado (11,0\% em 1997 e 0,6\% em 2001) e de pacientes com apenas um diagnóstico (39,4\% em 1997 e 7,1 \% em 2001), ambos com $\mathrm{p}<0,001$; além disso, conclui-se que a proporção de pacientes sem diagnóstico destas doenças aumentou de 49,6\% em 1997 para 92,3\% em 2001, com p < 0,001. 
Tabela 3 - Distribuição Anual da presença (n. ${ }^{0}$ e $\%$ ou não entre Hipertensão Arterial Sistólica e Diabetes Mellitus

\begin{tabular}{cccccc}
\hline & \multicolumn{5}{c}{ Hiperten são A rterial Sistólica / Diabetes Mellitus } \\
& $\operatorname{sim} / \mathbf{s i m}$ & $\operatorname{sim} / \mathbf{n}$ ã & não/sim & não/não & Total \\
\hline $\mathbf{1 9 9 7}$ & 39 & 103 & 36 & 175 & 353 \\
& $11,0 \%$ & $29,2 \%$ & $10,2 \%$ & $49,6 \%$ & $100,0 \%$ \\
\hline $\mathbf{1 9 9 8}$ & 23 & 78 & 41 & 211 & 353 \\
& $6,5 \%$ & $22,1 \%$ & $11,6 \%$ & $59,8 \%$ & $100,0 \%$ \\
\hline $\mathbf{1 9 9 9}$ & 14 & 82 & 42 & 215 & 353 \\
& $4,0 \%$ & $23,2 \%$ & $11,9 \%$ & $60,9 \%$ & $100,0 \%$ \\
\hline $\mathbf{2 0 0 0}$ & 7 & 27 & 34 & 285 & 353 \\
& $2,0 \%$ & $7,6 \%$ & $9,6 \%$ & $80,7 \%$ & $100,0 \%$ \\
\hline $\mathbf{2 0 0 1}$ & 2 & 8 & 17 & 326 & 353 \\
& $0,6 \%$ & $2,3 \%$ & $4,8 \%$ & $92,4 \%$ & $100,0 \%$ \\
\hline
\end{tabular}

Legenda: $\operatorname{sim}=$ Pressão Arterial Sistólica $\geq 140 \mathrm{mmHg}$ ou glicemia de Jejum $\geq 126 \mathrm{mg} / \mathrm{dl}$ não = Pressão Arterial Sistólica $\leq 140 \mathrm{mmHg}$ ou glicemia de Jejum $\leq 126 \mathrm{mg} / \mathrm{dl}$ 
Tabela 4 - Distribuição da presença (sim) em número e \% ou controle (não) entre as categorias combinadas de Hipertensão Arterial Sistólica e Diabetes Mellitus para os anos de 1997 e 2001.

\begin{tabular}{|c|c|c|c|c|c|c|}
\hline & \multicolumn{6}{|c|}{ Hipertensão Arterial Sistólica / Diabetes Mellitus em 2001} \\
\hline & & $\mathrm{sim} / \mathrm{sim}$ & sim/não & não/sim & não/não & Total \\
\hline \multirow{10}{*}{$\begin{array}{c}\text { Hipertensão } \\
\text { / Diabetes } \\
\text { em } 1997\end{array}$} & $\mathrm{sim} / \mathrm{sim}$ & 0 & 3 & 6 & 30 & 39 \\
\hline & & $0,0 \%$ & $0,8 \%$ & $1,7 \%$ & $8,5 \%$ & $11,0 \%$ \\
\hline & sim/não & 2 & 3 & 1 & 97 & 103 \\
\hline & & $0,6 \%$ & $0,8 \%$ & $0,3 \%$ & $27,5 \%$ & $29,2 \%$ \\
\hline & não/sim & 0 & 0 & 9 & 27 & 36 \\
\hline & & $0,0 \%$ & $0,0 \%$ & $2,5 \%$ & $7,6 \%$ & $10.2 \%$ \\
\hline & não/não & 0 & 2 & 1 & 172 & 175 \\
\hline & & $0,0 \%$ & $0,6 \%$ & $0,3 \%$ & $48,7 \%$ & $49.6 \%$ \\
\hline & Total & 2 & 8 & 17 & 326 & 353 \\
\hline & & $0,6 \%$ & $2,3 \%$ & $4,8 \%$ & $92,4 \%$ & $100.0 \%$ \\
\hline
\end{tabular}

Porcentagens calculadas em relação ao total de pacientes. 
5.7 - Comportamento da classificação do risco coronariano ao longo do tempo.

A Tabela 5 e Figura 11 mostram as proporçoes de pacientes classificados nas três categorias de risco coronariano: Alto, Moderado e Potencial ao longo dos anos.

Nota-se que a proporça de pacientes com risco coronariano potencial aumentou de 7,9\% em 1997 para 60,3\% em 2001.

As proporç̃es de pacientes com risco coronariano moderado e alto diminuíram, sendo que passaram de, respectivamente, $86,4 \%$ para $39,4 \%$ e de $5,7 \%$ para $0,3 \%$. Estas diferencas observadas são estatisticamente significantes $(p<0,001)$, de onde conclui-se que o perfil de pacientes com risco coronariano: potencial, moderado e alto mudou quando comparamos o início (1997) com o final do estudo (2001).

Tabela 5 - Distribuição da freqüência anual (n. ${ }^{0}$ e \%) segundo o risco coronariano: Potencial, Moderado e Alto; no período de 1997 a 2.001.

\begin{tabular}{rrrrr}
\hline \multicolumn{5}{c}{ Risco coronariano } \\
Ano & \multicolumn{1}{c}{ Potencial } & Moderado & \multicolumn{1}{c}{ Alto } & Total \\
\hline $\mathbf{1 9 9 7}$ & $28(7,9 \%)$ & $305(86,4 \%)$ & $20(5,7 \%)$ & $353(100 \%)$ \\
$\mathbf{1 9 9 8}$ & $40(11,3 \%)$ & $296(83,9 \%)$ & $17(4,8 \%)$ & $353(100 \%)$ \\
$\mathbf{1 9 9 9}$ & $46(13,0 \%)$ & $297(84,1 \%)$ & $10(2,8 \%)$ & $353(100 \%)$ \\
$\mathbf{2 0 0 0}$ & $113(32,0 \%)$ & $238(67,4 \%)$ & $2(0,6 \%)$ & $353(100 \%)$ \\
$\mathbf{2 0 0 1}$ & $213(60,3 \%)$ & $139(39,4 \%)$ & $1(0,3 \%)$ & $353(100 \%)$ \\
\hline
\end{tabular}


Figura 11: Distribuição das porcentagens de classificação do risco coronariano no período de 1997 a 2001.

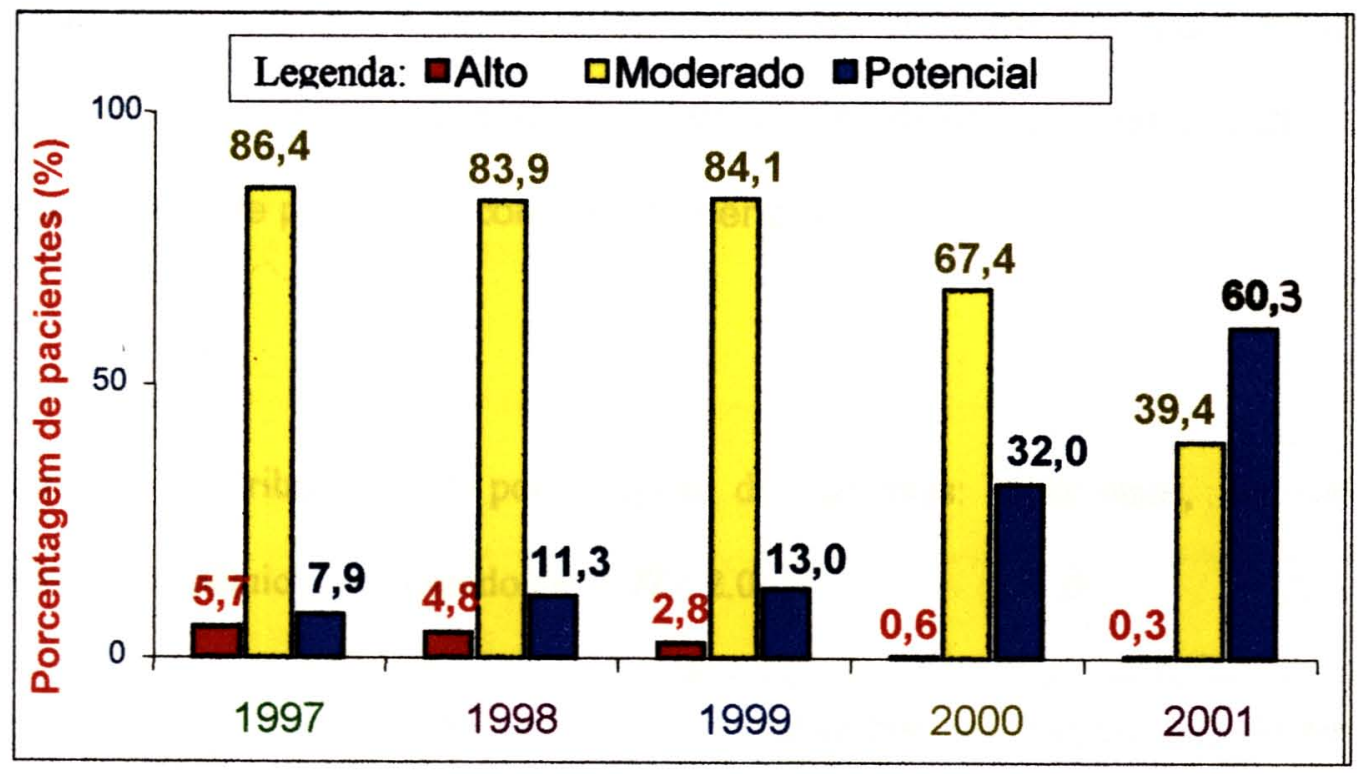

Tabela 6: Distribuição das frequeências (n. ${ }^{0} \mathrm{e} \%$ ) das categorias de risco coronariano: potencial, moderado e alto para os anos de 1997 e 2001.

2001

Potencial Moderado Alto Total

$\begin{array}{lllll}\text { Potencial } & 26(7,3 \%) & 2(0,6 \%) & 0(0,0 \%) & 28(7,9 \%)\end{array}$

1997 Moderado $183(51,8 \%) \quad 121(34,2 \%) \quad 1(0,3 \%) \quad 305(86,4 \%)$

Alto $\quad 4(1,1 \%) \quad 16(4,5 \%) \quad 0(0,0 \%) \quad 20(5,7 \%)$

Total $213(603 \%) \quad 139(394 \%) \quad 1(0,3 \%) \quad 353(100 \%)$ 
A Figura 12 apresenta as porcentagens de pacientes hipertensos, diabéticos, obesos (para peso $\geq 2$ pontos) e dislipêmicos. De acordo com esta figura, nota-se, ao longo dos anos de acompanhamento, um melhor controle destas patologias refletidos na diminuição na porcentagem de pacientes com estas doenças.

Figura 12: Distribuição das porcentagens de pacientes: hipertensos, diabéticos, obesos e dislipêmicos no período de 1997 a 2.001.

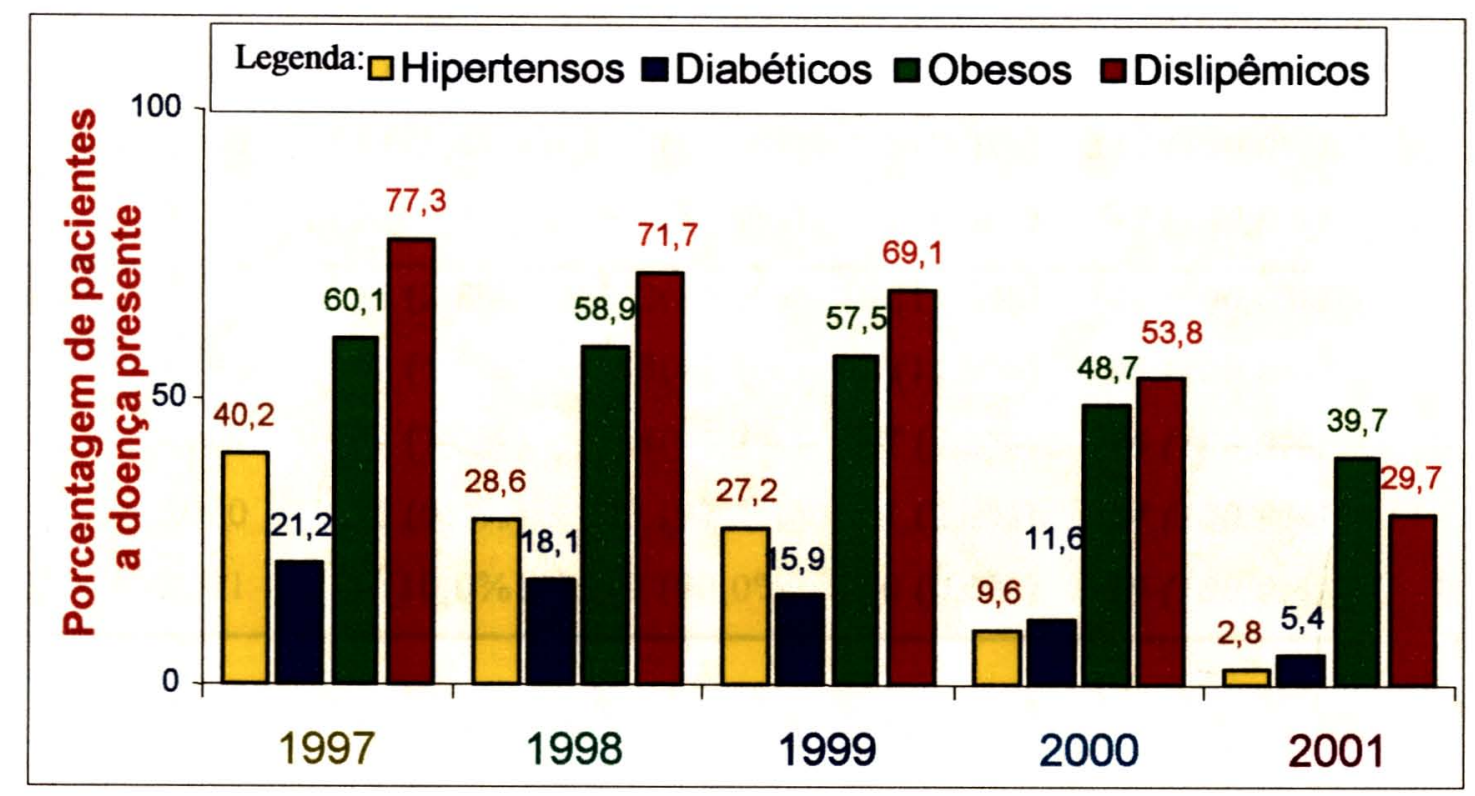

De forma complementar, as Tabelas de 7 a 10 mostram a distribuição de freqüências para a classificação do risco coronariano segundo pacientes: hipertensos, diabéticos, obesos e dislipêmicos ao longo dos anos de acompanhamento. 
Tabela 7: Distribuiçāo da freqüência anual $\left(n^{0}\right.$ e \%) segundo risco coronariano: potencial, moderado, alto e a presença de hipertensão arterial sistólica (hipertensos sim) ou pressão arterial sistólica controlada (hipertensos não) no periodo de 1997 a 2.001.

\begin{tabular}{ccrrrr}
\hline \multirow{2}{*}{ Hipertensos } & Ano & Potencial & \multicolumn{1}{c}{ Moderado } & Alto & Total \\
\hline não & 1997 & $24(11,4 \%)$ & $183(86,7 \%)$ & $4(1,9 \%)$ & $211(100,0 \%)$ \\
& 1998 & $39(15,5 \%)$ & $208(82,5 \%)$ & $5(2,0 \%)$ & $252(100,0 \%)$ \\
& 1999 & $45(17,5 \%)$ & $209(81,3 \%)$ & $3(1,2 \%)$ & $257(100,0 \%)$ \\
& 2000 & $113(35,4 \%)$ & $205(64,3 \%)$ & $1(0,3 \%)$ & $319(100,0 \%)$ \\
& 2001 & $212(61,8 \%)$ & $130(37,9 \%)$ & $1(0,3 \%)$ & $343(100,0 \%)$ \\
\hline sim & 1997 & $4(2,8 \%)$ & $122(85,9 \%)$ & $16(11,3 \%)$ & $142(100,0 \%)$ \\
& 1998 & $1(1,0 \%)$ & $88(87,1 \%)$ & $12(11,9 \%)$ & $101(100,0 \%)$ \\
& 1999 & $1(1,0 \%)$ & $88(91,7 \%)$ & $7(7,3 \%)$ & $96(100,0 \%)$ \\
& 2000 & $0(0,0 \%)$ & $33(97,1 \%)$ & $1(2,9 \%)$ & $34(100,0 \%)$ \\
& 2001 & $1(10,0 \%)$ & $9(90,0 \%)$ & $0(0,0 \%)$ & $10(100,0 \%)$ \\
\hline
\end{tabular}


Tabela 8: Distribuição da freqüência anual (n. ${ }^{0}$ e \%) segundo risco coronariano: potencial, moderado, alto e a presença de diabetes ( diabéticos sim) ou glicemia de jejum controlada ( diabeticos não) no período de 1997 a 2.001.

\begin{tabular}{cccccc}
\hline \multirow{5}{*}{ Diabéticos } & \multicolumn{5}{c}{ Ano coronariano } \\
& Potencial & \multicolumn{1}{c}{ Moderado } & \multicolumn{1}{c}{ Alto } & Total \\
\hline não & 1997 & $27(9,7 \%)$ & $246(88,5 \%)$ & $5(1,8 \%)$ & $278(100,0 \%)$ \\
& 1998 & $40(13,8 \%)$ & $245(84,8 \%)$ & $4(1,4 \%)$ & $289(100,0 \%)$ \\
& 1999 & $46(15,5 \%)$ & $250(84,2 \%)$ & $1(, 3 \%)$ & $297(100,0 \%)$ \\
& 2000 & $113(36,2 \%)$ & $199(63,8 \%)$ & $0(0,0 \%)$ & $312(100,0 \%)$ \\
& 2001 & $213(63,8 \%)$ & $121(36,2 \%)$ & $0(0,0 \%)$ & $334(100,0 \%)$ \\
\hline $\operatorname{sim}$ & 1997 & $1(1,3 \%)$ & $59(78,7 \%)$ & $15(20,0 \%)$ & $75(100,0 \%)$ \\
& 1998 & $0(0,0 \%)$ & $51(79,7 \%)$ & $13(20,3 \%)$ & $64(100,0 \%)$ \\
& 1999 & $0(0,0 \%)$ & $47(83,9 \%)$ & $9(16,1 \%)$ & $56(100,0 \%)$ \\
& 2000 & $0(0,0 \%)$ & $39(95,1 \%)$ & $2(4,9 \%)$ & $41(100,0 \%)$ \\
& 2001 & $0(0,0 \%)$ & $18(94,7 \%)$ & $1(5,3 \%)$ & $19(100,0 \%)$
\end{tabular}


Tabela 9: Distribuiçăo da frequiência anual (n. ${ }^{0}$ e $\%$ segundo risco coronariano: potencial, moderado, alto e a presença de obesidade (obesos sim) ou sem obesidade (obesos não) no período de 1997 a 2.001.

\begin{tabular}{|c|c|c|c|c|c|}
\hline \multirow[b]{2}{*}{ Obesos } & \multicolumn{4}{|c|}{ Risco coronariano } & \multirow[b]{2}{*}{ Total } \\
\hline & Ano & Potencial & Moderado & Alto & \\
\hline \multirow[t]{5}{*}{ n ão } & 1997 & $20(14,2 \%)$ & $119(84,4 \%)$ & $2(1,4 \%)$ & $141(100,0 \%)$ \\
\hline & 1998 & $23(15,9 \%)$ & $119(82,1 \%)$ & $3(2,1 \%)$ & $145(100,0 \%)$ \\
\hline & 1999 & $33(22,0 \%)$ & $115(76,7 \%)$ & $2(1,3 \%)$ & $150(100,0 \%)$ \\
\hline & 2000 & $82(45,3 \%)$ & $98(54,1 \%)$ & $1(0,6 \%)$ & $181(100,0 \%)$ \\
\hline & 2001 & $153(71,8 \%)$ & $60(28,2 \%)$ & $0(0,0 \%)$ & $213(100,0 \%)$ \\
\hline \multirow[t]{5}{*}{ sim } & 1997 & $8(3,8 \%)$ & $186(87,7 \%)$ & $18(8,5 \%)$ & $212(100,0 \%)$ \\
\hline & 1998 & $17(8,2 \%)$ & $177(85,1 \%)$ & $14(6,7 \%)$ & $208(100,0 \%)$ \\
\hline & 1999 & $13(6,4 \%)$ & $182(89,7 \%)$ & $8(3,9 \%)$ & $203(100,0 \%)$ \\
\hline & 2000 & $31(18,0 \%)$ & $140(81,4 \%)$ & $1(0,6 \%)$ & $172(100,0 \%)$ \\
\hline & 2001 & $60(42,9 \%)$ & $79(56,4 \%)$ & $1(0,7 \%)$ & $140(100,0 \%)$ \\
\hline
\end{tabular}


Tabela 10: Distribuição da frequêencia anual (n. ${ }^{0}$ e $)$ segundo risco coronariano: potencial, moderado, alto e a presença de dislipidemia (dislipidemia sim) ou colesterol total controlado (dislipidemia ño) no periodo de 1997 a 2.001.

\begin{tabular}{cccccc}
\hline \multirow{5}{*}{ Dislipidemia Ano } & Potencial & Moderado & Alto & Total \\
\hline não & 1997 & $19(23,8 \%)$ & $61(76,3 \%)$ & $0(0,0 \%)$ & $80(100,0 \%)$ \\
& 1998 & $29(29,0 \%)$ & $69(69,0 \%)$ & $2(2,0 \%)$ & $100(100,0 \%)$ \\
& 1999 & $36(33,0 \%)$ & $72(66,1 \%)$ & $1(0,9 \%)$ & $109(100,0 \%)$ \\
& 2000 & $96(58,9 \%)$ & $67(41,1 \%)$ & $0(0,0 \%)$ & $163(100,0 \%)$ \\
& 2001 & $189(76,2 \%)$ & $59(23,8 \%)$ & $0(0,0 \%)$ & $248(100,0 \%)$ \\
\hline sim & 1997 & $9(3,3 \%)$ & $244(89,4 \%)$ & $20(7,3 \%)$ & $273(100,0 \%)$ \\
& 1998 & $11(4,3 \%)$ & $227(89,7 \%)$ & $15(5,9 \%)$ & $253(100,0 \%)$ \\
& 1999 & $10(4,1 \%)$ & $225(92,2 \%)$ & $9(3,7 \%)$ & $244(100,0 \%)$ \\
& 2000 & $17(8,9 \%)$ & $171(90,0 \%)$ & $2(1,1 \%)$ & $190(100,0 \%)$ \\
& 2001 & $24(22,9 \%)$ & $80(76,2 \%)$ & $1(1,0 \%)$ & $105(100,0 \%)$
\end{tabular}




\section{8 - Referências bibliográficas da Análise Estatística}

A) Agresti, A. An Introduction to categorical data analysis. New York. Wiley; 1996.

B) Altman, D. G. Practical statistics for medical research. Chapman \& Hall; 1991.

C) Kirkwood B. Essentials of Medical Statistics. First Edition. Oxford. Blackwell Scientific Publications; 1988.

D) Neter J., Kutner M.H., Nachtsheim C.J. \& Wasserman W. Applied Linear Statistical Models. McGraw-Hill; 1996. 
G. Donsomin 


\section{Discussões dos Resultados}

Em nosso estudo, dos 373 idosos acompanhados no início do estudo (em 1997) 5,4\% (20 casos) morreram em menos de quatro anos de acompanhamento médico geriátrico. Discutiremos, em seguida, as causas de óbitos destes idosos.

\section{1 - Causas de óbitos}

Neste estudo, as doenças do aparelho circulatório foram as principais causas de óbitos hospitalares e residenciais o que representou $35 \%$ do total de casos de óbitos (20 casos). Esses dados vão ao encontro com os dados oficiais Nacionais do: $\operatorname{DATASUS}^{(197)}(1998)$, do Ministério da Saúde ${ }^{(219)}(2.000)$, IDB $2001^{(220)}$ e em outros estudos apresentados nos itens 1 e 2 do presente trabalho. Assim, o impacto das doenças do aparelho circulatório sobre as diferentes faixas etárias cresce progressivamente com a elevação da faixa etária ${ }^{(217)}$.

$\mathrm{Na}$ literatura, o Infarto Agudo do Miocárdio (IAM) é a primeira manifestação de cardiopatia isquêmica ${ }^{(191.216 .242)}$ em cerca de 50 a $70 \%$ dos pacientes. Não está estabelecido se algum dos fatores de risco tem participação independente na instabilidade da placa para o desenvolvimento do IAM como primeira manifestação ${ }^{(235)}$. Tem sido sugerido que o IAM sem angina prévia é mais prevalente em jovens e homens, estando relacionado ao acometimento de um único vaso e melhor evolução clínica. Outros estudos contradizem a importância destes fatores de risco. Persiste, dessa maneira, uma controvérsia a respeito dos vários aspectos que caracterizariam pacientes com IAM, como primeira manifestação da cardiopatia isquêmica $^{(216)}$ 
Segundo os dados do IDB $2001^{(220)}$ a taxa de mortalidade por doenças do aparelho circulatório no Estado de São Paulo esteve em 202,4 /100 mil habitantes, sendo a principal causa de óbito geral para o Estado. Neste estudo, dentre as doenças do aparelho circulatório o Infarto Agudo do Miocárdio foi a principal causa de óbito, representando $71,4 \%$ (5 casos) apresentando uma proporção homem : mulher de $4: 1$, com idade média de 79,8 anos ( $D P=7,05$ anos). Ocorreram três casos de óbitos residenciais, o que representou $15 \%$ do total de óbitos do estudo e todos tiveram como causa básica da morte o lAM. Estes óbitos foram do sexo masculino, com idade média de 78 anos (DP $=7,5$ anos $)$

A idade tem profundo efeito na incidencia e na evolução clínica do IAM resultando em maior mortalidade que no paciente jovem ${ }^{(205-6)}$

Embora segundo a Organização Mundial de Saúde ${ }^{(226)}$ o diagnóstico de IAM seja feito com base no encontro de pelo menos dois dos seguintes critérios: presença de dor precordial, alterações eletrocardiográficas, elevação e queda de marcadores séricos de necrose miocárdica, em grupos de idosos mostram particularidades nas apresentações clinicas, nas evoluções e nas respostas as intervenções terapêuticas $^{(190.206)}$. As apresentações pelos idosos de sinais e sintomas de formas inespecificas ou atipicas acabam mascarando o diagnóstico e tratamento correto para $\mathrm{o} \mathrm{lAM}^{(190.206)}$. Muitas vezes, o primeiro sinal nesses pacientes idosos é apenas uma deteriorização funcional, cognitiva ou queixas vagas como: fraqueza, cansaço, inquietação e menos freqüentemente dor ou desconforto torácico e sudorese. Por outro lado, a sincope, o acidente vascular cerebral e confusão aguda se tornam mais comuns e muitas vezes os únicos sintomas de apresentação ${ }^{(190,206)}$ 
Estima-se que $40 \%$ dos Infartos do Miocárdio na população idosa ocorreram de forma silenciosa ${ }^{(206)}$. Atualmente aceita-se que a grande maioria dos casos fatais é consequência de arritmias ventriculares, particularmente a fibrilação ventricular $^{(188.194)}$. O interesse no atendimento pré-hospitalar do IAM é resultado do fato de que aproximadamente $30 \%$ dos pacientes morrem antes de chegar ao hospital. Outro dado importante é que $50 \%$ dos óbitos ocorrem na primeira hora de evolução e aproximadamente $80 \%$ dos pacientes falecem nas primeiras 24 horas ${ }^{(188,224)}$. Assim, em nosso estudo, os óbitos ocorridos em residência por IAM reforçam a necessidade de melhorar a atenção da equipe de saúde bem como das pessoas que acompanham os idosos. A valorização das queixas dos idosos, a investigação e o controle mais adequado para as doenças do aparelho circulatório em idosos poderão levar a diminuição destes eventos, particularmente em ambiente residencial.

É interessante observar que, neste grupo de estudo, não houve caso de acidente vascular cerebral ou crise hipertensiva como causa de óbitos. Este fato poderia ser justificado devido ao monitoramento e ao controle dos fatores de risco coronariano realizado de forma constante durante o estudo particularmente quanto aos controles: da pressão arterial, da glicemia, do colesterol total, das frações do colesterol, dos triglicérides e do peso.

Muitos estudos como: MRC ${ }^{(178)}$, SHEP(183), Framinghan Study ${ }^{(28,33-4)}$, $\mathrm{EWP}^{(41)}, \mathrm{MRFIT}^{(102)}, \mathrm{IPPPSH}^{(152)}, \mathrm{HAPPHY}(166), \mathrm{VA}^{(159-60)}, \mathrm{MAPHY}^{(165)}, \mathrm{HOPE}^{(238)}$ e outros estudos apresentados nos itens 1 e 2 do presente trabalho, deixam claro que o controle da hipertensão arterial reflete diretamente na diminuição dos eventos cardiovasculares e da mortalidade por esta causa, o que também ficou demonstrado no presente trabalho. 
A maioria das neoplasias aumentam com a idade, particularmente a partir da 6. ${ }^{\text {a }}$ década de vida ${ }^{(201,204,213,223)}$. Em nosso estudo, as neoplasias foram a segunda causa de óbito onde $83,3 \%$ ( 5 casos) foram do aparelho gastrintestinal sendo: $60 \%$ ( 3 casos) por neoplasia do intestino e $40 \%$ ( 2 casos) por neoplasia gástrica.

Não houve caso de óbito por neoplasia de mama ou de pulmão, durante o acompanhamento destes idosos. Embora sejam as causas de óbitos mais freqüentes no Estado de São Paulo, segundo IDB 2001 ${ }^{(220)}$, apresentando uma taxa de mortalidade de 14,9 óbitos por 100 mil habitantes para neoplasia de mama e 11,5 óbitos por 100 mil habitantes para neoplasia de pulmão.

Os idosos do sexo masculino foram mais acometidos por neoplasia numa proporção de 5:1(homens : mulher) representando $83,3 \%$ dos casos de óbitos por neoplasia.

Segundo Berkow ${ }^{(192)}$ o carcinoma de colo é mais freqüente entre as mulheres e sua incidência aumenta com a idade principalmente entre 60 a 75 anos, em nosso estudo foram 3 casos numa proporção de 2:1 (homens : mulher). Populações com alta incidência de câncer de colo quando comparadas com populações com baixa incidência consomem dietas do tipo: pobre em fibras e rica em proteína animal, gordura e carboidratos refinados ${ }^{(192)}$. Segundo Kay ${ }^{(213)}$ fatores como hereditariedade e outros fatores podem também estar relacionados com câncer de colo.

A neoplasia gástrica é duas vezes mais freqüente entre homens e tem sido associado à exposição a fatores de risco como: fumo, ingestão de sal, nitritos, aflatoxina, deficiência vitamínica, gastrite atrófica e infecção pelo Helicobater pylori $^{(213,223)}$. Entre idosos a presença de Helicobater pylori está associada a um aumento de até oito vezes no risco de desenvolver câncer gástrico ${ }^{(213,223)}$. 
Em nosso estudo, foram 2 casos de óbitos por neoplasia gástrica ( $40 \%$ das neoplasias gastrointestinais) sendo ambos do sexo masculino com idade média de 70,5 anos $(\mathrm{DP}=4,5$ anos $)$

A prevalência e a mortalidade por câncer de próstata aumentam com a idade A probabilidade de se desenvolver câncer de próstata entre 60 a 79 anos é de $1 \mathrm{em} 8$ homens $^{(184,204.214 .234)}$. A neoplasia de próstata é a segunda causa de óbito mais freqüente entre os homens. Segundo os dados da IDB $2001^{(220)}$ no Estado de São Paulo a taxa de óbito por câncer de próstata está em 11,4 óbitos por 100 mil habitantes. Em nosso estudo, somente um caso (16,7\% das neoplasias) evoluiu para óbito. Durante o presente estudo, todos os idosos eram monitorizados anualmente com dosagem do PSA e/ou avaliação prostática por ultra-sonografia. Todos os idosos com qualquer alteração nos valores de PSA ou ultra-sonográficos de próstata eram acompanhados simultaneamente com urologista, o que certamente influenciou no diagnóstico precoce de câncer de próstata e conseqüentemente o seu tratamento e controle.

O mesmo cuidado foi observado para a prevenção de câncer de colo de útero e de mama, onde foram solicitados anualmente exames de mamografia e papanicolaou para todas as mulheres em acompanhamento geriátrico. Os casos suspeitos de neoplasia ou alterados foram encaminhados para o acompanhamento também com ginecologista. Com este fluxo assegurado, foram possiveis os diagnósticos e tratamentos precoces de forma adequada, o que se refletiu concretamente na ausência de casos de óbitos por neoplasias de mama ou de colo de útero durante o período de estudo. 
Por fim, neste estudo, a mortalidade geral para neoplasias para o sexo masculino ficou em $65 \%$ numa proporção de $1,86: 1$ (homens : mulher) sugerindo que os homens estariam num risco aumentando para estas patologias.

Os dados de mortalidade observados neste estudo estão de acordo com a literatura e os encontrados em levantamento realizado por Lima e Costa ${ }^{(215)}(2.000)$ quanto ao diagnóstico de saúde da população idosa brasileira. Onde se verificou uma maior taxa de mortalidade entre os homens do que entre as mulheres e aumento progressivo da taxa de mortalidade com o crescimento da idade em todas as regiões brasileiras e que são semelhantes aos observados em outros países ${ }^{(10,21,28,31,35,53,65)}$.

\section{2 - Fatores de risco coronarianos ao longo dos anos}

Em nosso estudo, o comportamento médio dos fatores de risco coronarianos particularmente: a pressão arterial sistólica, a glicemia de jejum e o risco coronariano total mostraram uma queda significativa ao longo dos anos, vide item 5.4, principalmente após três anos de acompanhamento.

Fazendo uma análise retrospectiva dos fatores que contribuíram para as mudanças no comportamento médio dos fatores de risco coronariano ao longo do tempo podemos destacar:

- A adesão dos idosos à proposta de revisão de saúde periódica com enfoque de risco particularmente quanto: aos fatores de risco coronarianos, a prevenção de câncer ginecológico e a prevenção de câncer prostático. 
- Ações educativas junto ao paciente e acompanhantes (familiares e/ou cuidadores de idosos) com a própria médica que acompanhava o idoso, através de instrumento pré-elaborado sobre fatores de risco coronarianos Este instrumento foi aplicado em todas as consultas médicas, vide item 4.5.

- Disponibilidade da maior parte dos medicamentos prescritos,

- Disponibilidade dos exames laboratoriais e da maioria dos exames complementares na própria unidade de saúde.

- Garantia da referência e contra-referência com outras especialidades médicas na própria unidade de saúde,

- Garantia do controle da pressão arterial e da glicemia capilar pela equipe de enfermagem, conforme solicitação médica-geriátrica. Ficou estabelecido que uma vez alterado o controle este era comunicado imediatamente a médica solicitante que orientava os procedimentos a serem realizados sem agendamento prévio de consulta.

Assim, foi possivel durante o estudo manter um alto grau de interesse por parte dos idosos e de seus familiares/acompanhantes em permanecer no atendimento médico-geriátrico.

Vale ressaltar que, a integração entre toda equipe de saúde, na unidade onde foi realizado o estudo, viabilizou informalmente uma melhor atenção ao paciente atendido no setor de geriatria.

Ao longo dos anos de estudo, pacientes, familiares/acompanhantes e equipe de saúde foram familiarizando com a metodologia de trabalho da médica do setor de geriatria; o que levou a um período de adaptação de mais ou menos dois anos e a 
partir do terceiro ano a proposta de atenção à saúde aos idosos foi integrada e aceita pelos seus componentes, refletindo diretamente nos resultados finais deste estudo, vide item 5 .

Através desta metodologia foi possível influenciar a concepção de saúde dos idosos e dos seus familiares/acompanhantes tornando-os participantes ativos dos processos de mudanças para o auto-cuidado refletindo na melhora do seu bem-estar. Assim, foi atendido a proposta da Carta de Ottawa, vide p. 5, onde define saúde “...a saúde é o resultado dos cuidados que cada um dispensa a si mesmo e aos demais, é a capacidade de tomar decisões e controlar a própria vida..."

Os fatores de risco que mais aumentaram a sua contribuição para o risco coronariano total ao longo dos anos foram em média: idade/sexo com $27,6 \%$ seguidos pela atividade física esportiva com $26,5 \%$, colesterol total com $15,4 \%$, pressão arterial sistólica com $9,2 \%$, peso com $8,1 \%$, glicemia de jejum com $7,7 \%$, antecedentes familiares com $3,2 \%$ e fumo com $2,3 \%$; vide Tabela 2 do item 5.5 .

O fator de risco Idade é um fator de risco independente, não modificável (vide item 1.3) assim, o aumento de sua contribuição para o risco coronariano total ao longo dos anos em $11 \%$ esteve dentro do esperado. É bem demonstrado, na literatura médica, que ser idoso é um fator de risco cardiovascular significante ${ }^{(207)}$ independente do $\operatorname{sexo}(1,28,33-4,82,85,161,241)$.

O fator de risco referente à atividade fisica esportiva foi o fator de risco modificável que mais contribuiu para o risco coronariano total ao longo dos anos com acréscimo de 10,3\%, no final do estudo a contribuição deste fator de risco ficou 
em $33,2 \%$ perdendo somente para a idade que ficou em $34,6 \%$, vide tabela 2 do item 5.5 .

Em estudo anterior realizado por $\operatorname{Rassi}^{(120)}$ (1998) na opinião dos idosos quanto aos fatores de risco coronarianos a que eles estavam expostos, eles foram capazes de identificar três fatores de risco coronarianos: o colesterol total alterado, a falta de atividade fisica esportiva e o excesso de peso, vide item 2.2 .

Uma vez que os próprios idosos identificaram como risco coronariano à falta de atividade fisica esportiva, esperávamos que ações educativas de reforço pudessem mobilizá-los para esta atividade, modificando este risco.

No entanto, a baixa adesão à prática de atividade física é observada em qualquer faixa etária. De uma forma geral, tem-se observado que cerca de $50 \%$ das pessoas que iniciam algum programa de atividade física desistiram desta prática dentro de seis meses ${ }^{(198.202)}$.

O sedentarismo constitui o fator de risco mais prevalente em idosos com doença cardiovascular estabelecida. No estudo EMI, realizado em $1995 \mathrm{em}$ ambulatórios de Geriatria e Cardiologia Geriátrica de 13 estados brasileiros, verificou-se a prevalência de sedentarismo em $74 \%$ dos idosos entrevistados. Observou-se ainda que o sedentarismo sofreu influencia da idade sendo presente em $70 \%$ no grupo com 65 a 74 anos, $76 \%$ no grupo com 75 a 84 anos e $88 \%$ no grupo com idade igual ou superior aos $85 \operatorname{anos}^{(2.36-7)}$. Estes dados estão de acordo com os achados deste trabalho

Acreditamos que uma das justificativas para esse acréscimo do risco coronariano total se deveu a falta de referência para atividade física esportiva ao idoso em acompanhamento em serviço público. 
As atividades fisicas disponiveis eram limitadas à fisioterapia motora na própria unidade de saúde, ao grupo de ginástica da terceira idade na própria unidade de saúde e em outros espaços públicos, hidroginástica em espaços privados e caminhadas.

Segundo American College Sports Medicine ${ }^{(185)}$, os exercícios aeróbicos, ou seja, as atividades realizadas com grandes grupos musculares movimentados de forma cíclica com baixa a moderada intensidade e longa duração feitas de três a cinco vezes por semana, são as mais recomendadas para a prevenção cardiovascular primária e secundária.

Atualmente é bem estabelecido que indivíduos sedentários que se tornam um pouco mais ativos reduzem expressivamente seu risco cardiovascular ${ }^{(193,203,225)}$.

Entretanto, de forma indireta, as impressões tanto da médica quanto dos idosos e seus acompanhantes foram que à medida que os anos se passaram, os idosos estavam mais ativos em suas Atividades de Vida Diárias - AVDs, mas este referencial não foi analisado neste estudo.

Os estudos de Framingham ${ }^{(210)}$ demonstraram que embora o peso seja um fator de risco independente para as doenças cardiovasculares, a perda de peso, mesmo quando modesta, diminui o risco cariovascular ${ }^{(227)}$ e se associam a uma melhora significativa dos niveis pressóricos $\mathrm{e}$ dos indices de controle metabólico ${ }^{(196,212,233)}$. Em nosso estudo, a contribuição do peso no risco coronariano total apresentou um pequeno decréscimo de $0,7 \%$.

Os fatores de risco coronarianos modificáveis que apresentaram maior decréscimo na contribuição para o risco coronariano total foram para: o colesterol total em $11,4 \%$, a glicemia de jejum em $5,5 \%$ e a pressão arterial sistólica em $5,0 \%$, vide figura 10 e tabela 2 do item 5.5 . 
O Censo Nacional em Diabetes, concluido em $1988^{(94)}$, avaliou a situação do Diabetes Mellitus em nove capitais brasileiras e mostraram que $20 \%$ da população com idade maior que 70 anos eram diabéticos

O Diabetes Mellitus apresenta risco equivalente à doença arterial coronária instalada porque acrescenta alto risco de evento coronariano em 10 anos e evolui freqüentemente com múltiplos fatores de risco associados ${ }^{(186-7,218,221,243)}$.

Segundo o Ministério da Saúde ${ }^{(221)}$ (2002), a possibilidade de associação da Hipertensão Arterial e do Diabetes Mellitus é de ordem de $50 \%$.

A Working Group Report on Hypertension in Diabetes ${ }^{(240)}$ (1994), estimou que $35 \%$ a $75 \%$ das complicações do Diabetes Mellitus possam ser atribuidos a Hipertensão Arterial. American Diabetes Association ${ }^{(186-7)}$ apresentou que a Hipertensão Arterial é duas vezes mais freqüente entre indivíduos com Diabetes Mellitus do que nos não diabéticos e sua prevalência aumenta com a idade. A Hipertensão Arterial Isolada, mais comum nos idosos, é consideravelmente mais comum entre diabéticos. Fatores ambientais são responsáveis por ambas as condições $^{(186-7,195,199,240)}$.

Em relação ao tratamento e controle do Diabetes Mellitus e da Hipertensão Arterial, estudos como UKPDS ${ }^{(156-8)}, \operatorname{HOT}^{(209)}$, Syst-Eur ${ }^{(239)}$, que analisaram o controle rigoroso da hiperglicemia e da hipertensão arterial foram capazes de reduzir as complicações do Diabetes Mellitus e a mortalidade. No estudo $\operatorname{MRFIT}^{(102)}$ demonstrou que para qualquer nível aumentado da pressão arterial entre pacientes diabéticos se observou uma incidência mais elevada de cardiovasculopatias em relação à identificada nos individuos não diabéticos. 
O estudo Systolic Hypertension in Europe - Syst-Eur ${ }^{(239)}$ analisou também os efeitos do controle da hipertensão arterial em pacientes diabéticos idosos e concluiu que o tratamento da hipertensão arterial sistólica isolada em pacientes com Diabetes Mellitus também diminui os eventos cerebrovasculares.

Nos resultados apresentados, no item 5.6, observamos que no início do estudo haviam 75 idosos com niveis de glicemia de jejum aumentadas, o que representava $21,2 \%$ dos idosos acompanhados ao longo do tempo. Destes, $52 \%$ (39 idosos) apresentaram associação entre Diabetes Mellitus com Hipertensão Arterial, vide Tabela 3 do item 5.6. No final do estudo esta associação ficou em 2,7\% ( 2 idosos) entre os idosos com Diabetes Mellitus o que representou $0,6 \%$ dos idosos que foram acompanhados. Este decréscimo, estatisticamente significativo, sugere a contribuição positiva para que não houvesse casos de óbitos por eventos cerebrovasculares, vide discussão dos resultados de óbitos item 6.1, o que foi semelhante aos estudos apresentados acima

Há fortes evidencias na literatura de que muitos pacientes hipertensos apresentam intolerância a glicose limitrofe e resistência a insulina ${ }^{(218,222,226)}$. Por definição o Diabetes Mellitus resulta de graus variáveis de resistência à insulina e/ou de deficiência relativa de secreção de insulina ${ }^{(218,222,226)}$. Segundo $\operatorname{Reven}^{(229-30)}$ (1995), o Diabetes Mellitus é considerado parte da chamada sindrome plurimetabólica ou síndrome de resistência à insulina e ocorre em $90 \%$ dos pacientes diabéticos. Denomina-se resistência à insulina o estado no qual ocorre menor captação de glicose pelos tecidos periféricos (especialmente muscular e hepático), em resposta à ação da insulina. As demais ações do hormônio estão mantidas ou mesmo acentuadas 
Em resposta a essa resistência tecidual, há uma elevação compensatória da concentração plasmática de insulina, com o objetivo de manter a glicemia dentro dos valores normais. A homeostase glicèmica é atingida às custas de hiperinsulinemia As principais características da síndrome concorrem para a doença vascular aterosclerótica com: Hipertensão Arterial, Diabetes Mellitus, hiperinsulinemia, tolerância a glicose diminuída, dislipidemia, obesidade central (abdominal ou andrógena), microalbuminúria, disfunção endotelial e defeitos da coagulação ${ }^{(218.222 .226)}$.

O diagnóstico da Sindrome Plurimetabólica ou síndrome da resistência a insulina é feito pela presença de pelo menos três dos cinco critérios seguintes ${ }^{(196.229-}$ 33)

- Obesidade abdominal (cintura maior $102 \mathrm{~cm}$ no sexo masculino e maior $88 \mathrm{~cm}$ no sexo feminino)

- Triglicérides maior igual a $150 \mathrm{mg} / \mathrm{dl}$

- HDL colesterol menor que $40 \mathrm{mg} / \mathrm{dl}$ nos homens e menor que 50 $\mathrm{mg} / \mathrm{dl}$ nas mulheres

- Pressão Arterial maior ou igual $130 \times 85$ mmHg

- Glicemia Jejum maior ou igual $110 \mathrm{mg} / \mathrm{dl}$.

A resistência à insulina é considerada como um fator de risco cardiovascular isolado ${ }^{(189.208 .229-30)}$.

A prevalência da sindrome plurimetabólica ou síndrome da resistência a insulina esteve presente em $21,2 \%$ no início do estudo apresentando um decréscimo estatisticamente significativo ao longo dos anos de $18,4 \%$ ficando 
a prevalência da sindrome em $2,8 \%$, vide figura 12 do item 5.7 . Os fatores de risco coronarianos que mais contribuíram para a diminuição da prevalência desta sindrome foram: colesterol total, glicemia de jejum e a pressão arterial, vide figura 10 e Tabela 2 do item 5.5. O que refletiu diretamente no comportamento da classificação do risco coronariano ao longo dos anos, vide item 5.7, com mudanças estatisticamente significantes na classificação do risco coronariano total

Assim, a proporção de pacientes com risco coronariano potencial aumentou de $7,9 \%$ no início do estudo para $60,3 \%$ no final do estudo e as proporções de pacientes com risco coronariano moderado e alto diminuíram respectivamente de $86,4 \%$ para $39,4 \%$ e de $5,7 \%$ para $0,3 \%$, vide Tabela 5 do item 5.7 .

Analisando os idosos na classificação de Alto Risco Coronariano, os idosos com glicemia alterada - com Diabetes Mellitus - foram os que apresentaram maior redução de risco de $14,7 \%$, vide Tabela 8 do item 5.7 .

No início do estudo, $142(40,2 \%)$ idosos apresentavam hipertensão arterial sendo que $11,3 \%$ estavam classificados no risco coronariano alto e ao longo dos anos $90 \%$ passaram para o risco coronariano moderado, vide Tabela 7 do item 5.7

Os idosos que no início do estudo estavam em risco coronariano alto e apresentavam obesidade ou colesterol total alterado, ao longo dos anos, apresentaram um decréscimo de $7,8 \%$ e $6,3 \%$ respectivamente no risco coronariano alto, vide Tabela 10 do item 5.7. 
Assim, com este estudo fica demonstrado que é possivel reduzir de forma eficaz o risco coronariano em idosos através do monitoramento e controle dos fatores de risco modificáveis e das ações educativas de saúde continuada para o idoso e seus acompanhantes.

O envelhecimento populacional tornou o estudo de idosos da maior importância, na medida em que são poucos os dados disponíveis para o planejamento das ações de saúde pública.

Entretanto, são necessárias maiores investigações sobre as condições de saúde da população idosa, suas demandas por atenção e promoção à saúde e o montante necessário para atender a essas demandas.

Politicas para promover a saúde do idoso e garantir um atendimento adequado de suas demandas são necessárias já no presente em nosso País. 


\section{3- Referências Bibliográficas Complementares}

184. Alfer Jr W. Adenocarcinoma de Próstata. [GERP'2001 EM CD ROM] promoção e realização da Sociedade Brasileira de Geriatria e Gerontologia secção São Paulo. II Congresso Paulista de Geriatria e Gerontologia. SP - SP2001 .

185. American College Sports Medicine. ACSM's Guidelines for exercise testing and prescription. Baltimore: Williams e Wilkins, 2.000 .

186. American Diabetes Association. Treatment of hypertension in diabetes (Consensus Statement). Diabetes Care 1996; 19(supl 1): 5107-10.

187. American Diabetes Association: Clinical Practice recommendations. Diabetic Nephropathy. Diabetes Care 1999; 22(supl 1): 566-9.

188. Antman EM, Braunwald E. Acute myocardial infarction. In:Braunwald E, Zipes DP, Libby $p$ editors. Heart Disease: a textbook of cadiovascular medicine. $6^{\text {th }}$ edition. Philadelphia, W. B. Saunders Company; 2001. p. 1114-21.

189. Barreto-Filho JAS, Consolim-Colombo FM, Lopes HF. Hipertensão arterial e obesidade: causa secundária ou sinais independentes da sindrome plurimetabólica? Rev Bras Hipertens 2002; 9:174-84. 
190. Bayer AJ, Chadha JS, Frag RR. Changing presentation of myocardial infarction with increasing old age. Am Geriatric Society 1986; 34:263-66

191. Bechar S, Reicher-Reiss H, Abinader E, et al. The prognostic significance of angina pectoris preceding the occurrence of a first acute myocardial infarction in 4,166 consecutive hospitalized patients. Am Heart J 1992; 123:1481-6.

192. Berkow R, editor chefe. Manual Merck de Medicina:diagnóstico e tratamento. 15a edição. São Paulo: Roca; 1990. p. 906-10.

193. Blair SN, Kohl HW, Barlow CE, Paffenbarger Jr RS. Changes in physical fitness and all-cause mortality. J A M A 1995; 273: 1093-8.

194. Braunwald E. Evolution of management of acute myocardial infarction: a $20^{\text {th }}$ century saga. Lancet $1998 ; 352: 1771-4$.

195. 1999 Canadian recommendations for the management of hypertension: CMAJ. Dec. 14, 1999; 161(12).

196. I Consenso Latino Americano de Obesidade, Associação Brasileira de Estudos sobre a obesidade; 2001. www. abeso.org.br 
197. DATASUS. Mortalidade CID 10 - Óbitos por ocorrência por causaCap. 10 segundo Unid. Federação - período 1998. Brasília - DF; 2001.

http / www datasus, gov br/cgi/tabcgi exe? $\operatorname{sim} /$ dybr def/

198. Dishman RK. Overview. In: Exercise Adherence: its impact on public health. Champaign, Human Kinetics, 1989. p $1-9$.

199. Epstein M, Sowers JR. Diabetes Mellitus and Hypertension. Hypertension $1992 ; 19: 403-418$.

200. Executive Summary of the Third Report of The National Cholesterol Education Program (NCEP) Expert Panel on Detection, Evaluation and treatment of high blood cholesterol in adults (Adult Treatment Panel III). J A M A 2001; 285(19):2486-97. www.nhlbi.nih.gov/

201. Ferriolli E, Moriguti JC. Envelhecimento do Aparelho Digestório. In: Freitas EU, Py L, Neri AL, Cançado FAX, Gorzoni ML, Rocha SM. Tratado de Geriatria e Gerontologia. Editora Guanabara Koogan S.A. RJ - RJ, 2002. p. 376-80.

202. Fortaz CLM, Tinuccit T. Estratégias de melhora da Adesão ao exercício como tratamento não-farmacológico de doenças crônicas. In: Mion Jr D, Nobre F. Risco cardiovascular global: convencendo o paciente a reduzir o risco. Lemos Editorial, 3.a ed. São Paulo - SP, 2002, p. 104-37. 
203. Forjaz CLM, Tinucci T, Bartholomeu T, Fernandes TEM, Casagrande V, Massucato JG. Avaliação do Risco Cardiovascular e da Atividade Física dos freqüentadores de um parque da cidade de São Paulo. Arq Bras Cardiol 2002; 79(1): $35-42$.

204. Gomes MA. Doenças da Próstata. In: Freitas EU, Py L, Neri AL, Cançado FAX, Gorzoni ML, Rocha SM. Tratado de Geriatria e Gerontologia. Editora Guanabara Koogan S.A. RJ - RJ, 2002. p. 430-56.

205. Gottlieb C, Friesenger GC. Doença Cardiovascular do Idoso. In: Clínicas Cardiológicas da América do Norte. Ed. Thomas Ryan. Gottlieb C, Friesenger GC. Cardiopatia Coronária, 1999; 17(1):121-52

206. Gramarki R, Mohallem KL. Doença arterial Coronariana.. In: Freitas EU, Py L, Neri AL, Cançado FAX, Gorzoni ML, Rocha SM. Tratado de Geriatria e Gerontologia. Editora Guanabara Koogan S.A. RJ - RJ, 2002. p. 288-96.

207. Guidelines Subcommittee. World Health Organization International Society of Hypertension. Guidelines for the management of hypertension. J Hypertens 1999; 17:151-83.

208. Haffner SM. Epidemiology of insulin resistance and its relations to coronary artery disease. Am J Cardiol 1999; 84:11j-14j. 
209. Hansson L, Zanchetti A, Carruthers SG, Dahlof B, Elmfeldt D, Menard J. HOT Study Group. Effects of intensive blood pressure lowering and low-dose aspirin in patients with hypertension: Principal results of the hypertension optimal treatment (HOT) randomized trial. Lancet 1998; 351: 1755-62.

210. Hubert HB, Feinleib M, McNamara PM, Castelli WP. Obesity as an independent risk factor for cardiovascular disease: a 26 years follow up of participants in the Framingham Heart Study. Circulation 1983; 67:968 - 77.

211. Hypertension in Diabetes Study Group. HDS 1: Prevalence of hypertension in newly presenting type 2 diabetic patients and the association with risk factors for cardiovascular and diabetic complications. J Hypertens 1993; 11:309, 17.

212. Kannel WB, Brand N, Skinner Jr JJ, Dawber TR, McNamara PM. The relation of adiposity to blood pressure and development of hypertension. The Framinghan Study. Ann Intern Med 1967; 67: 48-59.

213. Kay L. Prevalence, incidence and prognosis of gastrointestinal symptoms in a random sample of an elderly population. Age and ageing 1994; 23:149-6

214. Kurth KH. Renal Bladder and Prostate Cancer an update. New York, USA. The Parthenon Publishing Group. 1999. 
215. Lima e Costa MFF, Guerra HL, Barreto SM, Guimarães RM. Diagnóstico da Situação de saúde da população idosa brasileira: um estudo da mortalidade e das internações Hospitalares Públicas. Informe Epidemiológico do SUS 2000; $9(1): 23-41$.

216. Manfroi WC, Peukert C, Berti CB, Noer C et al. Infarto Agudo do Miocárdio. Primeira Manifestação da Cardiopatia Isquêmica e relação com fatores de Risco. Arq Bras Cardiol 2002; 78(4):388-91.

217. Medeiros SL, Rassi EPM. Impacto Social das Doenças Cardiovasculares. [GERP'2001 EM CD ROM] promoção e realização da Sociedade Brasileira de Geriatria e Gerontologia - seç̧ão São Paulo. II Congresso Paulista de Geriatria e Gerontologia. SP - SP- 2001.

218. Ministério da Saúde. Departamento de Atenção Básica.Área Técnica de Diabetes e Hipertensão Arterial. Hipertensão Arterial Sistêmica (HAS) e Diabetes Mellitus (DM): protocolo/ Ministério da Saúde. Brasília - DF, Ministério da Saúde 2001.

219. Ministério da Saúde. Programas e Projetos. Doenças Cardiovasculares. Brasília - DF; 2001. http //www. saude gov.br/programas/cardio/cardio.htm 
220. Ministério da Saúde. Rede Interagencial de Informações para a Saúde RIPSA, apoio da Organização Pan-americana da Saúde - OPAS. Indicadores e dados básicos para a saúde - IDB 2001 Brasil. Brasília - DF; 2002. www datasus gov br

221. Ministério da Saúde. Secretaria de Políticas de Saúde. Departamento de Ações Programáticas Estratégicas. Plano de Reorganização de Atenção à Hipertensão Arterial e ao Diabetes Mellitus: Hipertensão Arterial e Diabetes Mellitus/ Departamento de Ações Programáticas Estratégias - Brasília: Ministério da Saúde, 2001.

222. Modan $\mathbf{M}$, Halkin $\mathbf{H}$, Almong S. Hyperinsulinemia a link between hypertension, obesity and glucose intolerance. J Clin Invest 1985; 75: 809-17.

223. Moriguti JC. Doenças do Aparelho Digestório Alto. In: Freitas EU, Py L, Neri AL, Cançado FAX, Gorzoni ML, Rocha SM. Tratado de Geriatria e Gerontologia. Editora Guanabara Koogan S.A. RJ - RJ, 2002. p. 382-90.

224. National Heart Attack Alert Program Coordinating Committee-60 Minutes to Treatment Working Group. Emergency department: rapid identification and treatment of patients with acute myocardial infarction. Ann Emerg Med 1994; 23:311-29. 
225. Paffenbarger Jr RS, Hade RT, Wing AL, Lee IM, Jung DL, Kampert JB. The association of changes in physical activity and other lifestyle characteristics with mortality among men. N Engl J Med 1993; 328: 538 - 45.

226. Pedoe-Tunstal H, Kuulasmaa J, Amouyel P, et al. Myocardial Infarction and coronary deaths in the World Health Organization MONICA Project. Circulation 1994; 90:583-612.

227. Preventing and managing the global epidemic of obesity. Report of the world health organization consultation of obesity. WHO, Genebra, june 1997.

228. Ortega KC, Mion Jr D, Nobre F. Razões pelas quais os médicos não convencem os pacientes ao tratamento de algumas doenças crônicas e degenerativas. Sugestões para melhores invervenções em Hipertensão, Diabetes e Dislipidemias. In: Mion Jr D, Nobre F. Risco cardiovascular global: convencendo o paciente a reduzir o risco. Lemos Editorial, 3 . $^{2}$ ed. São Paulo SP, 2002; p. 162-92.

229 Reaven GM. Role of insulin resistance in human disease (syndrome X): an expanded definition. Annu Rev Med 1993; 44:121-31.

230. Reaven GM. Pathophysiology of insulin resistanse in human disease. Physiol Rev 1995; 75:473-86. 
231. Sociedade Brasileira de Cardiologia. III Consenso Brasileiro de Hipertensão Arterial. Arq Bras Cardiol 1998; Edição especial - Campos de Jordão - SP - 12 a 15 de fevereiro de 1998 .

232. Sociedade Brasileira de Cardiologia. III Diretrizes Brasileiras sobre dislipidemia e diretrizes de prevenção da aterosclerose da Sociedade Brasileira de Cardiologia. Arq Bras Cardiol 2001; 77(supl III): 1- 48.

233. Sociedade Brasileira de Cardiologia. Diretrizes para cardiologistas sobre o excesso de peso e doença cardiovascular dos departamentos de Aterosclerose, Cardiologia Clínica e FUNCOR da Sociedade Brasileira de Cardiologia. Arq Bras Cardiol 2002; 78 (supl 1): 1- 14.

234.Sociedade Brasileira de Urologia. Tumores Prostáticos: I Consenso Nacional, HPB - Hiperplasia de Próstata Benigna. São Paulo; BG Cultural, 1998.

235. Sullivan AK, Holdright DR, Wright CA, et al. Chest pain in women: clinical, investigative and prognostic features. Br Med J 1994; 308:883-6.

236. Taddei CFG, Ramos LR, Moraes C. Estudo multicêntrico em idosos atendidos em ambulatório de cardiologia e geriatria de instituições brasileiras. Arq Br Card 1997; 69(5):327-33. 
237. Taddei CFG, Franken RA. Aterosclerose: fisiopatologia e prevenção de fatores de risco. In: Freitas EU, Py L, Neri AL, Cançado FAX, Gorzoni ML, Rocha SM. Tratado de Geriatria e Gerontologia. Editora Guanabara Koogan S.A. RJ - RJ, 2002. p. 233-8.

238. The HOPE - Heart Outcomes Prevention Evolution Study. N Engl J Med 2000; 342:145-53. http://www. nejm.org

239. Tuomilehto J, Rastenyte D, Birkenhager WH. The systolic hypertension in Europe (Syst-Eur) Trial investigator. Effects of calcium channel blockade in older patients with diabetes and systolic hypertension. $\mathbf{N}$ Engl J Med 1999; 340: $677-84$.

240. Working Group Report on Hypertension in Diabetes, U.S. Department of Health and Human Service. Public Health Service, National Institutes of Health, Publication $1994 ; 3530$.

241. World Health Organization. World Health Statistics Annual. Geneva: World Health Organization; 1995.

242. Zucjer DR, Griffifh J, Beshansky JR, Selker HP. Presentations of acute myocardial infarction in men and women. J Gen Intern Med 1997; 12:79-87. 
7. 


\section{Conclusões}

- Analisando anualmente, os fatores de risco coronarianos entre os idosos em acompanhamento ambulatorial médico-geriátrico durante quatro anos consecutivos concluí-se que houve redução significante $(p<0,001)$ ao longo dos anos dos fatores de risco coronarianos estudados.

$\downarrow \quad$ O comportamento médio dos fatores de risco coronariano indicou diferenças significantes $(p<0,001)$ entre as médias ao longo dos anos.

\ A maior contribuição dos fatores de risco coronariano em relação ao risco coronariano total foram: idade/sexo e atividade física esportiva e os que menos contribuíram foram: fumo e antecedentes familiares.

$\downarrow \quad \mathbf{O}$ fator de risco coronariano referente ao colesterol total, que representou o terceiro de maior contribuição para o risco coronariano total apresentou uma queda acentuada até o final do estudo. O mesmo aconteceu, porém, menos acentuado, para glicemia de jejum e pressão arterial sistólica.

$\downarrow$ Os fatores de risco coronariano quanto ao peso e fumo mantiveram-se praticamente estáveis nas suas contribuições como fatores de risco coronariano ao longo dos anos.

+ Houve uma queda significante $(p<0,001)$ das proporções de pacientes com Hipertensão Arterial Sistólica associado a Diabetes Mellitus e de pacientes com apenas um diagnóstico de Hipertensão Arterial Sistólica ou de Diabetes Mellitus. A proporção de pacientes sem o diagnóstico destas patologias aumentou com $p<0,001$. 
+ O perfil de pacientes com risco coronariano: potencial, moderado e alto mudou de forma estatisticamente significantes $(p<0,001)$ quando comparamos o início e o final do estudo. Esta alteração do perfil coronariano se fez através de um aumento da proporção de pacientes com risco coronariano potencial e uma diminuição de pacientes com risco moderado e alto.

+ Houve um melhor controle das porcentagens de pacientes hipertensos, diabéticos, obesos e dislipêmicos ao longo dos anos de acompanhamento de forma estatisticamente significante. 


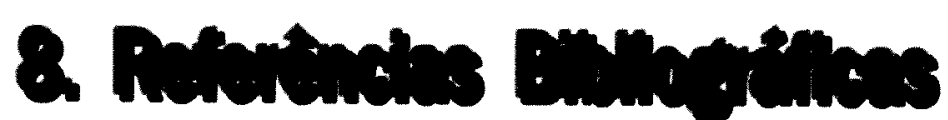




\section{Referências Bibliográficas}

1. Achutti A, Achutti VR. Fatores de risco para aterosclerose: elementos para descrição da situação no Rio Grande do Sul. Arq Bras Cardiol 1994; $63(5): 427-31$

2. Andrade J, Nogueira MZ. Prevenção de doenças cardiovasculares. Bol Bimensal da Escola de Ed. Física da USP 1972; set/out.

3. Andrade J. Estudo para organização de um serviço de reabilitação para pacientes cardíacos em um hospital geral. Rev Paul Hosp 1972; 20(9 Pt I):38-9.

4. Andrade J. Estudo para organização de um serviço de reabilitação para pacientes cardíacos em um hospital geral. Rev Paul Hosp 1972; 20(10 Pt II):40-2.

5. Andrade J. Estudo para organização de um serviço de reabilitação para pacientes cardiacos em um hospital geral. Rev Paul Hosp 1973; 21 (3 Pt III):131-5.

6. Alvarez FV, Banegas JRB, Enriquéz JG. Hacia la prevencion de las enfermedades crônicas. Rev San Hig Pública 1993; 67(1):1-4.

7. American Diabetes Association. Clinical practice recommendations. Diabetes Care 1999; 22 (suppl I):S1 14.

8. American Heart Association. Heart and stroke facts. Dallas, American Heart Association National Center, 1993.

9. American Heart Association. Fighling heart disease and stroke. Compêndio de cardiologia preventiva $1997 ; 4: 295-300$. 
10. Anderson KA, Castelli W, Levy D. Cholesterol and mortality 30 years of followup from the Framingham study. J A M A 1987; 257:2176-80.

11. Adissino D, Merlini PA, Gama G et al. Thrombin activity and early outcome in unstable angina pectoris. Circulation 1996; 93:1634-9.

12. Adissino D, Merlini PA, Eisenberg PR et al. Coagulation markers and outcomes in acute coronary syndromes. Am Heart J 1998; 136:S7-18.

13. Armaganijan D, Batlouni M. Impacto dos fatores de risco tradicionais. Rev Soc Cardiol Est de São Paulo 2000; 10(6):689-93.

14. Associação Brasileira para os Estudos de Obesidade (ABESO). J do Clinico $1997 ; 21: 1$

15. Associação para controle e educação em diabetes (ACED). Diagnóstico e Classificação do Diabetes Mellitus e tratamento do Diabetes Mellitus Tipo 2. Recomendações da Sociedade Brasileira de Diabetes. São Paulo, Brasil; 2001.

16. Bauters C, Amouyel P. Association between ACE genotype and coronary artery disease. Eur Heart J 1998; 9(suppl J):24-9.

17. Berg K, Dahlen G, Christophersen B et al. Lp(a) lipoprotein level predicts survival and major coronary events in the Scandinavian Sinvastatin Survival Study. Clin Genet 1997; 52:254-61.

18. Bostom AG, Gagnon DR, Cupples LA et al. A prospective investigation of $L p(a)$ detected by electrophoresis and cardiovascular disease in women. The Framingham Heart Study. Circulation 1994; 90:1688-95. 
19. Bostom AG, Cupples LA, Janner JL et al. Elevated plasma lipoprotein(a) and coronary heart disease in men aged 55 years or younger: a prospective study. J A M A 1996; 276:544-8.

20. Bricarello LP. A utilização de fitosteróis na alimentação: atuação sobre o colesterol? Rev Bras Med 2001; 58(3): 153-4.

21. Burke GL, Mamolio TA. Epidemiology of established major cardiovacular risk factors. In: Kapoot AS, Singh BN. Prognosis and risk assessment in cardiovascular disease. New York, Churchill Livingstone, 1993. p.61.

22. Burt VL, Whelton P, Roccella EJ. Prevalence of hypertension in the US adult population: results from the Third National Health and Nutrition Examination Survey. 1988-91. Hypertension 1995; 25:305-13.

23. Bush TL, Barret-Cannor E, Cowan LD. Cardiovascular mortality an noncontraceptive use of estrogen in women: results from the Lipid Research Clinics Program Follow-up study. Cirulation 1987; 75:1102-9.

24. Capra, F. O ponto de Mutação: ciência, a sociedade e a cultura emergente. São Paulo, Cultrix, 1995

25. Carvalho Filho ET, Curiati JAE. A insuficiência cardíaca no idoso. Rev Bras Med 2001; 58(3): 108-138.

26. Castelli WP, Garrison RJ, WILSON PWF et al. Incidence of coronary heart disease lipoprotein cholesterol levels. The Framingham Study. J A M A 1986; $256: 2835-8$ 
27. Castelli WP, Wilson PWF, Levy D. Serum lipids and risk of coronary artery disease. In: Leaf A, Weber PC. Prevention and noninvasive therapy of atherosclerosis. New York, Ravier, 1990 p. 7-19.

28. Castelli WP. Epidemiology of coronary disease: the Framingham study. Am Heart J 1992; 27:4-12.

29. Coelho OR, Ueti AA, Ueti OM. Hemostasia e doença arterial coronária. Rev Soc Cardiol Est de São Paulo 2000; 10(6):700-11.

30. II Consenso Brasileiro sobre Dislipidemias. Arq Bras Cardiol 1996; $67(2): 1-16$

31. Dahlof B, Lindholm HL, Hamsson L, Schersten B, Ekbom T, Wester PO. Morbidity and mortality in the Swedish Trial in Old patients with hypertension (STOP - Hypertension). Lancet 1991; 338:1281-5.

32. Danesch J, Whincup P, Walker $\mathbf{M}$, Lennon L, Thomson A, Appleby $\mathbf{P}$ et al. Clamydia pneumoniae IgG titles and coronary heart disease: prospective study and meta-analysis. Br Med J 2000; 321:208-12.

33. Dawber TR, Moore FE, Mann GV. Measuring the risk of coronary heart disease in adult population groups: II. Coronary heart disease in the Framinghan study. Am J Public Health 1957; 47:4.

34. Dawber TR. The epidemiology of atherosclerotic disease: The Framingham Study. Cambridge, Harvard University Press; 1980. 
35. Dever GEA. Community health analysis. Rockville, Aspen Systems Corporation, 1980.

36. Dever GEA. A epidemiologia na administração dos serviços de saúde. São Paulo, Pioneira, 1988

37. Diament J, Alves RJ, Forti N, Giannini D. Crianças, mulheres, idosos, pacientes submetidos a transplante e renais crônicos: estratégias e precauções na terapêutica das dislipidemias. Rev Soc Cardiol Est de São Paulo 2000; 6:802-10

38. Downs JR, Clearfield M, Weis S, Whitney E, Shapiro DR, Beere PA et al. Primary prevention of acute coronary events with lovastatin in man and women with average cholesterol levels: results of AFCAPS/TexCAPS, Air Force/Texas coronary atherosclerosis prevention study. J A M A 1998; 279:1615-22.

39. Endriks HFJ. Spreads enriched with three different levels of vegetable oil sterols and the degree of cholesterol lowering in normocholesterolemic and midly hipercholesterolemic subjects. Eur J Clin Nutr 1999; 53:319-27.

40. Expert Panel on Detection, Evaluation and Treatment of High Blood Cholesterol in Adult. National Cholesterol Education Program: second report of the Expert Panel on Detection, Evaluation and Treatment of High Blood Cholesterol (Adult Treatment Panel II). Circulation 1994; 89:1329-45. 
41. European Working Party on High blood pressure in the Elderly. Mortality and morbidity results from the European Working Party on High blood pressure in the Elderly trial. Lancet $1985 ; 1349-54$.

42. Farmer UA, Gotto AM. Risk Factors for Coronary Artery Disease. In: Braunwald E, Heart Disease. A Textbook of Cardiovascular Medicine. $4^{\text {th }}$ ed. Philadelphia: WB Saunders, $1992 ; 1135-9$.

43. Feher J. Reabilitação cardiovascular no idoso. Rev eletrônica da Soc de Cardiol do Estado de São Paulo: [edição em disquete janeiro/fevereiro], 1996.

44. Folson AR, Wu RR, Rosamond WD et al. Prospective study of hemostatic factors and incidence of coronary heart disease. The atherosclerotic risk in communities (ARIC) study. Circulation 1997; 96:1102-8.

45. Fuchs FD. Hipertensão Arterial Sistêmica. Epidemiologia e fatores de risco. Arq Bras Cardiol $1994 ; 63(5): 443-4$.

46. Galvão S. As vantagens dos cuidados preventivos. Rev. Incor 1996; $2(20): 28-32$.

47. Genest JJ, Ordovas JM, McNamara JR, Robbins AM, Meade T, Cohn SD et al. DNA polymorphisms of the apolipoprotein B gene in patients with premature coronary artery disease. Atherosclerosis $1990 ; 82: 7-17$. 
48. George JB, Leininger M. Teorias de enfermagem. Porto Alegre, Ed. Artes médicas, 1993.

49. Giannini SD, Góes JM, Dereviack BE, Machado C, Forti N, Diament J. Sinvastatina (MK-733), novo inibidor da HMG-CoA redutase no tratamento da hipercolesterolemia do idoso com doença aterosclerótica. Arq Bras Cardiol $1990 ; 54(6): 407-14$

50. Gil AC. Métodos e técnicas de pesquisa social. São Paulo. Atlas, 1989. Linhas de Pensamento p.37-81.

51. Glueck CJ, Margolin G. Metabolismo das lipoproteinas. In: ABRAMS RB, BERKOW R. Editores. Manual Merck de Geriatria. Roca, São Paulo, 1995. p. 904-33.

52. Goldberg M. Este obscuro objeto da epidemiologia, In:Costa DC (org.), Breilh J, Goldberg M, Lima Barreto M, Almeida Filho N, Costa N do R, Gonçalves RBM. Epidemiologia teoria e objeto. $2^{a}$ ed. HUCITEC-ABRASCO, São Paulo, 1994. p. $87-136$.

53. Goldman L, Cook EF. The decline in ischemic heart disease mortality rates: an analysis of the comparative effects of medical interventions and changes in lifestyle. Ann Intern Med 1984; 101:85. 
54. Gordon T, Castelli WP, Hjortland MC et al. High-density lipoprotein as protective factor against coronary heart disease. The Framingham Study. Am J Med 1977; 62: 707-14.

55. Grundy SM, Balady GI, Crique MH. Primary prevention of coronary heart disease: guidance from Framingham: statement for health care professionals from the American Heart Association's Task Force on Risk Reduction. Circulation 1998; $97: 1876-87$

56. Grupo de Estudio sobre Dieta, Nutrición y Prevención de Enfermidades no Transmisibles, Ginebra, 1989. Informe. Ginebra, 1990 (OMS. Séries de Informes Técnicos, 797).

57. Hamsten A, de Faire U, Walldius $G$ et al. Plasminogen activator inhibitor in plasma: risk factor for recurrent myocardial infarction. Lancet 1987; 2:3-9.

58. Heinisch RH. Determinação dos níveis plasmáticos de citocinas inflamatórias e proteínas de fase aguda em pacientes com doença arterial coronariana.[Tese de Doutoramento - Faculdade de Medicina da USP] 2000.

59. Helgeland A. Treatment of mild hypertension: A five-year controlled drug trial: The Oslo Study. Am J Med 1980; 69: 725-32.

60. Hoffmeister HM, Jur M, Ruf-Lechman $M$ et al. Endothelial tissue-type plasminogen activator release in coronary heart disease. J Am Coll Cardiol $1998 ; 31: 547-51$. 
61. Hjortland MC, McNamara PM, Kannel WB. Some atherogenic concomitants of menopause: the Framingham study. Am J Epidemiol 1976; 103:304-11.

62. Ikeoka DT, Caramelli B. O papel da infecção na instabilização da placa de ateroma. Rev Soc Cardiol Est de São Paulo 2000; 6:744-50.

63. International Lipid Information Bureau (ILIB). The ILIB Lipid Handbook for Clinical Practice. New York; 2000.

64. Instituto Dante Pazzanese de Cardiologia do Estado de São Paulo. SIH ( Sistema de Informação Hospitalar ) - Relatório de Morbidade Hospitalar dos meses de dezembro de 1999, fevereiro a dezembro de 2.000. São Paulo; 2.001.

65. Isso H, Jacobs Jr DR, Wentworth D, Neaton JD, Cohen JD, for the MRFIT Research Group. Serum cholesterol levels and six-years mortality from stroke in 350,977 men screened for the Multiple Risk Factor Intervention Trial. N Engl J Med 1989; 320:904-10.

66. Izar MCO, Ihara SSM, Relvas WGM. Preditores Genéticos da aterosclerose coronária. Rev Soc Cardiol Est de São Paulo 2000; 6:761-8.

67. Jauhiaen M, Koskienem P, Ehnholm C et al. Lipoprotein (A) and coronary heart disease risk: a nested case-control study of the Helsinki Heart Study participants. Atherosclerosis 1991; 89:59-67. 
68. Janson JH, Nilsson TK, Johnson O, Von Willebrand. Factor in plasma: a novel risk factor for recurrent myocardial infarction and death. Br Heart J 1991; $66: 351-5$

69. Joint National Committee on Prevention, Detection, Evaluation and Treatment of High Blood Pressure - The sixth report ( JNC-V ). National Institutes of Health, National Heart, Lug and Blood Institute, National High Blood Pressure Education Program. NIH Publication, november, 1997.

70. Kalache A, Gray JAM. Health problems of older people in the developing word. In: Pathy MSJ, et al. Principles and practice of geriatric medicine. Chichester, John Wiley and Son, 1985. p. 1279-87.

71. Kannel WB, Hjortland MC, McNamara PM. Menopause and risk of cardiovascular disease: the Framingham study. Ann Intem Med 1976; $5: 447-52$.

72. Kannel WB, Cupples LA., D'Agostino RB. Hypertension, antihypertensive treatment and sudden coronary death: The Framingham study. Hypertension $1988 ; 11($ supp II):45-50

73. Kjekshus J, Pedersen TR, for the 4 S Group - Reducing the risk of coronary events: evidence from the Scandinavin Simvastatin Survival Study Group (4S). Am J Cardiol 1995; 76:64-8C 
74. LaRosa JC. Lowering cholesterol in women, the elderly, and young adults. J Myocardial Ischemia 1994; 6:15-21.

75. Laurenti R, Buchalla CM, Caratin CVS. Doenças Isquêmicas do Coração Internações, Tempo de Permanência e Gastos. Brasil, 1993 a 1997. Arq Bras Cardiol $2000 ; 74(6): 483-7$.

76. Le NA. Hyperlipidemia and cardiovascular risk factors. Curr Opin Lipidol $2000 ; 11: 331-3$

77. Lewis SJ, Moye LM, Sacks FM, Johnstone DE, Timmio G, Mitchell J et al. Effect of provastatin on cardiovascular events in older patients with myocardial infarction and cholesterol level in the average range. Results of the Cholesterol and Recurrent Events (CARE) Trial. Ann Intern Med 1998; 129:681-9.

78. Lolio CA, Laurent R. Mortalidade por doença isquemica do coração no município de São Paulo. Evolução de 1950 a 1981 e mudanças recentes na tendência. Arq Bras Cardiol 1986 46:153-6.

79. Lotufo PA. Epidemiologia das doenças cardíacas no Brasil: história, situação atual e proposta de modelo teórico. Rev eletrônica da Soc de Cardiol do Estado de São Paulo: [edição em disquete setembro/outubrol, 1996. 
80. Maranhão RC, Vinagre CG, Arie S, Guimaraes JB, da-Luz P, Bellotti G et al. Lipoprotein(a) in subjects with or without coronary artery disease: relation to clinical history and risk factors. Braz J Med Biol Res 1995; 28:439-46.

81. Maranhão RC. Quilomícron e doença arterial coronária. Rev Soc Cardiol Est de São Paulo 2000; 6:728-33.

82. Mansur AP. Influência dos fatores de risco no homem e na mulher. Jornada Científica da InCor - Insuficiência Coronária, Emergência e Terapia Intensiva, p. 16-7, 1995

83. Marcopito LF, Shirassu M. Mortalidade por Infarto Agudo do Miocárdio e pelas Demais Doenças Isquêmicas do Coração no Estado de São Paulo, 1980 - 1996 Arq Bras Cardiol 2000 75(1):69-71.

84. Martinez T LR, Novazzi JP, Vale AAL, Leite PF. Obesidade e coração. Rev Soc Cardiol Estado de São Paulo 1996; 6(4):447-51.

85. Mayer RS. Fatores de risco em aterosclerose. Arq Brasil Cardiol 1994; $63(5): 437-8$

86. Meade TW, Ruddock V, Stirling Y et al. Fibrinolytic activity, cotting factors and long-term incidence of ischaemic heart disease in the Northwich Park Heart Study. Lancet $1993 ; 342: 1076-9$. 
87. Medeiros SL. Práticas Terapêuticas não convencionais usadas por idosos Estudo realizado em uma instituição estadual de saúde da cidade de São Paulo. São Paulo, 1997 [Tese de Doutorado - Faculdade de Saúde Pública da Universidade de São Paulo].

88. Medeiros SL. Secondary prevention in coronary disease: guide-lines for multidisciplinary health promotion program. Malta, 1999 [Post-graduate course in gerontology and geriatrics 1998-9 - University of Malta, Institute of gerontology, International institute on aging united nations].

89. Medical Research Council (MRC) trial of treatment of hypertension in older adults: principal results. Brit Med J 1992; 304:405-12.

90. Menagement Committee National Heart Foundation of Australia: The Australian therapeutic trial in mild hypertension. Lancet $1980 ; 1261-7$.

91. Mendall MA, Goggin $P$, Molineaux $N$ et al. Childhood living conditions and Helicobacter seropositivity in adult life. Lancet 1992; i:896-7.

92. Menezes AK. Avaliação funcional do idoso versus avaliação clínica tradicional In: Sociedade Brasileira Geriatria e Gerontologia. Caminhos do envelhecer, Rio de Janeiro, Editora Revinter, 1994, p.63-72. 
93. Miettinen TA, Pyorala K, Olsson AG et al. Cholesterol-lowering therapy in women and elderly patients with myocardial infarction or angina pectoris: finding from the Scandinavian Simvastatin Survival Study (4S). Circulation 1997; 96:4211-8.

94. Ministério da Saúde. Estudo multicentrico sobre prevalência do Diabetes Mellitus no Brasil. Coordenação de Doenças Cardiovasculares, 1988.

95. Ministério da Saúde. Doenças Cardiovasculares no Brasil. Brasilia, Sistema Único de Saúde - SUS , Coordenação de Doenças Cardiovasculares, 1993.

96. Ministério da Saúde. Departamento de assistência e promoção à saúde, coord. doenças crônico-degenerativa. Diabete Mellitus - Guia básico para diagnóstico e tratamento. Brasilia - DF, 1996.

97. Montague TJ, Montague P, Teo KK. Primary and secondary prevention of coronary heart disease by pharmacological therapy: recommendations based on critical appraisal of the epidemiological and clinical trials evidence. Rev Soc Cardiol Estado de São Paulo 1996; 6(3):280-4.

98. Morbidade hospitalar proporcional por grupo de doenças, Ministério da Saúde/SE/Datasus - Sistema de Informações Hospitalares do SUS - SIH/SUS periodo 1997; http://www.datasus.gov.br/cgi/tabcigi.exe?idb98/d12.def. 
99. Morbidade Hospitalar proporcional por grupo de doenças, para faixa etária de 20 a 80 anos e mais, período de 1997. Ministério da Saúde/SE/Datasus - Sistema de Informações Hospitalares do SUS - SIH/SUS http://www.datasus.gov.br/cgi/tabcigi.exe?idb98/d12.def

100. Morbidade Hospitalar do SUS - CID 10 - Internações por Unidade de Federação segundo CID - Período de Maio 2.000. Ministério da Saúde/SE/Datasus - Sistema de Informações Hospitalares do SUS - SIH/SUS http://www.datasus.gov.br/cigi/tabcig.exe?sih/mbr

101. Mortalidade CID 10 - Óbitos por Ocorrência por Causa Cap. CID 10 segundo Unidade Federação - período 1998 http://www.datasus.gov.br/cgi/tabcgi.exe?sim/dybr.def .

102. Multiple Risk Factor Intervention Trial (MRFIT) research group: Baseline rest electrocardiographic abnormalities, antihypertensive treatment and mortality in the MRFIT. Am J Cardiol 1985; 55: 1-15.

171. National Cholesterol Education Program. Second report of the expert panel on detection, evaluation, and treatment of high blood cholesterol in adults. Circulation, $1994 ; 89: 1364-405$. 
103. National Education Program working group report on the management of patients with hypertension and high blood cholesterol. Ann Int Med 1991; $114: 224-37$

104. Nassar BA, Dunn J, Title LM, O'Neill BJ, Kirkland AS, Zayed E et al. Relation of genetic polymorphisms of apolipoprotein E, angiotensin converting enzyme, apolipoprotein B-100 and glycoprotein IIIa and early-onset coronary heart disease. Clin Biochem 1999; 32:275-82.

105. Nobre F, Costa Lima NK, Tumeler RT, Amodeo, C. Terapia medicamentosa da hipertensão arterial: avaliação crítica dos estudos clínicos e recomendações baseadas em evidencias. Rev Soc Cardiol Estado de São Paulo 1996; $6(3): 300-6$.

106. Nygard O, Nordrehaug JE, Refsum $\mathrm{H}$ et al. Plasma homocysteine levels and mortality in patients with coronary artery disease. $\mathbf{N}$ Engl J Med $1997 ; 337: 230-6$

107. Oigman W, Spritzer N, Carvalho JGR, Feitosa G, Andrade J e col. Arq Bras Cardiol 1991; 56(A):A1-16. 
108. Organizacion Panamericana de la Salud. Oficina Sanitária Panamerica, Oficina Regional de al Organizacion Mundial de la Salud. La administracion estrategica , lineamientos para su desarrollo: los contenidos educacionales. Desarrollo y fortalecimiento de los Sistemas Locales de Salud en la transformacion de los Sistemas Nacionales de Salud. Washington, 1994.(OPAS- HSS/SILOS,32)

109. Patsch JR, Miesenböck G, Hopferwieser T, Mühlberger V, Knapp E, Dunn JK et al. Relation of triglyceride metabolism and coronary disease - studies in the posprandial state. Aterioscler Thromb 1992; 12:1336-45.

110. Peasron TA. National Cholesterol Education Program - NCEP- Expert Panel on Detection, Evoluation and Treatment of High Blood Cholesterol in Adults. Arch Int Med 2000; 160:459-67.

111. Pachter LM. Culture and clinical care. Folk, illness, beliefs and behaviors and their implications for health care delivery. J A M A 1997; 271(9):690-4.

112. Parry EHO. La gente y la salud. Foro Mundial de la salud, 1984; 5:58-62.

113. Prevention of cardiovascular events and death with pravastatin in patients with coronary heart disease and a broad range of initial cholesterol levels: the Long-term Intervention with Pravastatin in Ischemic Disease (LIPID) study group. N Engl J Med 1998; 339:1349-57. 
114. Prevention of Coronary Heart Disease: Scientific Background and New Clinical Guidelines. European Atherosclerosis Society. International Task Force for Prevention of Coronary Heart Disease. Nutrition, Metabolism and Cardiovasc Dis 1992; 2:113-56.

115. Produção Hospitalar da Secretaria de Estado de Saúde de São Paulo Tabela 1 - Relação dos 50 procedimentos em internações hospitalares, com maior impacto no valor pago pelo SUS, Estado de São Paulo, 1998 http://www saude.sp.gov.br.

116. Produção Hospitalar da Secretaria de Estado de Saúde de São Paulo Tabela 2 - Relação dos 50 primeiros procedimentos mais freqüentes em internações hospitalares do Estado de São Paulo, 1998 http:// www saude.sp.gov.br.

117. Programas e Projetos - Doenças Cardiovasculares. Ministério da Saúde 2000 http://www. saude.gov.br/programas/cardio/cardio.htm.

118. Ramos LR, Veras $R$, Kalache A. Population aging: Brasilian reality. Rev Saúde Pública 1987; 21(3):211-24.

119. Rangel C. Estenose Aórtica e Doença Coronaria - Análise dos fatores de risco. São Paulo, 2001 [Tese de Doutorado - Universidade de São Paulo]. 
120. Rassi, EPM. Fatores de Risco Coronariano e riscos auto-criados em idosos. São Paulo, 1998 [Tese de Mestrado - Faculdade de Saúde Pública da Universidade de São Paulo].

121. Reaven GM. Role of insulin resistance in human disease. Diabetes $1998 ; 37: 1595-607$

122. Ridker PM, Rifai N, Stampfer MJ, Hennekens CH. Plasma concentration of interleukin- 6 and the risk of future myocardial infarction among apparently healthy men. Circulation 2000; 101:1767-71.

123. Ridker PM, Hennekens CH, Buring JE, Rifai N. C-reactive protein and other markers of inflammation in the prediction of cardiovascular disease in women. N Engl J Med 2000; 342:836-43.

124. Rockley CE, Schlant RC. Prevention of coronary artery disease. In: Hurst W. The heart: arteries and veins. 8th ed. McGraw-Hill,1994.

125. Rosengren A, Wilhelmsem L, Eriksson E et al. Lipoprotein(a) and coronary heart disease risk: a prospective case-control study in general population sample of middle-aged men. Br Med J 1990; 301:1248-51.

126. Rubin GM, Sidney S, Black DM et al. High blood cholesterol in elderly men and excess risk for coronary heart disease. Ann Intern Med 1990; 133:916-20. 
127. Rubins HB, Rubins SJ, Collins d, Fye CL, Anderson JW, Elam MB et al. Gemfibrozil for the secondary prevention of coronary heart disease in men with low levels of high-density lipoprotein cholesterol. N Engl J Med 1999; $341(6): 410-8$

128. Rulope LM. As $\mathbf{1 0 0}$ perguntas mais freqüentes em hipertensão arterial. São Paulo, AP Americana de Publicações, 1995.

129. Samuels M, Samuels N. The well adults. Summit Books, 1988

130. Santos RD, Maranhão RC. Importância da lipoproteína(a) na aterosclerose. Rev Soc Cardiol Est de São Paulo 2000; 6:723-7.

131. Scandinavin Simvastatin Survival Study Group (4S) - Randomised trial of cholesterol lowering in 4,444 patients with coronary heart disease: the Scandinavin Simvastatin Survival Study Group (4S). Lancet 1994; 344:1383-9.

132. Schaefer EJ, Lamon-Fava S, Janner $J$ et al. Lipoprotein(a) levels and risk of coronary heart disease in men: the Lipid Research Clinics Primary Prevention Trial. J A M A 1994; 271:999-1003.

133. Scheen AJ, Lefèbvre PJ. Management of the obese diabetic patient. Diabetes Reviews 1999;7:77-93. 
134. Seed M, Crook D. Post-menopausal hormone replacement therapy, coronary heart disease and plasma lipoproteins. Current Opinion Lipidology 1994; $5: 48-58$

135. Serrano Jr CV, Ganem F, Nicolau JC. Marcadores inflamatórios e eventos coronarianos. Rev Soc Cardiol Est de São Paulo 2000; 6:751-60.

136. Shor A, Phillips JI. Chlamydia pneumoniae and atherosclerosis. J A M A $1999 ; 282(21): 2071-3$.

137. Smith SC, Blair SN, Criqui MH et al. Preventing heart attack and death in patients with coronary disease. American Heart Association. Consensus Panel Statement. Circulation 1995; 92:2-4.

138. Sociedade Brasileira de Cardiologia Consenso de dislipidemia. Rev eletrônica da Soc de Cardiol do Estado de São Paulo: [edição em disquete março/abril], 1996.

139. Sociedade Brasileira de Cardiologia. II Consenso Brasileiro para Tratamento de Hipertensão Arterial. Arq Bras Cardiol 1994; 63, (4):334-47.

140. Sociedade Brasileira de Cardiologia 1992-6. II Consenso Brasileiro para tratamento da hipertensão arterial. Publicações Eletrônicas 1:[edição em disquete],1996.

141. Sociedade Brasileira de Cardiologia. Tabela de Risco Coronariano. Publicações Eletrônicas 1:[edição em disquete],1996. 
142. Sociedade Interamericana de Cardiologia, Fundação Interamericana do Coração. Prevenção secundária da enfermidade coronariana e outras enfermidades vasculares: uma proposta para a América Latina. Soc Brasil de Cardiol 1996; 3(17): 10-1.

143. Staessen JA, Fagard R., Thus L. Systolic Hypertension Europe (Syst-Eur) trial investigators. Morbidity and mortality in the placebo-controlled european trial on isolated systolic hypertension in the elderly. Lancet 1997; $360: 757-64,1997$.

144. Stamler J, Wentworth DN, Neaton JD. Is the relationship between serum cholesterol and risk of death from coronary heart disease continuous and graded? Findings on the 356,222 primary screenes of the Multiple Risk Factor Intervention Trial (MRFIT). J A M A 1986; 256:2823-8

145. Stamler J, Vaccaro O, Neaton JD. Diabetes and other risk factors in 12 years cardiovascular mortality from screened for multiple risk factor intervention trial. Diabetes Care 1993; 16:434-44.

146. Stamler J. Prólogo. In: American Heart Association. Fighting Heart Disease and Stroke. Texas, 1994. p. VII-X. 
147. Stampfer MJ, Colditz GA, Willet WC. Postmenopausal estrogen therapy and cardiovascular disease. Ten years follow-up from Nurses's Health Study. N Engl J Med 1991; 325:756-62.

148. Stampfer MJ, Watt HC, Law MR et al. Homocysteine and ischemic heart disease. Results of prospective study with implications regarding prevention. Arch Intern Med 1998; 158:862-7

149. Summary of the Second Report of the National Cholesterol Education Program (NCEP) Expert Panel on Detection, Evaluation and Treatment of High Blood Cholesterol in Adults (Adults Treatment Panel II). J A M A $1993 ; 269: 3015-23$.

150. Systolic Hypertension in the Elderly Program (SHEP) cooperative research group: Prevention of stroke by antihypertensive drug treatment in older persons with isolated systolic hypertension: final results of the SHEP. J A M A $1991 ; 265: 3255-64$.

151. Tavares JR, Stefanini E, Lima VC, Carvalho AC. Homocisteína e coronariopatia. Rev Soc Cardiol Est de São Paulo 2000; 6:712-22.

152. The International Prospective Primary Prevention Study in Hypertension (IPPPSH.) collaborative group: Cardiovascular risk and risk factors in a randomized trial of treatment based on the beta-blocker oxprenolol: The IPPPSH. J Hypertens 1985; 3: 379-92. 
153. The Sixth Report of Joint National Committee on prevention, detection, evaluation and treatment of high blood pressure. Bethesda, MD: National Institutes of Health, National Heart, Lung and Blood Institute 1997, NIH publication $98-4080$.

154. Tracy RP. Inflammation markers and coronary heart disease. Curr Opin Lipidol 1999; 10: 435-41

155. Trelle D. Women and coronary heart disease. A review with special emphasis on some risk factors. Lipid Rev 1990; 4:33-8.

156. UK Prospective Diabetes Study Group. Intensive blood-glucose control with sulfonylureas or insulin compared with conventional treatment and risk of complications in patients with type 2 diabetes: UKPDS 33. Lancet 1998; $352: 837-53$

157. UK Prospective Diabetes Study Group. Effect of intensive blood-glucose control with metformin on complications in overweight patients with type 2 diabetes:UKPDS 34. Lancet 1998; 352:854-65

158. UK Prospective Diabetes Study Group. Tight blood pressure control and risk of macrovascular and microvascular complications in type 2 diabetes:UKPDS 38. В М J 1998; 317: 703-12. 
159. Veterans Administration cooperative study group on antihypertensive agents: Effects of treatment on morbidity in hypertension. I. Results in patients with diastolic blood pressure averaging 115 through $129 \mathrm{mmHg}$. J A M A 1967; $202: 1028-34$

160. Veterans Administration cooperative study group on antihypertensive agents: Effects of treatment on morbidity in hypertension. II. Results in patients with diastolic blood pressure averaging 90 through $114 \mathrm{mmHg}$. J A M A 1970; $213: 1143-52$

161. Vitola D. Fatores de risco coronariano Arq Bras Cardiol 1994; 63(5):435-6.

162. Zhou YF, Leon MB, Waclawiw MA. Association between prior cytomegalovirus infection and the risk of restenosis after coronary atherectomy. N Engl J Med 1996; 335:2144-8.

163. Wald NJ, Watt HC, Law MR et al. Homocysteine and ischemic heart disease. Results of a prospective study with implications regarding prevention. Arch Intern Med 1998; 158:862-7.

164. Wenger NK, Speroff L, Packard B. Cardiovascular health and disease in women. N Engl J Med 1993; 329:247-56.

165. Wikstrand J, Warnold I., Olsson G. Primary prevention with metoprolol in patients with hypertension: Mortality results from the MAPHY study. J A M A 1988; 259: 1976-82. 
166. Wilhelmsen L, Bergkybd G, Elmfledt D. Beta-blockers versus diuretics in hypertensive men: main results from the HAPPHY trial. J Hypertens 1987; 5:561-72.

167. Wilson PWF, Garrison RJ, Castelli WP. Postmenopausal estrogen use cigarette smoking and cardiovascular morbidity in women over 50. The Framingham Study. N Engl J Med 1985; 313:1038-43.

168. Wilson PW, D'Agostino RB, Levy D, Belonger AM et al. Prediction of coronary heart disease using risk factor categories. Circulation 1998; 97: 1837-47.

169. Willianson DF, Pamuk E, Thun M. Prospective study of intentional weight loss and mortality in never-smoking overweight US white women age 40-64 years. Am Epidemiol 1995; 141:1128-141.

170. Yudkin JS. Abnormalities of coagulation and fibrinolysis in insulin resistance: evidence for a common antecedent? Diabetes Care 1999; 22:C25-30.

171. National Cholesterol Education Program. Second report of the expert panel on detection, evaluation, and treatment of high blood cholesterol in adults. Circulation 1994; 89:1364-405. 
9. Anexus 


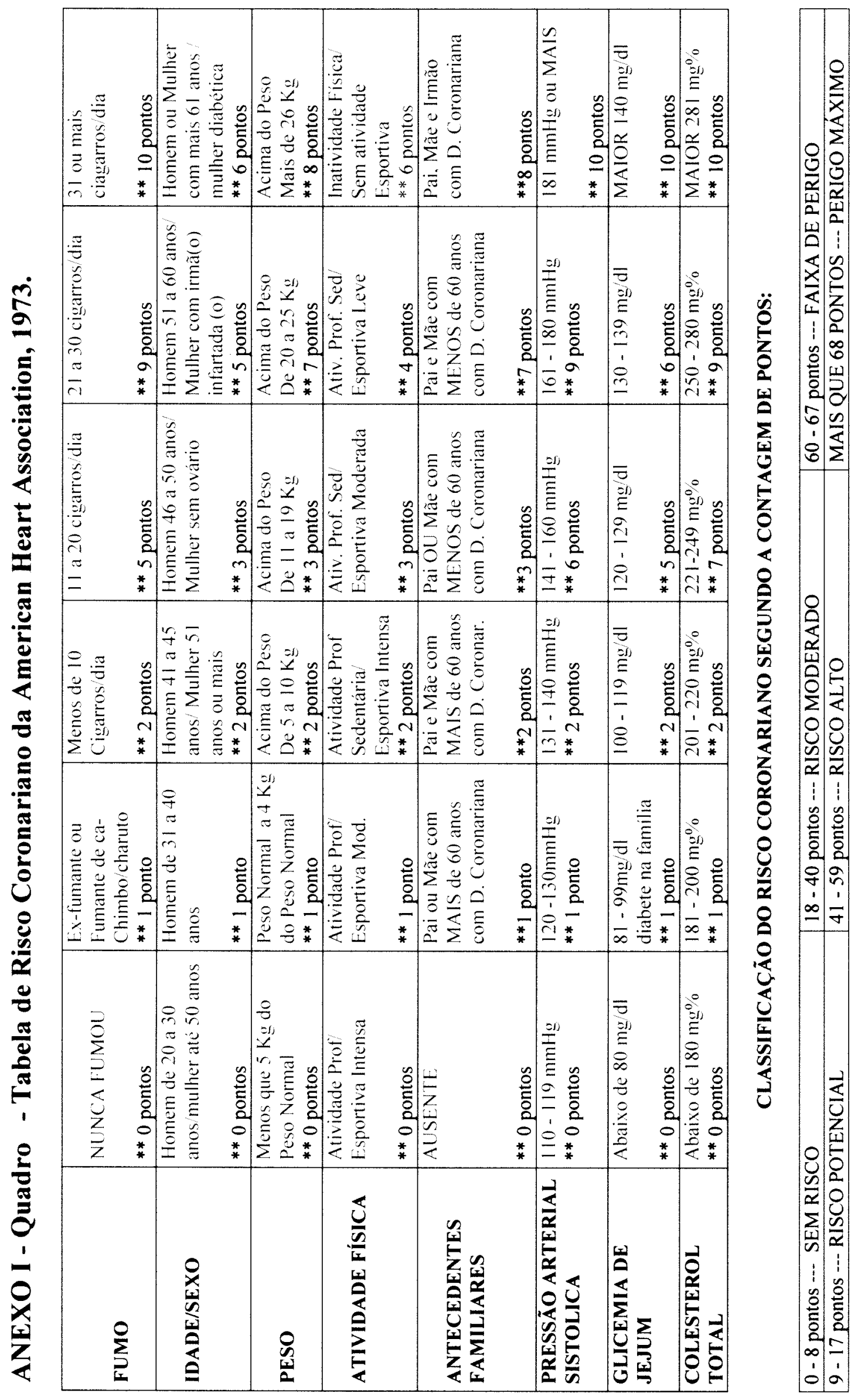

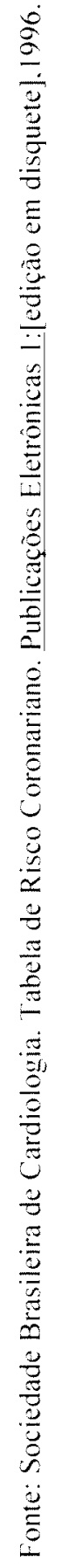


ANEXO II - Tabela de Distribuição da Altura (m) e Peso Normal (Kg) segundo o IMC de 24,9.

\begin{tabular}{|c|c|c|c|}
\hline $\operatorname{Ama}(m)$ & Peso normal (Kg) & $\operatorname{Ang}(m)$ & Peso normal (Kg) \\
\hline 1,3 & 42,08 & 1,6 & 63,74 \\
\hline 1,31 & 42,73 & 1,61 & 64,54 \\
\hline 1,32 & 43,39 & 1,62 & 65,35 \\
\hline 1,33 & 44,05 & 1,63 & 66,16 \\
\hline 1,34 & 44,71 & 1,64 & 66,97 \\
\hline 1,35 & 45,38 & 1,65 & 67,79 \\
\hline 1,36 & 46,06 & 1,66 & 68,61 \\
\hline 1,37 & 46,73 & 1,67 & 69,44 \\
\hline 1,38 & 47,42 & 1,68 & 70,28 \\
\hline 1,39 & 48,11 & 1,69 & 71,12 \\
\hline 1,4 & 48,80 & 1,7 & 71,96 \\
\hline 1,41 & 49,50 & 1,71 & 72,81 \\
\hline 1,42 & 50,21 & 1,72 & 73,66 \\
\hline 1,43 & 50,92 & 1,73 & 74,52 \\
\hline 1,44 & 51,63 & 1,74 & 75,39 \\
\hline 1,45 & 52,35 & 1,75 & 76,26 \\
\hline 1,46 & 53,08 & 1,76 & 77,13 \\
\hline 1,47 & 53,81 & 1,77 & 78,01 \\
\hline 1,48 & 54,54 & 1,78 & 78,89 \\
\hline 1,49 & 55,28 & 1,79 & 79,78 \\
\hline 1,5 & 56,03 & 1,8 & 80,68 \\
\hline 1,51 & 56,77 & 1,81 & 81,57 \\
\hline 1,52 & 57,53 & 1,82 & 82,48 \\
\hline 1,53 & 58,29 & 1,83 & 83,39 \\
\hline 1,54 & 59,05 & 1,84 & 84,30 \\
\hline 1,55 & 59,82 & 1,85 & 85,22 \\
\hline 1,56 & 60,60 & 1,86 & 86,14 \\
\hline 1,57 & 61,38 & 1,87 & 87,07 \\
\hline 1,58 & 62,16 & 1,88 & 88,01 \\
\hline 1,59 & 62,95 & 1,89 & 88,95 \\
\hline & & 1,9 & 89,89 \\
\hline
\end{tabular}

Fonte: Formula IMC $=$ Peso $(\mathrm{kg}) /$ Altura $^{2}\left(\mathrm{~m}^{2}\right)$ 


\section{ANEXO III a - Termo de Anuência para participação no estudo}

\section{"Fatores de Risco Coronariano em Idosos"}

O objetivo do presente estudo é o de acompanhamento do paciente com exames laboratoriais de rotina anuais além dos necessários para o acompanhamento clínico do paciente.

Enquanto você permanecer no estudo será realizado rotineiramente exame clínico com: medida da pressão arterial, medida do peso, ausculta cardíaca, ausculta pulmonar medida da pressão arterial, medida do peso, ausculta cardíaca, ausculta pulmonar e avaliação dos membros superiores e inferiores. Também será aplicado um roteiro de educação médica sobre os fatores de risco coronariano.

Sua participação no estudo será voluntária, podendo ser interrompida a qualquer momento, sob sua vontade/ acompanhante responsável, sem que isto lhe acarrete qualquer represália ou prejuíso no atendimento médico.

Seus dados médicos permanecerão sob sigilo e apenas poderão ter acesso a eles, você, autoridades sanitárias ou legais. 


\section{A III b}

\section{ANEXO III b - Termo de Anuência para participação no estudo \\ "Fatores de Risco Coronariano em Idosos"}

Fui informado pelo médico abaixo-assinado do tipo estudo e curso do estudo a partir da presente data. Tive suficiente oportunidade de fazer perguntas e não tenho mais nenhuma a fazer no momento.

Minha participação no estudo é voluntária. Posso interrompê-la a qualquer momento, sem sofrer nenhuma desvantagem. Não sou obrigado a dar motivos para minha decisão. Enquanto estiver participando, vou seguir as instruções médicas.

Estou de acordo que meus dados médicos sejam revisados por autoridades sanitárias ou legais. Estes dados deverão ser mantidos em sigilo.

Sob as condições mencionadas acima, concordo em participar deste estudo.

$$
\text { São Paulo, }
$$
de. de 1997.

\section{PACIENTE}

NOME:

MATRÍCULA DO PRONTUÁRIO N. ${ }^{0}$

RG:

Assinatura do paciente/acompanhante responsável.

\section{PESQUISADORA:}

Nome: Eneide Pompiani de Moura

RG: $7140679-4$

CPF: 087740608-13

Assinatura: 


\section{UNIVERSIDADE DE SÃO PAULO FAOULDADE DE SAÚDE PÜBLICA \\ COMITÉ DE ÉTICA EM PESQUISA-COEP \\ Av. Dr. Arnaldo, 715 - Cerqueira César \\ Sajo Paulu-SP - CEP: 01246-9014}

Telefoae: (0xx11) 3066-7779 - e-mail: mdgracas(âasp.br

Of.COEP/126/01

08 de agosto de 2001

Pelo presente, informo que o Comitê de Ética em Pesquisa da Faculdade de Saúde Pública da Universidade de São Paulo-COEP, analisou e aprovou, em sua 6.\%1, Sessão Ordinária, realizada em 07.08.01, de acordo com os requisitos da Resolução CNS/196/96, o Protocolo de Pesquisa n. ${ }^{\circ} 480$, intitulado: "FATORES DE RISCO CORONARIANO EM IDOSOS - ESTUDO PROSPECTIVO”, apresentado pela pesquisadora Eneide Pompiani de Moura.

Atenciosamente,

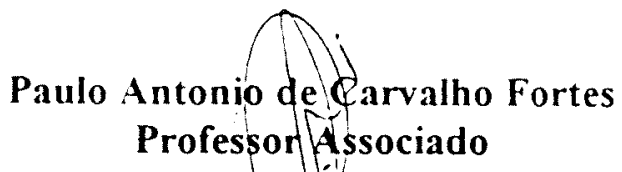

Vice-Coordenador do Comitêlde Ética em Pesquisa da FSP-COEP 


\section{COMUNICADO}

De ordem do Prof. Arnaldo Augusto Franco de Siqueira, Presidente da CPG, comunico que será realizado nesta Faculdade o EXAME DE QUALIFICAÇÃO da(o) candidata(o) ao título de "Doutor em Saúde Pública" - área de concentração Serviços de Saúde Pública.

- Eneide Pompiani de Moura -

Data: 16 de agosto de 2001, às 9 horas

Local: Sala Prof. Alfredo Reis Viegas da FSP/USP

Título do Projeto: "FATORES DE RISCO CORONARIANO EM IDOSOS ESTUDO PROSPECTIVO"

Membros:

- Professor Livre-Docente Helio Maximiano de Magalhães - Instituto Dante Pazzanese de Cardiologia,

- Professora Doutora Alice Moreira Derntl- Departamento de Prática de Saúde Pública da FSPIUSP,

- Professor Associado Januário de Andrade - Departamento de Prática de Saúde Pública da FSPIUSP - Orientador.

Suplentes:

- Doutor Mauricio Wangarten - Chefe do Setor de Geriatria do INCOR,

- Doutora Amanda Guerra de Moraes Rego e Sousa - Setor de Angioplastia do Instituto Dante Pazzanese.

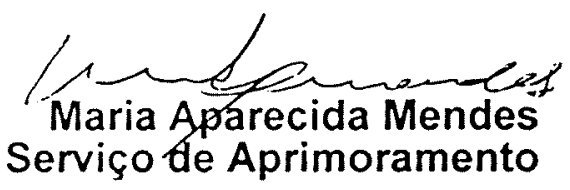

